\title{
Civil Discovery: Lawyers' Views of Its Effectiveness, Its Principal Problems and Abuses
}

\author{
Wayne D. Brazil
}

\section{Contents}

I. INTRODUCTION 790

II. The Health of the System as A Whole 793

A. Comparing Profiles: Differences Between Attorneys Who Were Positive and Those Who Were Negative About the Discovery System

B. Comparing Subgroups: General Assessments of the Discovery System

802

III. The EFfectiveness of Discovery as A System For INFORMATION DISTRIBUTION

IV. Principal Problems with and Abuses of the Discovery SYSTEM

V. The Major Obstacles to Conducting Discovery 832

VI. The Role of TACTICS IN Discovery $\quad 846$

VII. Some Clues About the Roles of Clients $\quad 859$

VIII. Lawyers' Attitudes Toward Possible Changes IN the Roles OF COURTS AND THE SCOPE OF Discovery 862

$\begin{array}{ll}\text { IX. CONCLUSION } & 869\end{array}$

APPENDIX A. QUESTIONNAIRE $\quad 875$

Appendix B. How the Attorneys in the Sample Were SELECTED 890

Appendix C. Profiles of the Sample as a Whole 891

Appendix D. Profiles of Major Subgroups 895 
. 


\title{
Civil Discovery: Lawyers' Views of Its Effectiveness, Its Principal Problems and Abuses
}

\author{
Wayne D. Brazil
}

This article, the second in a three-part series based on interviews of 180 civil litigators in Chicago, describes lawyers' assessments of the health of the discovery system and their views about the relative severity of several major problems and abuses that burden the discovery process. The data present a disturbing picture of the way the discovery system functions, especially in larger cases. Big case litigators are much unhappier with the current state of affairs in discovery than are their smaller case counterparts, and apparently for good reason. Tactical jockeying, evasive and dilatory practices, and various forms of harassment play major and costly roles in a high percentage of large lawsuits. And in at least one of every two big cases the discovery system fails to distribute the relevant information to all the parties. Perhaps the most dramatic evidence of disaffection with the current state of affairs in major litigation, however, is the widespread support the lawyers expressed for more aggressive judicial involvement in the process and for more frequent, telling use of sanctions to punish its abusers.

The third article in this series will report the lawyers' reform proposals and will explore some of the implications of the data described here.

Wayne D. Brazil is Associate Professor of Law, Hastings College of the Law, University of California, San Francisco; Affiliated Scholar, American Bar Foundation. B.A., 1966, Stanford University; M.A., 1967, Ph.D., 1975, Harvard University; J.D., 1975, University of California, Berkeley.

The project's research associate was Janna Dee Bounds (now Janna Tetzlaff), a law student who had completed two and one-half years of course work at the School of Law, University of Missouri, Columbia. Jennifer Ballsrud and Kenneth Ashlock, as research assistants, carefully prepared most of the data for computer analysis.

The author has prepared numerous tables that record the attorneys' answers to most of the questions posed during the interviews and that systematically compare the responses of lawyers in different subgroups. The author would be happy to share these tables with anyone who could use them. Written inquiries should be addressed to Professor Brazil care of the American Bar Foundation.

The author would like to express his gratitude to the American Bar Foundation for the generous support it has provided for this research. From the outset, the Foundation's executive leadership has demonstrated its belief in the importance of this kind of study not only by funding field work and data analysis but also by offering personal encouragement and making important suggestions for the design and execution of the project. While the author is indebted to many members of the Foundation's staff for their contributions, he feels a special sense of gratitude to Spencer Kimball and Barbara Curran, both of whom committed many hours to advising the project team at every stage of the work. Without their encouragement and help, this study would not have been made. The author also would like to acknowledge the careful and handsome work the Foundation's Editorial Department has done with the graphic presentations in this article. 


\section{INTRODUCTION}

During the summer of 1979 the author and a research associate interviewed 180 Chicago area litigators ${ }^{1}$ to explore their attitudes toward, assessments of, and experiences with the system of civil discovery. ${ }^{2}$ This is the second article describing results of those interviews. ${ }^{3}$

This report focuses primarily on the attorneys' quantifiable responses to questions about how effectively discovery is working, the principal abuses of the system, and the major obstacles to conducting discovery. It also examines the extent to which tactical considerations affect discovery decisions, the impact of clients, and how litigators would react to possible changes in the roles of the courts and in the scope of discovery and of the attorney-client privilege.

The sections that follow show that discovery in big case litigation differs greatly from discovery in smaller cases and that in larger lawsuits discovery is seriously infected by debilitating abuses as well as by evasive and tactical practices. In smaller, less complex lawsuits, discovery is by no means free of problems, but it provokes fewer complaints and appears to be less frequently abused than in larger case litigation. Smaller case lawyers have fewer problems with discovery than their larger case counterparts in part because discovery plays a lesser role in smaller cases, in part because the predictability of issues and evidence leaves fewer opportunities for and less to be gained by adversarial machinations, and in part because there simply is not enough money involved to justify major commitments to tactical subtlety.

The contrast with discovery in larger cases is both striking and disconcerting. In big cases the process regularly involves evasion, overdiscovery, harassment, and huge costs. These characteristics of the system are attributable in part to the fact that in big cases more money is at stake, clients who can commit more resources to litigation are involved, more information must be exchanged, theories of liability and damages often are more complicated, and the existence, character, and location of evidence are less predictable. These factors conspire to create strong incentives, numerous opportunities, and ample resources to obstruct or burden the discovery process and to misuse its tools in pursuit of adversarial advantages. While attorneys of all kinds often may feel little incentive to cooperate with an opponent's discovery, big case lawyers often are confronted with powerful temptations not only to resist disclosures but also to use the machinery of discovery as an offensive weapon, as an independent means of imposing pressure or seeking leverage.

1. This process yielded only $\mathbf{1 7 7}$ completed questionnaires because in three interview sessions two attorneys participated simultaneously.

2. The questionnaire that guided the interviews is reproduced in appendix A.

3. The first article was Wayne D. Brazil, Views from the Front Lines: Observations by Chicago Lawyers About the System of Civil Discovery, 1980 A.B.F. Res. J. 217. 
The characteristics of the practices of the attorneys who were interviewed are described in detail in appendices $C$ and $D$. Although the method used to select the attorneys to be interviewed would not produce a statistically representative sample of Chicago litigators, it was designed to obtain a diverse and well-balanced subgroup of this universe and thus to permit comparison of the attitudes, perceptions, and experiences of differently situated litigators. ${ }^{4}$ Such comparisons produce some of the study's most important findings.

I used several sets of characteristics of litigation practice to divide the sample as a whole into sets of contrasting subgroups (all of the subgroups are described in appendix D). One subgroup, for example, was composed of all the attorneys whose median size case was $\$ 1,000,000$ or more, while the contrasting group consisted of those whose median size case was $\$ 25,000$ or less. These two subgroups formed a subgroup set for case size. The data show that the perceptions and attitudes of attorneys in four sets of subgroups form a remarkably consistent pattern. These four sets of subgroups include, in addition to the set for case size, lawyers (1) whose work included antitrust (or securities) matters and those who handled tort actions arising out of automobile accidents, (2) those whose principal clients were large corporations and those who received the lion's share of their work from individuals, and (3) those who committed most of their time to matters filed in federal court and those whose time was consumed primarily by actions in state court.

In each of these sets the attorneys in one subgroup consistently reported (1) having substantially more trouble conducting discovery, (2) using discovery tools much more often for tactical purposes, and (3) believing that their opponents more frequently failed to discover significant information from them. There also was an uncanny consistency across sets of subgroup lines in the percentage of respondents complaining about discovery abuse and in the reported severity of specified problems with discovery: the subgroups in which a higher percentage of respondents offered negative overall assessments of discovery regularly fixed the severity of most problems at similarly high levels, while the subgroups in which a lower percentage of respondents offered negative assessments of the system fixed the severity of the same problems at consistently lower levels.

The consistency in the pattern of perceptions by these subgroups, coupled with the modest number of attorneys in each category, make it impossible to prove (with this data) which factors are the principal causes of given problems with discovery. As argued in subsequent sections, however, it seems unlikely that levels of difficulty with discovery are primarily a function either of the character of the clients served or the jurisdiction in which the litigation has been filed. It is much more likely that the size

4. Appendix B describes in detail how the attorneys were selected. 
(dollar value) and complexity (in terms of legal theories and volume of information involved) of the litigation contribute most to fixing the severity of most problems with discovery. The causal roles of case size and complexity are difficult to isolate, however, because large, complicated lawsuits tend to be filed in federal courts and to involve large corporate clients, whereas smaller, more straightforward suits tend to be filed in state courts and to involve individuals as clients. In other words, the four factors that are the most reliable predictors of the severity of the discovery system's problems and the level of its overall effectiveness tend to "cluster."

Despite these analytical hurdles, one generalization is clearly safe: the discovery process is much less likely to distribute information evenly among the parties and much more likely to be heavily encumbered by various forms of resistance, abuse, and tactical jockeying in large, complex cases than it is in smaller, more routine lawsuits.

A few general observations about the data are in order before beginning a detailed examination of it. The interviews were designed to explore the attorneys' assessments of the discovery system and their perceptions of what discovery is like in their practices. In many questions the lawyers were asked to estimate how often (i.e., in what percentage of their cases during a fixed period) they experienced certain difficulties or acted with specified tactical purposes. Obviously, it is impossible to answer such questions precisely. It follows that the data produced by the lawyers' responses cannot establish with scientific accuracy the prevalence or magnitude of any of the phenomena examined. Nonetheless, the data provide rough estimates of the gross dimensions of some of the discovery system's most troublesome problems and serve as a basis for comparing the experiences of differently situated attorneys with discovery.

There are, of course, reasons for not relying completely on lawyers' evaluations of a system lawyers designed, lawyers operate, and in which lawyers make their livelihood. One such reason may not be obvious but may affect the accuracy of the responses to many of the questions. All lawyers are in some measure "professionally acculturated." They have learned a specialized vocabulary, embraced certain assumptions, adopted unique habits of thought and action, and, in varying degrees, accepted or reached some form of experience-based accommodation with the "system." Every lawyer's professional vocabulary, assumptions, habits, and experiences affect not only how she reacts to reality (i.e., her attitudes toward it) but also how she perceives, defines, and understands it. The interviewing process taught us that some lawyers had experienced certain phenomena so often (e.g., evasive tactics of opposing counsel) that they no longer perceived or defined as "problems" many things that an outsider could define in no other way. 
This product of professional acculturation created communication problems during the interviews, and undoubtedly caused some lawyers to overlook routine points of friction in their practices and thus to understate (by some undeterminable amount) the difficulty of conducting discovery, the prevalence of certain problems, and how often their behavior was motivated by certain objectives. Thus the data may well not disclose the full dimensions of the problems which beset the current system of civil discovery.

\section{The Health of the System as a Whole \\ "The rules are excellent. The enforcement of the rules stinks. The system moves poorly."}

-a Chicago litigator

One of the goals of this project was to explore litigators' attitudes toward and assessments of the system of pretrial discovery as a whole. What do litigators think about the overall effectiveness of the system of civil discovery, about how well or how poorly it is working? Are trial lawyers generally satisfied with the system? If there is disaffection, how widespread and intense is it? Is there anything approaching a crisis of confidence in civil discovery?

To explore these topics we began the substantive portion of each interview by asking three open-end questions: (1) "What is your general impression about how well the current system of discovery is working?" (2) "Do you feel there are any problems with the current system?" and (3) "What are the most troublesome kinds of discovery abuses, if any?" Just before concluding the interviews we offered the lawyers another opportunity to make general observations by asking: "Do you have any comments or complaints about the current system of discovery that our other questions have not permitted you to express?"

It is important to bear in mind during this discussion of the lawyers' general assessments of civil discovery that there is no one "system" that all the attorneys are describing. Instead, there are many different subsystems of discovery. Most obviously, there are systems in state courts (Illinois for our respondents) ${ }^{5}$ that differ in some ways from the system in federal courts. ${ }^{6}$ And within the federal and state apparatuses the charac-

5. According to several lawyers there also can be considerable differences within the state system in how discovery functions, e.g., between the courts in Cook County and those in the less densely populated part of the state, where trial dockets are substantially less crowded and pretrial procedures are less infected by delay.

6. The two differences between the Illinois and the federal systems of discovery that the interviewed attorneys mentioned most often were (1) the fact that in the law division of the state courts discovery disputes are resolved by specialist motion judges, whereas in the federal system one judge is responsible for all stages of each case and either that judge or a magistrate rules on the discovery controversies that arise in given litigation and (2) unlike the Federal Rules of Civil Procedure, the II- 
ter of discovery practices and problems can vary considerably with, among other things, the size and complexity of the litigation. Some of the distinguishing features of some of the discovery subsystems were described in an earlier article; ${ }^{7}$ others will be explored in the pages that follow. Despite significant differences, however, all of the discovery systems familiar to our respondents have a great deal in common; they are designed and used to achieve many of the same ends and operate under formal rules that are in many important respects indistinguishable. Thus describing the way the sample group as a whole assessed discovery as a system establishes an instructive point of reference for evaluating assessments by attorneys grouped according to distinguishing characteristics of their practices.

When viewed as a whole, the sample group gave the discovery system mixed general reviews and what is at best a tepid endorsement. While intense disaffection with the system was not widespread (about 12 percent of the litigators expressed aggressively negative assessments), comparatively few attorneys (approximately 10 percent) praised the system with essentially unqualified enthusiasm. Most lawyers' attitudes toward discovery combined, in widely varying degrees, some positive and some negative sentiments. Given that fact, the most instructive way to describe general attitudes toward the system was to divide the interviewed attorneys into three groups: (1) those whose assessments, on balance, were clearly predominantly positive, ${ }^{8}(2)$ those whose characterizations of how well discovery is working were clearly predominantly negative, ${ }^{9}$ and (3) those whose views fit neither of the first two categories, but ranged from modestly positive to modestly negative. ${ }^{10}$ We have labeled these groups positive, negative, and mixed.

linois Supreme Court Rules distinguish "a discovery deposition" from "an evidence deposition," the latter being usable for more purposes at trial than the former. See Ill. Sup. Ct. R. 202, 212.

7. See Brazil, supra note 3.

8. Lawyers who expressed their general assessment of how well the discovery system is working in any of the following words or phrases qualified for the "clearly positive" category: "excellent," "quite well," "very good," "very well," “well," "good," "fine," "very workable." There were a few attorneys who did not use any of these words or phrases but who were placed in this first category because they clearly expressed a solidly positive attitude toward the current system of discovery (e.g., one respondent who was placed in this category said the system is "overall effective and efficient"').

9. Attorneys who articulated their evaluation of the system as a whole in any of the following words or phrases qualified for the "clearly negative" category: "bad" or "badly," "terribly abused," "awful," "very badly," "terrible," "abused horrendously," "abused more often than not," "poorly," "lousy," "stinks," "abused," "not well," "not very well," "not terribly well," "not as effective as it should be." As in the "clearly positive" category, there were a few respondents who did not use any of these words or phrases but who were placed in this category because they expressed a clearly negative overall evaluation of the operation of the current system (e.g., one attorney qualified for this category by beginning his answer to the open-end questions about the system and its problems by declaring that discovery "costs a fortune, wastes time [and] doesn't work to the ends of justice").

10. This middle category is the largest of the three and includes attorneys whose general attitudes toward discovery cover a relatively wide range of views. Respondents were placed in this category 
The largest number of litigators fall into the mixed category: 46 percent of the attorneys interviewed were in some measure ambivalent about the system, endorsing it with reservations or attaching some noncommittal label to it (e.g., "o.k.," "mediocre," "fair," or "adequate"). Moreover, while 20 percent of the attorneys expressed clearly positive evaluations of discovery as they experienced it, a larger group, 33 percent, offered overall assessments that were clearly negative. These results are depicted graphically in figure 1.

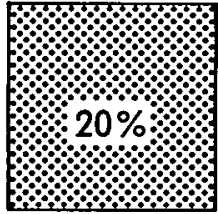

Clearly

Positive

$(\mathrm{N}=34)$

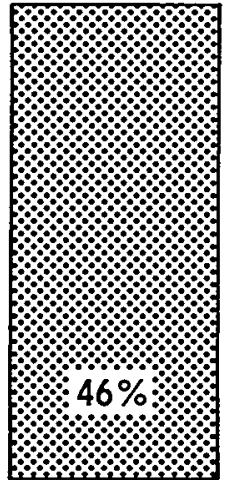

Mixed

$(N=79)$

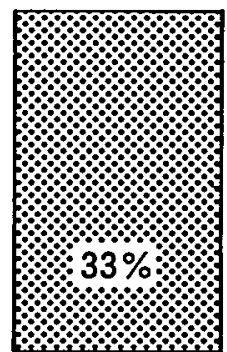

Clearly

Negative

$(N=56)$

Fig. 1. Attorneys' assessments of how well the discovery system works

Before detailing differences between the positive and negative groups, it is important to describe a few communications problems which may have affected how the attorneys responded both to the open-end questions about the system and to inquiries about specific problems. Often there was considerable tension between a given lawyer's general characterization of the discovery system and his specific observations about its operation. Many lawyers whose initial broad characterizations of discovery were relatively favorable became much more negative when they focused on more specific features of the system. ${ }^{11}$ For example, two lawyers who described the system in general as "excellent" subsequently said

when they expressed mixed feelings about how well discovery is working or when they offered obviously qualified endorsements (e.g., by saying discovery works "fairly well" or "moderately well" or "as well as can be expected," or by saying it works "pretty well" or "pretty good" while simultaneously pointing out substantial problems) or when they expressed only a passive or halting acceptance of the system (e.g., by characterizing it as "mediocre" or "o.k." or "adequate" or as showing "room for improvement").

11. This change in tone sometimes occurred while the attorneys were responding to the first general question about how discovery was working, before the interviewer asked if there were any problems with the current system. In other interviews the change did not occur until more specific questions encouraged the lawyers to focus on potentially troublesome aspects of the discovery process. 
that they were having difficulty discovering the information they needed in virtually all of their currently active cases. One of these lawyers also reported that his "requests for production usually produce[d] nothing for the first several times and even for the first or second court orders." Another litigator who opined that "overall [the system] is working well" later complained that "discovery becomes a matter of avoidance rather than the free flow of information." Similarly, two attorneys who characterized the system in general as working "fairly well" went on to observe, respectively, that "deliberate obstruction of discovery by counsel occurs in every phase of discovery" and that "it is normally like pulling teeth to get opponents to comply with my discovery." And a lawyer who first described the system as working "quite well" and affording a "significant opportunity to evaluate cases for settlement" later heatedly denounced the practice of responding evasively or incompletely to discovery requests, insisting that "everyone does it to each other and it's wasteful and valueless and costly and needs to be studied and corrected."

In describing the discovery system several attorneys made a distinction that may help explain this tension between general impressions and specific observations. That distinction is between the machinery provided for conducting discovery, that is, the formal rules that theoretically confer rights and impose responsibilities, on the one hand, and, on the other, how that machinery is used by attorneys and maintained by the courts. The lawyers who made this distinction tended to agree that the machinery itself was well designed and capable, in theory, of performing most of the functions and satisfying most of the needs for which it was intended. They also agreed, however, that the machinery is neither self-starting nor self-maintaining and that how well it works is determined in large measure by how attorneys use it and how judges react to that use. ${ }^{12} \mathrm{Ab}$ sent disruptive interference by clients (a problem which appears to be serious for a relatively small percentage of civil litigators) these lawyers contended that discovery can function effectively and efficiently if the attorneys involved in a given matter are competent and want the system to work. Unfortunately, the system also is quite vulnerable to the predations of attorneys and clients who do not want it to work: ${ }^{13}$ As one lawyer phrased it, the system is easily "perverted by abuses."

The fact that so many litigators believe that the attitudes and actions of individual attorneys (and, to a lesser degree, clients) can have such a pronounced negative impact on the effectiveness of the discovery system probably helps explain why so many lawyers ascribed such importance to the role played by the judiciary in monitoring the conduct of discovery

12. For example, one lawyer said, in the same sentence, that the system generally works "well, but can be horribly abusive."

13. See section VII infra. 
and punishing those who misuse its tools or refuse to honor its rules. ${ }^{14}$ In the words of a litigator who thought that on the whole the system worked pretty effectively, "everything depends on the motion judges-regardless of the rules in theory-which [are] good-but the current motion judges are very bad." Another lawyer summarized with panache what appeared to be a widely shared view when he declared: "The rules are excellent. The enforcement of the rules stinks. The system moves poorly."

Obviously this lawyer and many others distinguish the "rules" (formal discovery machinery) from the "system" and believe that the rules as such have less to do with the nature of the system as it operates on a dayto-day basis than does the behavior of litigators and judges. It is almost as if discovery rules exist independently of discovery reality: the rules may set the stage, but they leave the actors great freedom to determine the content and character of the play. Since many lawyers in the sample conceived of the "rules" and the "system" separately it may be that when first asked for a general assessment of how well discovery is working they focused on the "rules" rather than on the "system" as a functional whole. This kind of narrow initial focus could help explain why the general assessments of discovery so frequently seem more positive than the specific observations about how the system works.

The existence of this tension or inconsistency between many of the lawyers' relatively positive general impressions of discovery and their specific descriptions of its shortcomings illustrates another communication problem that may have affected responses to many of the questions posed during the interviews. That problem was caused by "professional acculturation," a phrase I use to describe how lawyers who have been educated for our adversarial system and who have practiced in it and become accommodated to it tend to make certain assumptions about it and to accept uncritically many of its principal features. After such acculturation lawyers sometimes lose their consciousness of the system as a system and embrace its premises with an unarticulated sense of their inevitability. What such lawyers have lost, if only partially and temporarily, is the capacity to view the litigation process as outsiders would view it. Acculturated lawyers are unable or at least unlikely to compare the system in which they function successfully to hypothetical models or abstract alternatives; they do not evaluate their system by absolute standards. Instead, they evaluate it according to its own terms, using concepts and standards that the system itself has produced.

Some examples are in order. One litigator responded to the initial, open-end question about how well discovery is working by declaring that the "system is excellent." He proceeded to report, however, that during 
the preceding five years opponents had impaired his discovery efforts in 95 percent of his cases by failing for protracted periods (a year or more) to respond to his discovery requests and in 50 percent of his cases by providing evasive or incomplete answers to his probes. Later in the interview he said he was having difficulty discovering the information he needed in "virtually all" of his currently active civil cases (of which he said there were about 200). In conjunction with this response he made an observation that may help explain how an attorney who has difficulty with discovery in almost all of his cases can characterize the system as "excellent." After conceding that he was having difficulty in virtually all of his active cases he added "that's the nature of the beast-but it's more irritating than substantially troublesome." Thus, to this litigator, difficulty inhered in "the nature of the beast" discovery. "Answers" that were evasive or incomplete or that were not even offered for a year or more had become mere irritants because they were perceived as inevitable. Since such irritants were inevitable, "realistic" lawyers accepted them. And since realistic lawyers assumed that such inevitable defects would accompany any system, these lawyers evaluated the current system of civil discovery as if such defects did not exist. Hence a system which would appear seriously flawed when judged by detached standards can be considered "excellent" by an acculturated lawyer.

Communication problems attributable to acculturation also surfaced in responses to questions about difficulty with discovery in currently active cases. When such questions were first posed, a lawyer's impulsive first response might be, "No, I'm not having difficulty discovering the information I need." In the project's earlier stages this kind of response provoked the interviewer to pose one or two follow-up questions: Did the lawyer have to ask several times for the same information? Was he receiving evasive answers? Almost invariably, the lawyer answered these follow-up questions in the affirmative and explained that it had not occurred to him that such routine problems as evasion and dilatoriness by opponents constituted "difficulty." Thus many litigators had become so accustomed to certain levels of friction and inefficiency that they no longer conceived of them as problems. Instead, such lawyers perceived a "difficulty" only when conflict or delay obviously exceeded the "normal" level. After learning that many lawyers had developed this kind of tolerance for limitations in the information exchange process, the interviewers began prefacing their questions about active cases with a request that the attorney compare his experiences with discovery to a perfectly lubricated, open process in which information flowed freely and promptly between parties with every request. After that kind of preface, very few 
(if any) attorneys said they were having no difficulty discovering the information they needed. ${ }^{15}$

\section{A. Comparing Profiles: Differences Between Attorneys Who Were Positive and Those Who Were Negative About the Discovery System}

The 34 attorneys ( 20 percent of the entire sample) who expressed clearly positive general impressions of the discovery system were distinguishable as a group in several interesting respects from the 56 lawyers ( 33 percent of the entire sample) who expressed clearly negative general assessments of the system. When compared to their counterparts in the negative group, the attorneys in the positive group tended to have considerably smaller cases (measured in dollar value), to work in smaller law firms, to commit much less time to matters filed in federal courts (as opposed to state courts), to spend more of their time representing plaintiffs (than defendants), ${ }^{16}$ and to have been in practice a few more years. ${ }^{17}$ The most dramatic differences between the group that was positive about the system and the group that was negative are presented graphically in figure $2(A),{ }^{18}(B),{ }^{19}$ and $(C)$.

The data collected during the interviews also suggest that, when compared to the attorneys in the negative group, lawyers who expressed positive assessments of the discovery system were more likely to represent individuals and less likely to represent large corporations. Figure 3 depicts graphically the percentages of attorneys in the two groups who indicated

15. Of $\mathbf{1 7 5}$ attorneys, $\mathbf{1 7 0}$ said they were having difficulty discovering the information they needed in one or more of their active civil cases. See also pp. 832-46 infra.

16. The median percentage of time during the five years preceding the interviews committed to plaintiffs' matters by attorneys in the "positive" group was 50 percent; the figure for lawyers in the "negative" group was 36 percent.

17. The median year of first admission to a bar for attorneys in the positive group was 1961; that year for lawyers in the negative group was 1966.

18. The question that produced this data was phrased: "During the past five years, approximately what is the median or typical size (measured by amount of judgment or settlement or amount realistically in dispute) of the cases on which you have worked?"

For a variety of reasons many lawyers found this question very difficult to answer. The range of the value of the cases on which some attorneys worked was very large. In addition, some lawyers typically were responsible for modest sized cases but had committed a substantial percentage of their time to one very large lawsuit. Other attorneys said that a sizable portion of their time was consumed by actions in which relatively little money changed hands but whose economic impact was considerable, e.g., suits for injunctive relief or civil rights actions aimed primarily at establishing precedents rather than recovering damages.

Because of situational variables such as these, the figures which reflect median size cases are rough approximations, reliable only for broad comparisons based on large differences.

19. The question that produced this data was phrased: "During the past five years approximately what percentage of your time in civil litigation has been consumed by matters filed in federal court -and what percentage has been consumed by matters filed in state court?" Few attorneys had difficulty answering this question. 


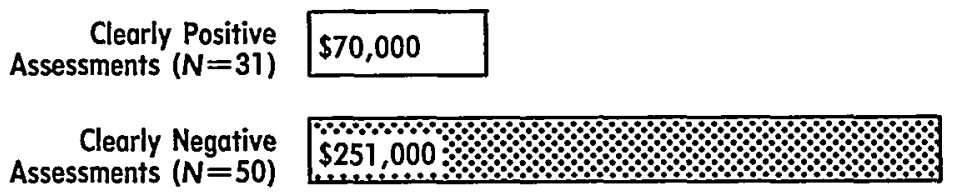

\section{A. Median Case Size}

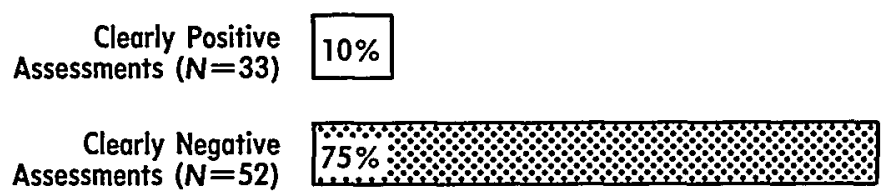

B. Median Percentage of Time Spent on Federal Court Matters ${ }^{b}$

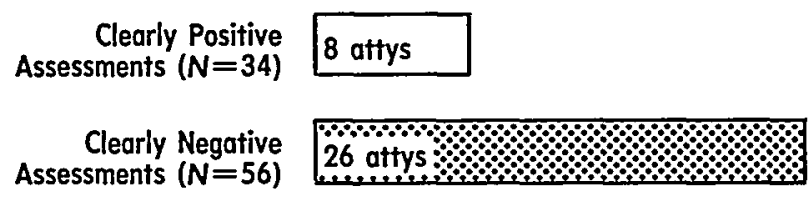

\section{Median Firm Size}

asee text note 18.
bee text note 19.

Fig 2. Attorneys' assessments of the discovery system by $(A)$ case size, $(B)$ percentage of time spent on federal court matters, and $(C)$ law firm size.

Percentage of Attorneys

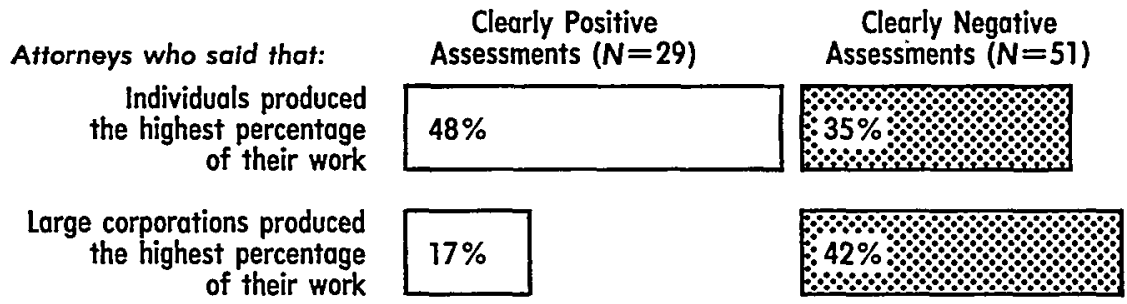

Fig. 3. Attorneys' assessments of the discovery system by whether the attorneys represented chiefly individuals or large corporations. 
that (1) individuals and (2) large corporations produced the highest percentage of their work. ${ }^{20}$

As figure 4 shows, ${ }^{21}$ attorneys in the group with clearly positive general impressions of how discovery is working also were more likely (than attorneys in the negative group) to litigate tort matters and less likely to be involved in antitrust or securities actions.

Percentage of Attorneys

Substantive Area

Miscellaneous Torts

Products Liability

Auto Personal Injury

Antitrust

Securities
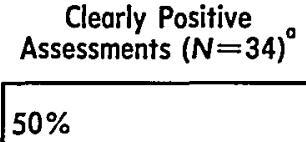

$41 \%$
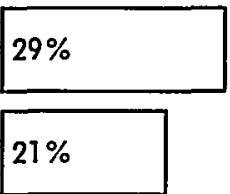

$12 \%$
Clearly Negative

Assessments $(N=56)$
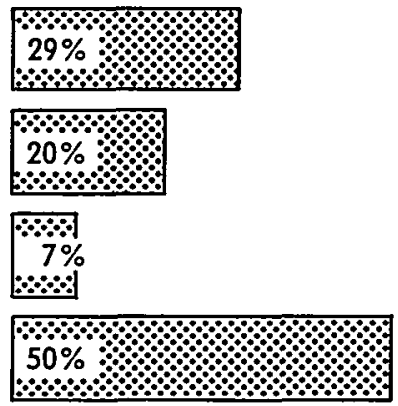

$32 \%$

${ }^{a}$ See text note 21.

Fig. 4. Attorneys' assessments of the discovery system by selected substantive areas of litigation.

20. To identify principal client types, the interviewers asked the attorneys: "Focusing on your work in civil litigation over the past two years, has any one type of client or institution been the source of more than ten percent of your litigation work during that period?" Attorneys who answered in the affirmative then were asked: "Would you please identify the client types?" and "What percentage of your work has each client type produced?"

For purposes of grouping attorneys by the kinds of clients they served, all of the following client types were treated as "large corporations": larger manufacturing or retailing corporations (distinguished from smaller, privately owned businesses or corporations), transportation or utility corporations, banks, other commercial services corporations, and diversified or conglomerate corporations.

"Professionals (doctors, lawyers, architects, engineers, etc.)" are defined as a separate type of client and are not treated as "individuals" for purposes of grouping and comparing lawyers in the sample.

21. The data reported in figure 4 was produced by the following question: "In your practice in civil litigation during the past five years, what are the principal kinds of cases you have handled?" Most of the attorneys were not asked the follow-up question, which was designed to identify areas of specialization. The following kinds of responses were treated as "miscellaneous torts": "torts" or "personal injury" matters (other than those arising out of automobile accidents-for which a separate category was created), "slip and fall," "premises," "property damage," "dram shop," and "libel" or "slander." The "antitrust" category also included "trade regulation" and "unfair commercial competition." Lawyers were treated as doing "securities" work when they used that word or any of the following phrases in response to this question: " $10 \mathrm{~b}-5$," "stockholders' derivative actions," "corporate opportunities," "breach by corporate officers or directors of fiduciary obligations." Appendix C, which describes the entire sample, lists each major "type" of case and the number of attorneys who said that type was among the principal kinds of matters on which they had worked during the preceding five years. 


\section{B. Comparing Subgroups: General Assessments of the Discovery System}

Generally, litigators whose cases tend to be smaller (in dollar value), less complex (in volume of information to be digested and in legal theories), and filed in state court are substantially less likely to feel that the discovery system is seriously defective than are lawyers whose cases tend to be larger, more complex, and filed in federal court. Comparing general assessments of the system offered by lawyers with different kinds of practices reinforces these inferences. To determine whether differently situated litigators have measurably different attitudes toward and experiences with discovery we used major characteristics of lawyers' practices to identify 17 subgroups of attorneys. ${ }^{22}$ Each subgroup included all the attorneys whose practices had in common the characteristic that defined that group. To increase the likelihood of detecting differences between differently situated lawyers the subgroups were defined so as to capture and separate the attorneys on the opposite ends of the experience spectrum that identified the category in question (e.g., attorneys who committed 80 percent or more of their time to matters filed in state court were placed in one subgroup, while those who committed 80 percent or more of their time to actions in federal court were placed in another subgroup). The two related subgroups were then compared for various characteristics. General assessments of how well the discovery system is working varied considerably between subgroups. The pattern suggested by the profiles of the groups of attorneys who expressed clearly positive or clearly negative attitudes toward the system is even more obvious in comparisons of the subgroups: big firm lawyers who primarily service large corporate clients and whose practices feature large, complex cases filed in federal court are, on balance, far less happy with the current discovery system than are smaller firm lawyers whose principal clients are individuals and whose practices tend to involve smaller, less complicated cases filed in state court. These differences between subgroups are shown in figure $5 .^{23,24}$

Plaintiffs' attorneys (those committing 75 percent or more of their time to plaintiffs' matters), as a group, were only slightly more positive about the discovery system than were defendants' attorneys (those who committed 75 percent or more of their time to defendants' matters). Figure 6 compares the general assessments offered by these two subgroups.

The direction of the difference in these overall evaluations (the plain-

22. Appendix $D$ describes the 17 subgroups.

23. Attorneys who committed 80 percent or more of their time to matters filed in state court were placed in the subgroup of "predominantly state court" respondents; similarly, lawyers who committed $\mathbf{8 0}$ percent or more of their time to matters filed in federal court were placed in the "predominantly federal court" subgroup.

24. A type of client that produced 50 percent or more of a lawyer's work was defined as "principal" or "dominant." 


\begin{tabular}{|c|c|c|}
\hline Small Coses & $31 \%$ & \\
\hline Lorge Coses & \begin{aligned} $7 \% \\
$\hdashline$i+\infty\end{aligned}$ & \% Clearly Positive \\
\hline Smoll Cases & $46 \%$ & \\
\hline Lorge Coses & $50 \%$ \% & $\%$ Mixed \\
\hline $\begin{array}{l}\text { Small Coses } \\
\text { Lorge Coses }\end{array}$ & \begin{tabular}{|l|l|}
$23 \%$ & \\
$43 \% \% \%$
\end{tabular} & $\%$ Clearly Negative \\
\hline
\end{tabular}

A. Attorneys Handling Small Coses (Median Size Case $\$ 25,000$ or Less, $N=35$ ) Versus Attorneys Handling Large Cases (Median Case Size \$1,000,000 or More, $N=42$ ).

$\begin{array}{rll}\text { Auto Personal Injury } & 34 \% \\ \text { Antitrust } & 10 \% \% & \% \text { Clearly Positive } \\ \text { Auto Personol Iniury } \\ \text { Antitrust }\end{array}$

B. Attorneys Doing Auto (Personal injury) Work $(N=29)$ Versus Attorneys Doing Antitrust Work $(\mathrm{N}=68)$.

$\begin{array}{rll}\text { State Courts } & 32 \% \\ \text { Federal Courts } & 10 \% \% & \\ \text { Stote Courts } & 47 \% \\ \text { Federal Counts } & 41 \% \% \text { Clearly Positive } \\ \text { State Courts } & 21 \% & \\ \text { federol Courts } & 49 \% \% & \\ & & \end{array}$

C. Attorneys with Cases Predominantly in State Courts $(N=62)$ Versus Attorneys with Coses Predominantly in Federal Courts $(N=49)$.

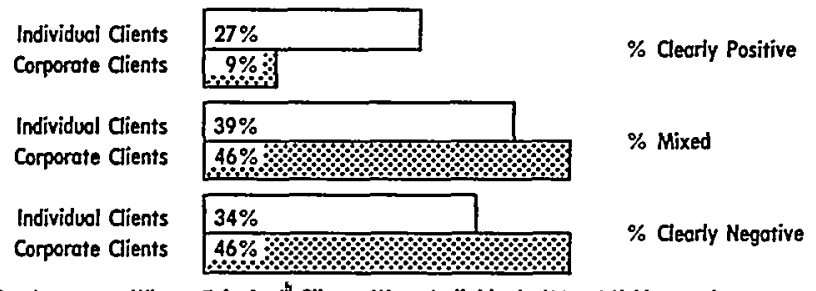

D. Attomeys Whose Principol Clients Were Individuals $(N=44)$ Versus Attorneys Whose Principal Clients Were Corporations $(N=35)$.

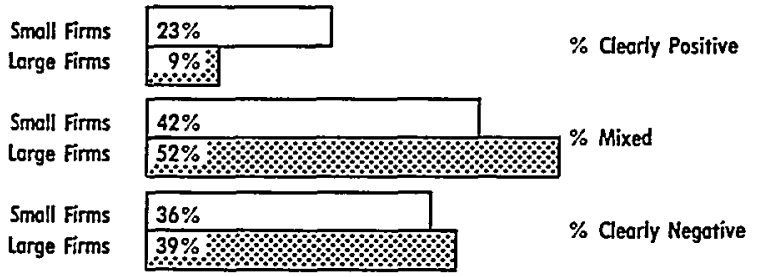

E. Attorneys in Small Firms ( 5 or Fewer, $N=53$ ) Versus Attorneys in Large Firms (120 or More, $N=33$ ).

$$
\begin{aligned}
& \text { isee text note } 23 . \\
& \text { See text note } 24 .
\end{aligned}
$$

Fig. 5. Attorneys' assessments of the discovery system compared for contrasting sets of practice characteristics. 
Represented:

$\begin{array}{rll}\text { Plaintiffs } & 30 \% \\ \text { Defendants } & 20 \% \text { \% } & \\ \text { Plaintiffs } & 43 \% \\ \text { Defendants } & 46 \% \text { Clearly Positive } \\ \text { Plaintiffs } & 27 \% & \% \text { Mixed } \\ \text { Defendants } & 34 \% \text { \% }\end{array}$

Fig. 6. Attorneys' assessments of the discovery system by whether the attorneys represent predominantly plaintiffs $(N=44)$ or predominantly defendants $(N=61)$.

tiffs' group being more positive) is consistent with the direction of the differences between the subgroups shown in figure 5. Comparing plaintiffs' attorneys and defendants' attorneys reveals that the former are more likely to represent individuals (as opposed to large corporations), ${ }^{23}$ to practice in small firms, ${ }^{26}$ and have smaller (in dollar value) ${ }^{27}$ and less complicated cases $^{28}$ filed in state courts. ${ }^{29}$ The difference between the general assessments by these two groups, however, is noticeably smaller than are the comparable differences between the five sets of subgroups whose general impressions are shown in figure 5. One factor that might help explain this is that the difference in median size case between these two groups was a great deal smaller than it was in the other five sets of subgroups. Moreover, the median size case of the defendants' group (which was more negative about the system than the plaintiffs' group) was substantially smaller than the median size case of the more negative of the two groups in the other five sets of subgroups. Figure 7 illustrates these differences.

Similarly sharp contrasts were visible when the six subgroups were compared with respect to the percentage of professional time the attor-

25. Thirty-seven of the $\mathbf{4 7}$ predominantly plaintiffs' lawyers reported that individuals produced 50 percent or more of their work (the median of these percentages was 97 percent). Only 1 of these lawyers identified large corporations as a principal client type (and large corporations produced only 25 percent of that lawyer's work).

In sharp contrast, among the 62 predominantly defendants' attorneys only 3 - said that individuals accounted for 25 percent or more of their work, whereas 20 reported receiving 23 percent or more of their work from large corporations and an additional 21 said that insurance companies generated 55 percent or more of their business.

26. The median size firm in which the attorneys in the predominantly plaintiffs' group practiced was 5 lawyers, whereas for the attorneys in the defendants' group it was 66.

27. See fig. 7 infra.

28. See the profiles of the subgroups in appendix $D$ and note that higher percentages of defense lawyers (than plaintiffs' attorneys) identified antitrust, commercial contracts, and securities matters as among their principal types of cases.

29. For the attorneys in the plaintiffs' group the median percentage of time consumed by matters filed in federal court was only 10 percent, whereas that figure was 34 percent for the lawyers in the defendants' group. 
No. 4
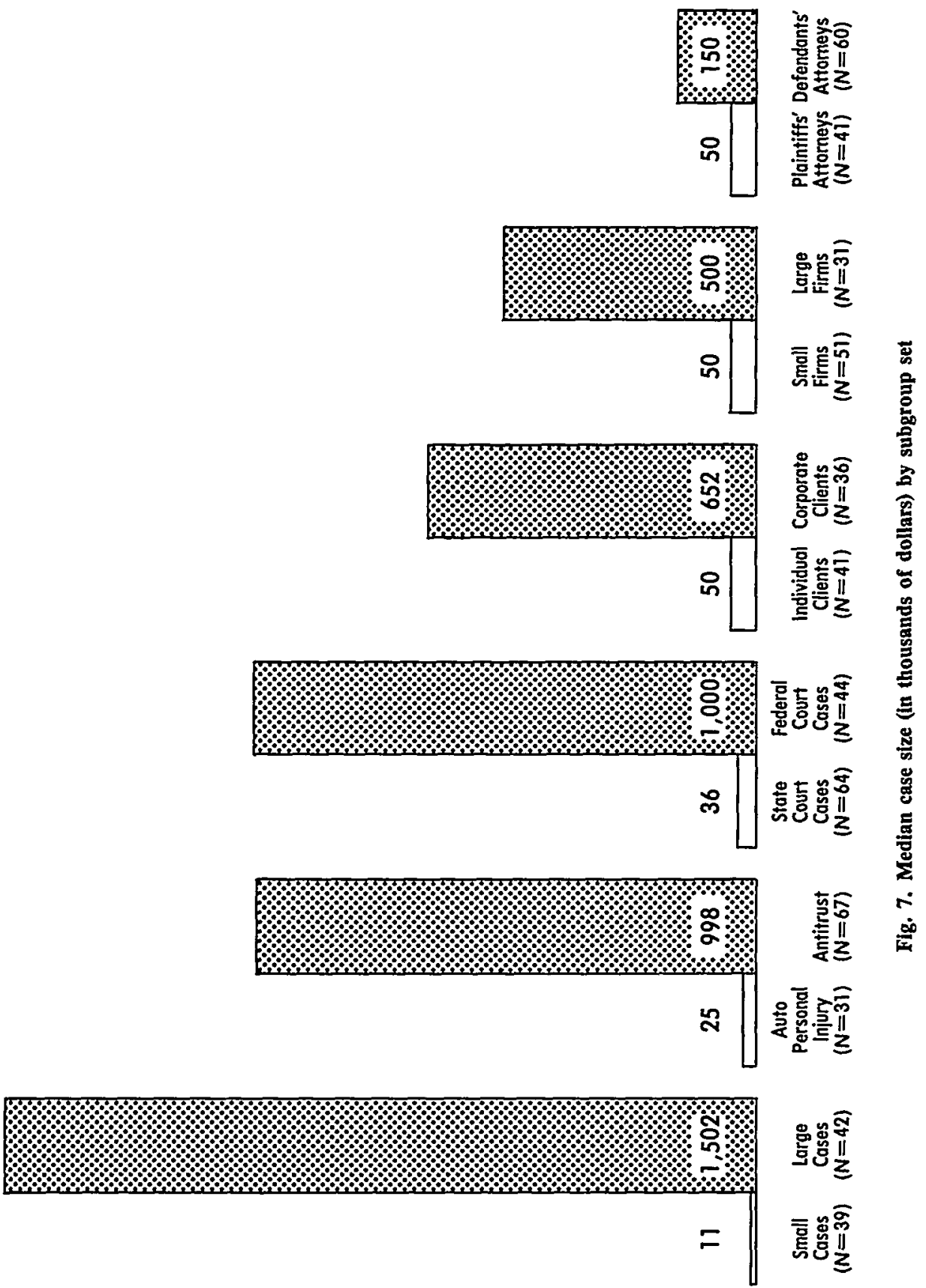
neys committed to matters filed in federal courts. The difference between the median percentage of time committed to federal court actions by the plaintiffs' group and by the defendants' group was a great deal smaller than it was in the other five sets of subgroups and that percentage for the defendants' group (which was higher than it was for the plaintiffs' attorneys) was much smaller than it was for the more negative of the two groups in the other five sets of subgroups. Figure 8 presents these findings.

These comparisons of subgroups suggest that there is a relatively direct relationship between, on the one hand, the degree of general disaffection with the discovery system lawyers are likely to feel and, on the other hand, the median dollar value of their cases and the percentage of their time committed to matters filed in federal court. An examination of the data for the subgroups defined by size of law firm reinforces this inference. The differences in general assessments of discovery between the small firm lawyers and their large firm counterparts were smaller than were the differences in general evaluations between the sets of subgroups defined by size of case, type of case, percentage of time consumed by federal court actions, or client types. Correspondingly, the differences in median size case and in percentage of time committed to actions in federal court between the subgroups defined by size of firm were smaller than were those differences between the groups composing the other four sets of subgroups. Similarly, the attorneys in the large firm group, who were less negative about the system than the lawyers in any of the other four negative subgroups, also had smaller median size cases and committed lower percentages of their time to federal court actions than did the litigators in the other four negative subgroups. These comparisons suggest (but, of course, cannot prove) that among (1) size of case, (2) percentage of time spent on actions in federal court, (3) size of firm, and (4) percentage of time spent representing plaintiffs, the most reliable predictors of disaffection with discovery are the first two and the least reliable is how a lawyer divides his time between plaintiffs and defendants. ${ }^{30}$

One set of subgroups' general assessments of how well the discovery system is working remain to be compared: the more experienced attorneys ( 25 years or more in practice) and the lawyers with less experience (fewer than 10 years in practice). The differences in general assessments

30. As suggested in the introduction to this article, the median size of lawyers' cases appears to be the most reliable single predictor not only of degree of disaffection with the way the discovery system is working but also of the likelihood in any given case that various kinds of obstacles (including tactical maneuvering) will impede the information exchange process. The strong correlations between percentage of time consumed by federal court matters, on the one hand, and, on the other, general negative assessments of the discovery system and the likelihood of experiencing difficulties with discovery, seem to be primarily a function of the fact that in federal court the typical civil cases tend to be much larger and more complex than they are in state court. 


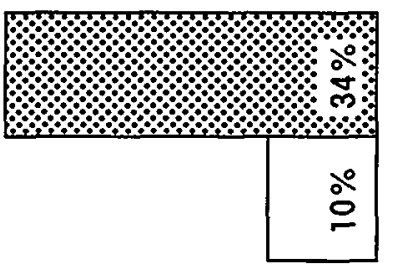

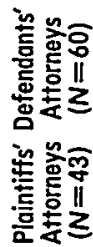

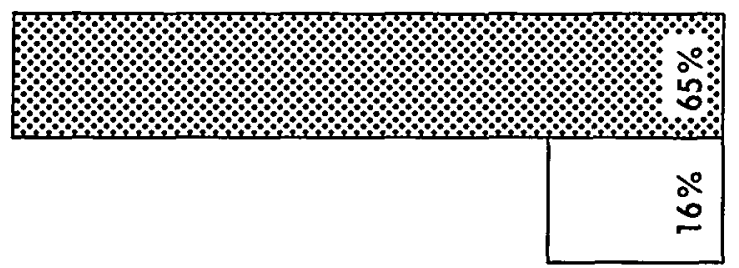

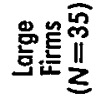

유 홀츈

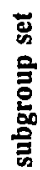

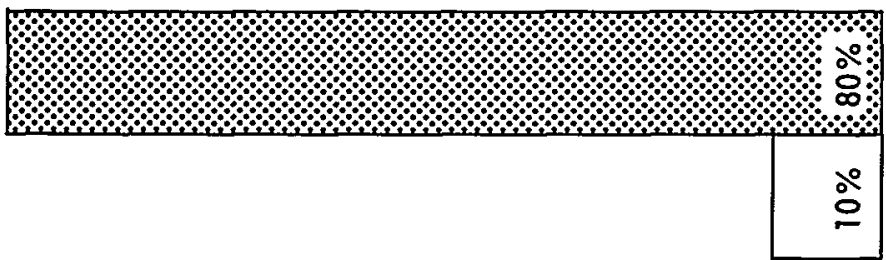

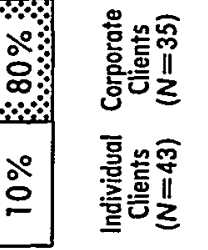

s

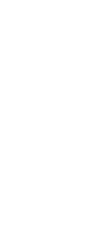

冚

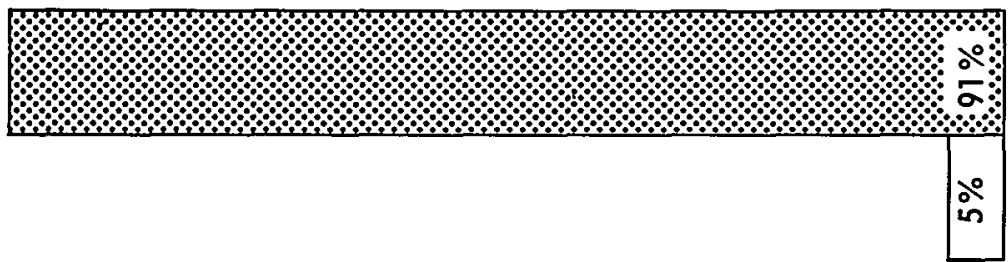

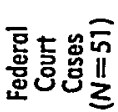

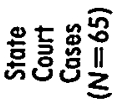

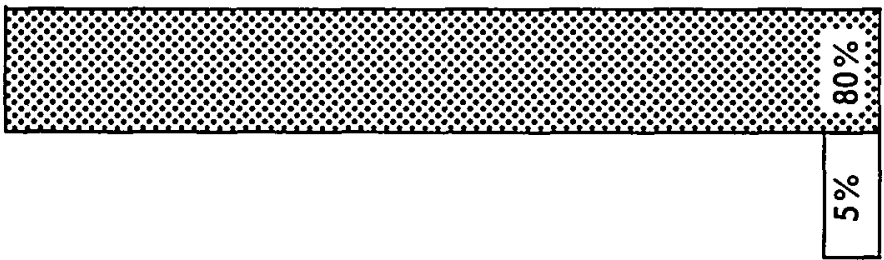

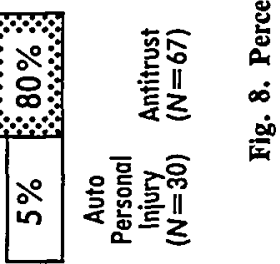

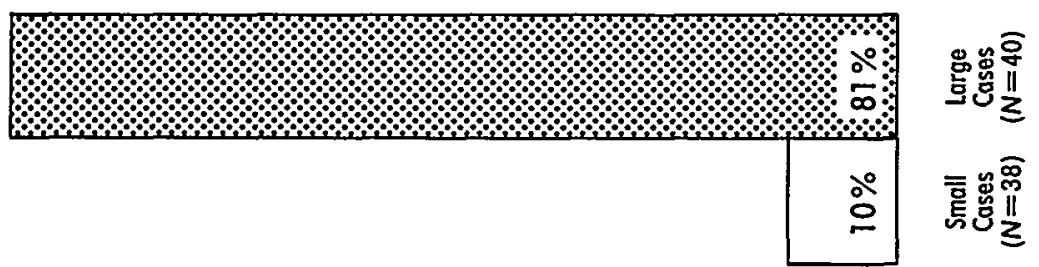


between these two groups are relatively small: the senior litigators were only slightly more positive about the way civil discovery is working. Figure 9 portrays the assessments by these two subgroups.

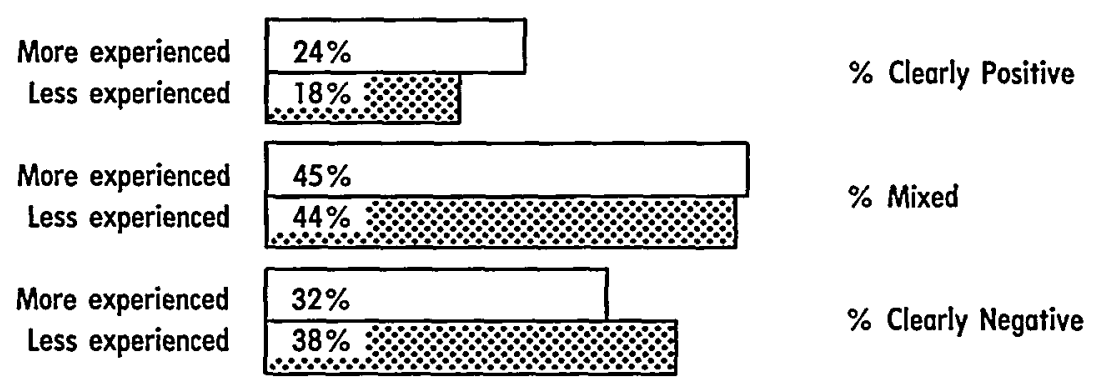

Fig. 9. Attorneys' assessments of the discovery system compared for more experienced attorneys ( 25 or more years in practice, $N=38$ ) and less experienced attorneys ( 9 years or less in practice, $N=39$ ).

Comparing the profiles of these two subgroups offers clues about why the differences in their general assessments of the discovery system were so slight. The two subgroups were relatively similar with respect to five of the six other characteristics by which attorneys were compared: in the aggregate, the lawyers in each group spent virtually identical percentages of their time on federal court actions, ${ }^{31}$ the pattern of principal case types was quite similar between the two groups, ${ }^{32}$ and, relative to the other sets of subgroups, there were only modest differences between these two subgroups with respect to median size case, ${ }^{33}$ principal client types, ${ }^{34}$ and proportion of time devoted to plaintiffs' matters. ${ }^{35}$ The one situational variable on which the two subgroups differed significantly was size of law firm: the median size of the firms in which the more experienced lawyers practiced was 12, while for the less experienced attorneys it was 40 . The fact that despite this difference in firm size the two groups expressed relatively similar views about the general effectiveness of the discovery system suggests that size of law firm may not be as reliable a predictor of attitudes toward discovery as such factors as size and nature of cases, principal client types, and proportion of time spent in federal court. ${ }^{36}$

31. The median percentage of time committed to matters filed in federal court was 42 percent for the attorneys in the more experienced group and $\mathbf{4 0}$ percent for the lawyers in the less experienced group.

32. See the profiles of subgroups in appendix $D$.

33. The median size case for the lawyers in the senior group was $\$ 250,000$, while for the less experienced litigators it was $\$ 50,000$. This difference between these two subgroups was substantially smaller than the difference in median size cases between subgroups in five of the other sets of subgroups. See fig. 7 supra.

34. See the profiles of subgroups in appendix $D$.

35. The median percentage of time committed to plaintiffs' matters was 40 percent for the more experienced litigators and 50 percent for the less experienced lawyers.

36. Comparing the profiles of the attorneys in the more experienced and the less experienced groups also reveals, however, some inconsistencies with the patterns established in the other sets of 
The differences between subgroups in general assessments of discovery are clearly associated with one dominating tendency: the lawyers whose cases are likely to involve the most discovery (because they are complicated and because a lot of money is at stake in them) are likely to be the least happy with the system. These lawyers are the most likely to complain that the discovery process fails to produce all the significant evidence and is seriously infected by tactical machinations.

subgroups. On the basis of the patterns described above, differences in three situational variables would support a prediction that the more experienced group would be moderately more negative about the discovery system (instead of moderately more positive) than the less experienced group. Perhaps most significant, the median size case for the senior group was larger than it was for the less seasoned litigators. While relative to other sets of subgroups the degree of that difference was relatively small, in absolute terms it was not insignificant (the median size case for the senior group was $\$ 250,000$, while for the less experienced lawyer it was $\$ 50,000$ ). Litigators in the senior group also appeared to represent large corporations and defendants somewhat more often than did the less experienced attorneys, although the differences between groups with respect to these variables was not sizable. See the profiles of the subgroups in appendix $D$.

Because the recording and categorizing of the lawyers' general assessments was an imprecise process, and because the differences between these two subgroups in overall evaluations of discovery were so slight, it may well be that the inconsistencies described in the preceding paragraph are insignificant. If not, the following considerations may help account for them. Thirty-two percent of the lawyers in the subgroup of less experienced lawyers indicated that civil rights actions were among their principal types of cases-a higher percentage than in any other subgroup. In sharp contrast, only 1 of the attorneys in the senior group ( 3 percent) indicated that civil rights litigation consumed a sizable percentage of his time. This difference between the two groups is significant because attorneys who did civil rights work were among the more critical of the overall effectiveness of the discovery system. General assessments of how well discovery is working were recorded for 26 of the 29 attorneys who identified civil rights actions as among their principal types of cases. While only 3 (12 percent) offered clearly positive evaluations, 11 (42 percent) expressed clearly negative views. The remaining 12 (46 percent) had mixed general impressions of the system.

One factor that may help account for the relatively negative assessments of the discovery system by attorneys who litigated civil rights matters may be that the defendants in such actions often are governmental entities. Thirty-five of 105 responding attorneys identified "governmental bodies" of various kinds as among the types of parties from whom discovery was noticeably more difficult than from others. Large corporations were the only other kinds of parties mentioned with anything like comparable frequency. Several attorneys also volunteered complaints about problems they had encountered trying to discover information from governmental opponents, blaming such factors as unresponsive bureaucratic attitudes and poor records management. In addition, some government lawyers reported having difficulty securing the full cooperation of the departments or agencies they had defended, citing, among other things, the departments' reluctance to be completely open with their own counsel and their resistance to producing all relevant documents.

Another hypothesis that might explain the more negative views of discovery expressed by the less experienced attorneys is that younger lawyers may have greater expectations of the discovery system (as well as of the larger process of dispute resolution) than have more seasoned litigators. The less experienced lawyers may have reached a less complete accommodation with the system as it in fact operates. If younger lawyers expect more of the system, their more negative assessments of it may be more a function of disappointment than of differences in experience. One senior litigator made a related observation that appears to support this hypothesis. He suggested that when asked for an overall impression of how well discovery is working, older lawyers are apt to compare the current system to its historical predecessor: a process that permitted very little discovery of any kind. Thus when asked how things are, an older and a younger lawyer may be likely to answer by comparing their perceptions of the current system to two quite different alternatives: the older lawyer using as a basis for comparison a discredited system with next to no discovery and the younger lawyer using the purer model he associates with a "perfect" system of justice. 


\section{The Effectiveness of Discovery as a System for INFORMATION DISTRIBUTION}

"In the adversarial system it's one group's job to get in-
formation and the other's not to give it to them."
-a Chicago litigator
"The most central information in the case is always hard
to discover." -a Chicago litigator

According to the United States Supreme Court, one of the primary purposes of the rules of civil discovery is to assure "[m] utual knowledge of all the relevant facts gathered by both parties [that] is essential to proper litigation." ${ }^{37}$ One objective of this field survey was to ascertain the views of civil litigators about how well the discovery system is achieving this end. The interviews included several questions to determine how often, in the judgment of the litigating bar, cases are resolved (i.e., closed by settlement or judgment after trial) with at least one party not having all the significant evidence gathered by the other parties. There are, of course, many different reasons that can explain why cases are resolved even though the parties do not enjoy "mutual knowledge of all the relevant facts," for example, economic pressures, doctrinal protections of certain communications (e.g., the attorney-client privilege) or types of private information (e.g., trade secrets), ineffective lawyering (or effective "avoidance lawyering"), and dishonesty by clients or counsel, to name some of the more obvious. While we examined the roles of some of these causes, we also were interested in assessing the gross dimensions of the phenomenon itself. Regardless of the reasons, we wanted to know how often there are significant imbalances in information between parties when cases are formally resolved. If such imbalances occur frequently, discovery as a system to distribute information evenly is in some measure failing. It is important to evaluate how the rules work in the economic and psychological environment in which they are used and not merely to consider how much information the rules in theory empower parties to acquire. If, for example, evasive tactics make the cost of using theoretically available tools prohibitive in all but the biggest litigation and if that fact forces many parties to settle claims without significant information, it would be appropriate to ask whether some alternative system might more efficiently and evenly distribute information between litigants.

37. Hickman v. Taylor, 329 U.S. 495, 507 (1947); for a description of similar views by other courts and by the drafters of the federal discovery rules, see Wayne D. Brazil, The Adversary Character of Civil Discovery: A Critique and Proposals for Change, 31 Vand. L. Rev. 1295, 1298-1303 (1978). 
What does the data suggest about how effectively the discovery system distributes information? In one of the questions designed to gauge litigators' views on this subject the interviewers asked whether "it ever happened that after you . . . settled a case (as distinguished from trying it to completion) you or your client still had arguably significant information (including information protected by privilege) which, to the best of your knowledge, another party had not discovered." If the responding attorney answered in the affirmative, the interviewer then asked, "During the past five years, in approximately what percentage of the cases you have settled has this occurred?" Of the 176 lawyers who answered the first of these two questions, 168 (96 percent) said yes. The answers to this question reflect no significant differences between subgroups; among the 17 subgroups whose answers were systematically compared, ${ }^{38}$ the lowest percentage of respondents indicating that they had at least once settled a case believing they knew something significant that an opponent had not discovered was 87 percent. $^{39}$

There were, however, significant differences between subgroups with respect to how often this phenomenon occurred. The 164 lawyers in the sample as a whole who responded to the second question reported that in about one of every three settled cases they believed they still knew (after settlement) something significant that the other side did not know. ${ }^{40} \mathrm{By}$ contrast, the lawyers whose median size case was $\$ 1,000,000$ or more reported that in one of every two settled cases their opponents had not discovered something arguably consequential. ${ }^{41}$ Lawyers whose median size cases were much smaller ( $\$ 25,000$ or less) reported such settlements much less often: in only one of every four settlements. ${ }^{42}$ Comparing other subgroups revealed a similar pattern: the groups whose lawsuits tended to be large and complex reported knowing something significant that opponents had not discovered in about 50 percent of the cases they settled; the figures for the groups whose cases tended to be smaller and less complex ranged between 16 percent and 25 percent. Figure 10 presents this data graphically. ${ }^{43}$

38. The 17 subgroups whose responses were compared are listed in appendix $\mathrm{D}$.

39. This was the subgroup of predominantly plaintiffs' attorneys, i.e., those who committed 75 percent or more of their time to plaintiffs' matters. There were 47 such lawyers in the sample.

40. While the median of the percentages for the 164 respondents was 30 percent, the mean was 37 percent.

41. The median for this subgroup ( 39 of 42 responding) was 50 percent; the mean was 56 percent.

42. The median for this subgroup ( 37 of 39 responding) was 24 percent; the mean was 26 percent.

43. The data in fig. 10 and elsewhere in this article reflect the medians of the percentages provided by the respondents in each group. The means of the percentages are consistently higher for these responses as well as for a great many others reported in this article. Differences between means and medians are reported where they seem particularly noteworthy. The fact that so many of the means are higher than their corresponding medians suggest that some respondents experience some problems much more often than other respondents in the subgroups.

For the subgroup whose dominant client type was individuals the mean of these responses was considerably higher: 27 percent. 


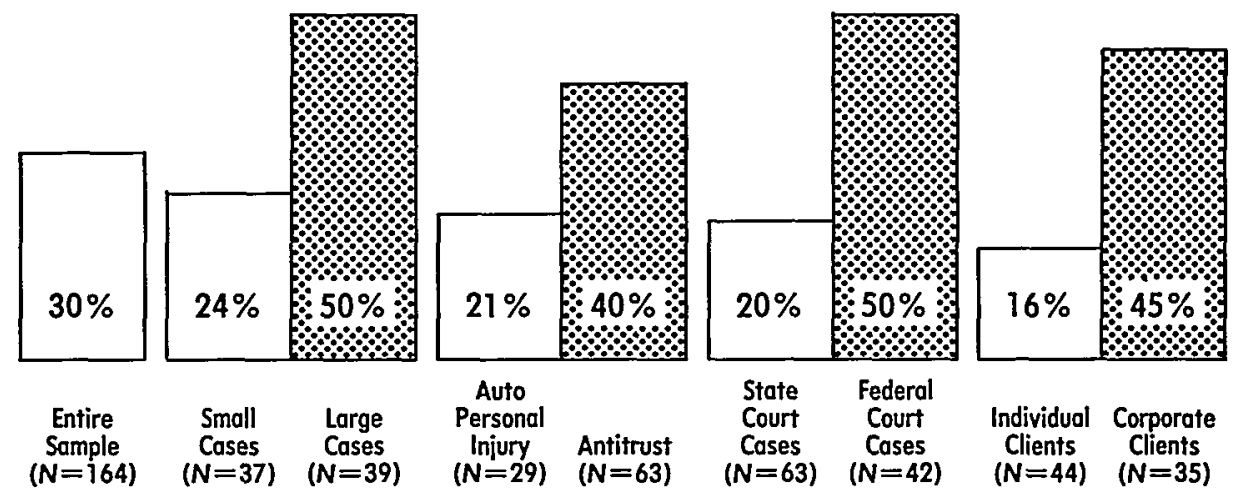

Fig. 10. Median percentages of settled cases in which the attorney believed that the opponent had not discovered all significant information by subgroup set (see text note 43).

It is clear from the data presented in figure 10 that the likelihood of a case being settled with one party believing it has significant information that other parties do not have increases substantially as the size and complexity of the litigation increases. While it might be tempting to attribute this important difference between large and small case litigation solely to the fact that the former generally involves greater quantities of information and, arguably, more subtle theories of liability, other data derived from the interviews suggest that additional factors are at work. It is obvious that the amount of discovery conducted tends to increase with the size of litigation (the economic facts of life permit nothing else), and many lawyers suggested that the thoroughness of discovery also tends to vary directly with the amount at stake. One would expect these differences in the character of discovery efforts to offset, at least in some measure, the fact that in larger cases there generally is more evidence to be discovered. However, as data presented in subsequent sections of this article indicate, attorneys litigating larger cases are more likely than smaller case lawyers to invoke privileges and to use tactical ploys to try to protect information from disclosure; they also are more likely to feel frustrated by the evasions and maneuvers of opposing counsel. In short, it appears that the adversarial forces that militate against relatively complete information exchange are much harder at work in the bigger cases.

It would be unwise, however, to permit debate about causes to distract our attention from the dimensions of the phenomenon: after settlement, in at least one of every two of the larger cases and one in every four of the smaller cases, something important reportedly remains undiscovered by at least one party. Since most cases are settled (rather than tried to judgment), these figures apply to most cases. They include cases in which information is protected by privilege, but that consideration offers little solace to the concerned because (as will be discussed in subsequent para- 
graphs) intervention of privilege reportedly is not the reason that most often accounts for opponents' failure to discover important evidence. Moreover, since there are at least two attorneys in virtually every lawsuit, it is reasonable to infer that the percentage of settled cases in which a party has failed to discover some arguably significant evidence is substantially higher than the percentage of cases individual attorneys reported settling with an informational advantage. If each big case lawyer, for example, settles half of his cases knowing something consequential that an opponent has not discovered, the likelihood is greater than 50 percent that in any given big case that is settled at least one party will have failed to discover something important.

Lawyers' responses to similar questions about cases that were tried to judgment offer more encouraging figures. This is true even though 79 percent of the attorneys in the sample group as a whole (with 169 responding) said that at least once after they had tried a case to completion they believed they still knew something significant about the matter that another party had not discovered. The comparable percentages for the subgroups were around 79 percent. ${ }^{44}$

The data generated by the follow-up question, however, indicate that the likelihood of significant information remaining undiscovered is substantially smaller in cases tried to completion than in cases that are settled. The interviewers asked the lawyers who said they had tried at least one case to judgment believing that an opponent had failed to discover something significant from them to estimate the percentage of the trials they had completed during the preceding five years in which such a failure had occurred. Because the responses for the sample group as a whole covered a wide range, there was a significant difference between the median and the mean of the percentages: while the median was 15 percent, the mean was 26 percent. There were even greater differences between the means and the medians for several of the key subgroups, for example, for the attorneys whose median size case was $\$ 1$ million or more, the median percentage was 22 percent but the mean was 41 percent. ${ }^{45}$ Figure 11 describes, in terms of both medians and means, how often attorneys in four sets of subgroups reportedly completed trials knowing something significant that an opponent had not discovered.

As the last set of bar graphs in figure 11 shows, defendants' attorneys

44. These percentages ranged from a low of 66 percent for the lawyers who committed 80 percent or more of their time to matters filed in federal court to a high of 85 percent, the median figure for two subgroups: attorneys in firms of 120 or more lawyers and litigators who represented defendants 75 percent or more of their time. The modest differences between subgroups formed no pattern; e.g., the subgroups associated with smaller cases did not consistently report smaller (or larger) percentages than the subgroups associated with larger cases.

45. Eight of the 29 lawyers in this group who answered this question said that opponents failed to discover arguably significant information in 85 percent or more of the cases they had tried in the five-year period. 

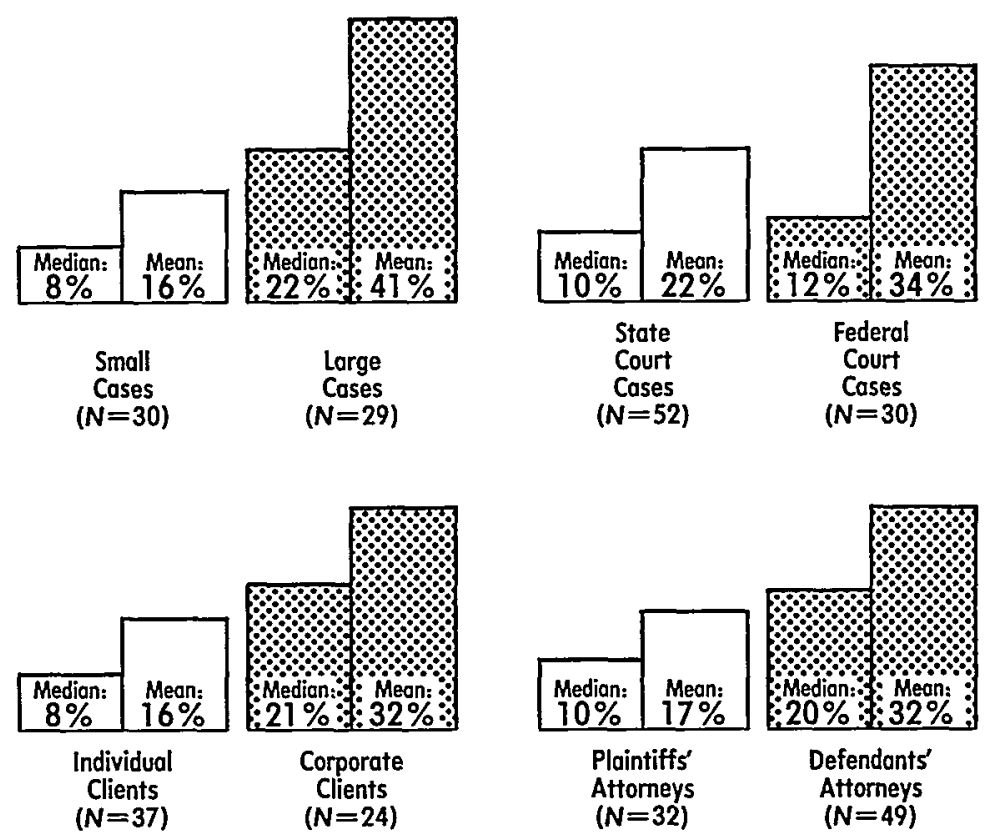

Fig. 11. Median and mean percentages of tried cases in which the attorney believed that the opponent did not discover all significant information by subgroup set.

were more likely than plaintiffs' attorneys to believe, after trial, that they knew something of consequence about the case that opposing counsel had not discovered. Defendants' attorneys also were more likely than plaintiffs' counsel to settle cases with this belief: for the defendants' subgroup the median percentage of cases so settled was 30 percent and the mean was 39 percent, while for the plaintiffs' subgroup the comparable figures were 20 percent and 29 percent. ${ }^{46}$ These comparisons are among the relatively few between plaintiffs' lawyers and defense counsel that appear to reflect consequential differences in experience with discovery. Interestingly, these comparisons suggest that of these two subgroups, the one that expressed more positive general assessments of the discovery system (the plaintiffs' group) was also the least successful in using that system to acquire relevant evidence. It also is noteworthy that among all the sets of subgroups compared, the groups that offered the most negative overall evaluations of how well discovery is working also were the most likely to settle or try cases believing their opponents had not discovered some significant information from them.

The graphs in figure 11 also suggest that in matters that were tried to completion, the likelihood of significant information remaining undis-

46. This difference between the plaintiffs' group and the defense group may suggest that plaintiffs generally have more to discover than defendants. 
closed was substantially greater in large, complex litigation than in smaller cases. Comparing the experiences of two specially defined subgroups reinforces this inference. There were 38 attorneys in the sample who had tried ten or more lawsuits and whose median size case was $\$ 500,000$ or more. They made up the first of these special subgroups. Thirteen lawyers claimed to have had 100 or more civil trials and a median size case of $\$ 25,000$ or less. They made up the second subgroup. As a group, the lawyers with the larger cases claimed that they had completed between 20 percent (median) and 30 percent (mean) of their trials with an opponent having failed to discover something arguably significant from them. For the lawyers with the smaller cases, in sharp contrast, the parallel figures were 5 percent (median) and 8 percent (mean).

The interviewers asked two additional sets of questions concerning attorneys' perceptions of how well discovery works to distribute information. The first explored litigators' feelings about the completeness of the knowledge that informed their settlement advice. The interviewers asked: "Have you ever suspected, when you settled a case, that another party had relevant information (including information legitimately protected by privilege or other rules) that you had not discovered?" The first followup question for the lawyers who answered in the affirmative was: "During the past five years in approximately what percentage of the civil cases you have settled have you had that feeling." 47

Before examining the data these questions generated it is important to point out that several lawyers appeared to view an admission that they had negotiated settlements without first discovering all the relevant evidence as a serious negative reflection on their competence. That feeling may have induced some attorneys to deny ever settling a case without complete information or to understate the frequency of such settlements.

Perhaps the most striking thing about the responses to these questions is that they present a picture of discovery's effectiveness as a system for distributing information that is, with one notable exception, identical to the picture presented by the responses to the questions about how often lawyers settled cases believing that they retained significant information that an opponent had not uncovered. The similarity between these pictures is even more noteworthy in light of the fact that the sets of questions that produced the two pictures were so widely separated in the inter-

47. One of this project's goals was to explore lawyers' attitudes toward the effectiveness of the discovery system. Answers to these questions help expose such attitudes. Since part of what these questions explore is the subjective state of mind in the responding attorney, the answers offered by some lawyers could be informed as much by their personality traits as by objective evidence. Answers so informed obviously cannot serve independently as reliable guides to reality. There are many circumstances, however, when a lawyer's feeling that evidence remains "out there" but undiscovered can be well grounded, e.g., when an opponent has successfully asserted a privilege or for some other reason refused to comply with a discovery request or when economic pressures compel a premature termination of discovery efforts. 
views that it is very unlikely that the lawyers consciously made any connection between them. In brief, both pictures depict a system in which about one-third of all civil cases, about one-half of the larger cases, and about one-fourth of the smaller cases are settled with at least one side believing it has evidence which the other side does not have.

Of the 176 lawyers in the sample who responded, 154 ( 88 percent) said that they had settled one or more cases suspecting that another party still had relevant but undisclosed information. Among the principal subgroups examined this percentage ranged from a low of 79 percent (for attorneys whose dominant client type was individuals) to a high of 98 percent (for attorneys whose median size case was $\$ 1$ million or more). The data about how often litigators were likely to feel this way after settlement are more instructive. Viewed as a whole, the sample indicated that in about one-third of all settlements lawyers suspected that opponents retained undisclosed information. ${ }^{48}$ For most of the major subgroups the percentages closely paralleled the figures that reflect how often lawyers settled believing they knew something significant their opponents had not discovered. ${ }^{49}$ For example, the median and mean percentages for the smaller case lawyers were 20 percent and 31 percent, respectively, while for the large case attorneys they were 50 percent and 49 percent.

As suggested above, there is one notable exception to the generalization that the lawyers were likely to feel that an opponent had not discovered something from them in about the same percentage of settled cases as they were likely to feel that they had not discovered something from an opponent. That exception occurred in every subgroup in which the attorneys committed substantially more than 50 percent of their time to plaintiffs' matters: attorneys whose dominant client type was individuals, those who practiced in firms of five or fewer attorneys, those whose principal types of cases included tort actions arising out of automobile accidents, and, of course, those who committed 75 percent or more of their time to representing plaintiffs. In each of these subgroups the attorneys were about twice as likely to settle a case suspecting that their opponent still had undisclosed information than believing that their opponent had not discovered something significant from them. Thus, after settlement, attorneys who usually represented plaintiffs were likely to suspect that they had not uncovered information from an opponent in about 40 percent of their cases, whereas they were likely to believe an opponent had failed to discover something from them in only about 20 percent of their cases. ${ }^{50}$ Moreover, the data suggest that the plaintiffs' law-

48. Median of the percentages provided by the responding lawyers was 30 percent; the mean was 41 percent.

49. See fig. 11 supra.

50. This is another difference between the plaintiffs' group and the defense group that may suggest that plaintiffs generally have more to discover than defendants. See text at note 46 supra. 
yers' suspicions were well grounded in reality. For the subgroups in which litigators tended to commit substantially more than 50 percent of their time to the defense side ${ }^{51}$ the median percentage of cases the lawyers settled believing their opponent had failed to discover something significant from them was approximately 40 percent (thus remarkably close to the percentage the plaintiffs' lawyers suspected).

Answers to another set of questions on surprise during trial also shed some light on how well discovery works to distribute information. The interviewers asked: "Has it ever happened that something relatively significant has come up at trial that had not been disclosed by another party or that you had not discovered during the discovery stage of litigation?" The follow-up question for attorneys who said yes was: "During the past five years in approximately what percentage of the civil cases you have tried has this occurred?" 52

Eighty-three percent (141 of 171) of the litigators in the sample said they had been surprised at one or more trials by something relatively significant. Among the subgroups this percentage ranged from a low of 72 percent for the lawyers with less than 10 years experience (they had tried fewer cases than lawyers in other subgroups) to a high of 97 percent for the lawyers with more than 25 years experience (who had tried more cases than attorneys in other subgroups)..$^{53}$ The response to the follow-up question about how often the lawyers were surprised at trial by evidence they had not uncovered during the discovery stage established no dramatic differences between subgroups. The medians and means for virtually all of the subgroups indicate that the lawyers were likely to have been surprised during between 10 percent (the median for the entire sample and for most of the subgroups) and 22 percent (the mean for the entire sample) of their trials. The figures were no higher for the lawyers whose practices were dominated by large, complex cases.

These relatively low percentages for the big case litigators provoke a question the data cannot fully answer: why is there such a sizable difference between the percentage of large cases settled with at least one party reportedly having failed to discover something significant from another

51. The groups (1) whose median size case was $\$ 1$ million or more, (2) whose principal types of cases included securities matters, (3) whose dominant client type was large corporations, and (4) who practiced in firms of 120 or more lawyers.

52. As we discovered during some of the early interviews, the first of these two questions is not free from ambiguity: a few lawyers construed it to include information from their own clients by which they were surprised at trial as well as new evidence from opponents. While it is not clear how many attorneys so construed the question, the number probably is small, in part because the interviewers often orally clarified the focus of the inquiry and in part because the median percentages produced by the follow-up question were surprisingly low.

53. The median number of cases the lawyers in the less experienced group had tried was 15; that figure for the more experienced group was 151 . The median number of trials for the other subgroups ranged between 18 (for lawyers whose median size case was $\$ 1$ million or more) to 100 (for attorneys who committed 80 percent or more of their time to matters filed in state court). 
(about 50 percent) and the percentage of cases in which new information surprises at least one party during trial (10-20 percent)? Figure 12 graphically compares (in terms of means and medians) the differences for big case lawyers between: (1) the percentage of cases they settled believing an opponent had not discovered something significant, (2) the percentage of cases they tried to completion with a similar belief, and (3) the percentage of trials in which they were surprised by information they had not discovered.

A. Attorney believed that the opponent had not discovered significant information:

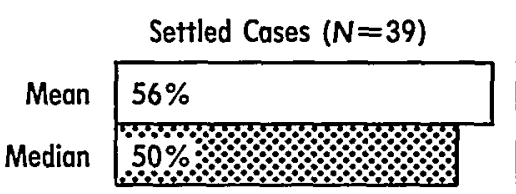
Tried Cases $(\mathrm{N}=29)$

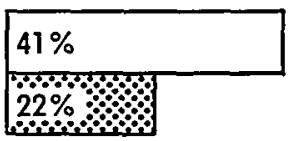

B. Trials during which the attorney was surprised by evidence he had not discovered $(\mathrm{N}=32)$

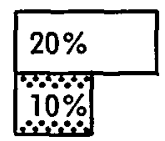

Fig. 12. Big case lawyers: Mean and median percentages of $(A)$ settled and tried cases in which the attorney believed that the opponent had not discovered significant information and of $(B)$ trials during which the attorney was surprised by evidence he had not discovered.

Common sense suggests two considerations that may help account for these differences. One is the probability that lawyers generally conduct substantially less discovery in cases that are settled than in those that are tried. Primarily for economic reasons, even some large cases are settled well before the lawyers would consider discovery to be completed. This probably occurs much more often in smaller cases, where the costs of discovery and trial, relative to the amount in controversy, can make early settlement the only economically reasonable alternative. The probability that less discovery is conducted in settled cases than in tried cases appears to be the most likely explanation for the significant difference between the percentage of large cases that reportedly were settled with at least one party not having discovered significant evidence (about 50 percent) and the percentage of large cases tried to completion in a similar condition (approximately 25-30 percent). More intensive and complete discovery efforts, however, cannot explain the difference between the percentage of large cases tried to completion with at least one side reportedly having failed to discover something significant (25-30 percent) and the percentage of large case trials in which at least one party is surprised by evidence he had not discovered (about 15 percent). That difference may well be attributable to the fact that some undiscovered information is potentially damaging to the party controlling it-and litigants who have succeeded in avoiding disclosure of such information during protracted periods of discovery are unlikely to disclose it at trial.

The questions discussed in the preceding several paragraphs focused di- 
rectly on the net results, in terms of information distribution, of the discovery system. The interviews also included many questions designed to explore why the discovery process sometimes fails to distribute the evidence evenly between the parties. Responses to some of these questions offer additional evidence about how well the system works to distribute information.

One set of questions yielded information about how often opposing counsel fail, during depositions, to learn significant information from the witness or party being deposed. This set of questions, which was suggested by one of the attorneys interviewed during the pretest period, began by asking: "Has the way you have prepared a client or witness to be deposed ever resulted in other parties not learning something of arguable significance from your client or witness during his deposition?" Attorneys who said yes were asked: "During the past five years, in roughly what percentage of your cases has this occurred?" The phrasing of these inquiries encouraged the lawyers to focus on the effectiveness of their deposition preparation techniques rather than simply on opponents' failures to uncover information during depositions. ${ }^{34}$ It follows that the data generated by these questions understates (perhaps by a substantial margin) how often witnesses emerge from depositions without having disclosed potentially important evidence. Even understated, however, the figures suggest that deposing counsel frequently conclude depositions before uncovering significant information.

Ninety-five percent of the responding attorneys (163 of 171) said that on one or more occasions opposing counsel had failed to learn something arguably significant during the deposition of a witness they had prepared. The comparable figure was more than 90 percent for each of the subgroups. The frequency of this phenomenon, however, varied considerably between subgroups. According to the 157 lawyers who responded to the follow-up question, an opponent was likely to fail to discover something consequential during a desposition in one of every two cases. ${ }^{55}$ Among the subgroups, the comparable frequency estimates ranged from a low of 30 percent (by the small case and the predominantly state court groups) to a high of 63 percent (by the large case group). Comparisons in

54. As a few respondents pointed out, the first of these questions assumes that attorneys who perceive that opposing counsel failed to uncover something from their deponent can know what caused that failure. In many instances such an assumption would be unjustified. It often might be difficult to determine whether opposing counsel's failure to elicit certain testimony during a deposition was attributable to how the deponent was prepared, the shortcomings of the lawyer taking the deposition, economic constraints, or some combination of these factors. A few of the litigators in the sample attempted to isolate the instances in which they were relatively confident that it was their preparation of the witness that caused the nondisclosure. Because some respondents tried to limit their answers to such instances, the data as a whole understate how often deposing counsel fail to elicit significant testimony.

55. The median of the percentage responses was 50 percent; the mean was 47 percent. 
figure 13 of the median percentages for four sets of subgroups indicate that the percentage of cases in which an opponent failed to elicit potentially important testimony during deposition was likely to be substantially higher in large, complex litigation than in smaller lawsuits.

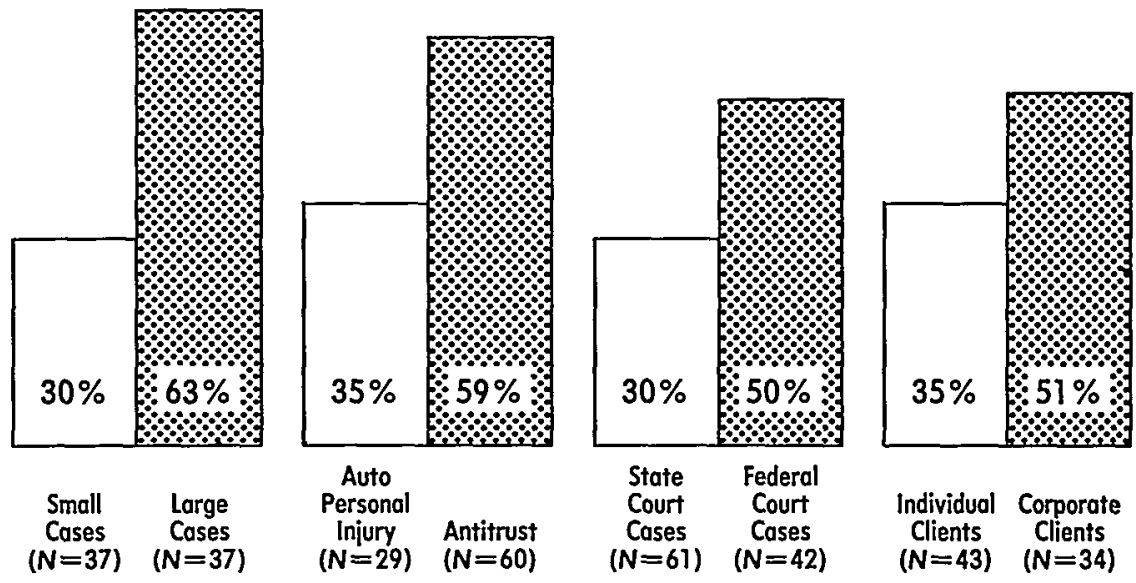

Fig. 13. Median percentages of cases in which the opponent failed to learn something significant during deposition by subgroup set.

Posing these questions about preparing clients (or friendly witnesses) to be deposed provoked some unquantifiable but noteworthy comments by interviewed attorneys. For example, some lawyers felt constrained to offer explanations when they reported that the way they prepared deponents only rarely caused opposing counsel not to discover something. A few such explanations recurred with some frequency. One which was not likely to be offered by smaller case lawyers was that in a high percentage of cases the attorneys who represented opposing parties were, as a matter of course, so experienced, sophisticated, and tenacious that they usually learned everything important a deponent knew regardless of how well the deponent had been prepared. Some smaller case lawyers, by contrast, explained that what their clients knew about the subject of the litigation tended to be so simple and predictable (e.g., about the circumstances surrounding the accident or the symptoms of routine injuries) that predeposition coaching could have little effect on what opponents were likely to learn. A few smaller case attorneys with high volume practices also confessed (their admissions, in fact, had a confessional tone) that the value of the suits on which they worked often was too small to justify the cost (in attorney's fees) of anything but perfunctory predeposition admonitions (e.g., the proverbial "don't volunteer").

The questions about preparing deponents also elicited comments that reflected sharply contrasting philosophies of client control. A few lawyers 
declared that attempting to manipulate a client and to control the character of his testimony was both ethically unjustifiable and professionally unwise. According to this view, the most effective witnesses are those who appear the least rehearsed and restrained. One suspects that this view is prevalent only among lawyers blessed with clients who have nothing to hide. In any event, only a few attorneys indicated that preparing deponents was unimportant in their philosophy of lawyering. Instead, the predominant view was that a good litigator very carefully prepares a client for his deposition and takes great professional pride in his (the lawyer's) ability to affect the flow of information when a client is testifying.

Lawyers also can affect the likelihood that an opponent will discover all the significant evidence their client possesses by the timing of efforts to negotiate settlements. One option available to an attorney who wants to prevent disclosure of otherwise discoverable information is to make serious settlement offers in the early stages of the development of litigation. The first question in a short series designed to explore the prevalence of this motivation for settlement was: "Have you ever initiated settlement negotiations in order to try to resolve a matter before another party discovered information that could be damaging to your client (damaging either in the lawsuit that you attempted to settle or in some other action or contest)?"' Eighty-one percent of the 176 attorneys who responded said yes. Among the subgroups, the percentage of lawyers who admitted having initiated at least one settlement for this purpose was highest ( 97 percent) for the attorneys whose median size case was $\$ 25,000$ or less (the small case lawyers). The fact that the comparable percentage was somewhat lower for the subgroups in which the cases tended to be larger (e.g., 72 percent for the lawyers whose principal cases included antitrust work and 83 percent for lawyers who did 50 percent or more of their work for large corporate clients) probably is a function of larger case lawyers having settled fewer lawsuits.

The second question in this sequence asked the lawyers to estimate the percentage of cases they had settled during the preceding five years in which they initiated negotiations at least in part to try to close matters before opponents discovered damaging evidence. Responses to this question indicate that the larger case lawyers were only marginally more likely to initiate negotiations for this purpose than their smaller case counterparts and that even the attorneys whose median size case was $\$ 1$ million or more (the group with the highest median response to this question) were likely to try to settle for this reason in only one of five cases.

The interviewers also asked for the litigators' impressions about how often other attorneys initiated settlement negotiations in an effort to terminate an action before disclosing damaging information. Because it made little sense to ask the lawyers to estimate the percentage of cases in 
which other litigators initiated negotiations for this purpose, the interviewers asked the attorneys to answer by selecting one of four options: (1) never, (2) seldom, (3) moderately often, or (4) quite often. ${ }^{36}$ Only 10 percent of the 117 attorneys who responded to this question selected the "quite often" category. While 48 percent estimated that other lawyers initiated settlement discussions in order to spare their clients from having to make damaging disclosures "moderately often," 42 percent estimated that that desire "seldom" motivated other counsels' settlement efforts. No lawyers said that other attorneys were "never" so motivated. Thus, at least as a group, our respondents were not inclined to impute different behavior in this respect to "other" litigators than they admitted in themselves.

If early settlements prompted by a desire to avoid damaging disclosures do not often account for opponents not discovering significant evidence, what are the principal factors that cause such failures? One question was designed to examine the roles of two causes that the lawyers in the pretest group suggested were important. The question was:

During the past 5 years in roughly what $\%$ of the cases you have closed (by settlement, judgment or otherwise) and in which another party had not discovered some arguably significant information from you or your client was the reason for that failure by the other party:

1. Opposing counsel's failure to ask the right questions or for the right documents or to depose the right people?

$\%$

2. The operation of a privilege or the $\mathrm{W} / \mathrm{P}$ [work-product] doctrine? $\%$

An overwhelming majority of the 157 attorneys who answered this question indicated that of the two factors, ${ }^{57}$ limitations in opponents' discovery were far more likely than the intervention of a privilege to be the reason significant information remained undisclosed. Of the 157 respond-

56. The interviews included several similarly framed questions that asked for impressions about how often other attorneys were motivated by specified purposes (the responses to most of these questions are discussed in subsequent sections of this article). The interviewers prefaced these questions by explaining that they were designed only to ascertain opinions (a "pure opinion survey") and not to establish the frequency in the "real world" of the phenomena under discussion.

The interviewers also prefaced these questions by saying: "In giving us your impressions about other attorneys please draw upon all of your sources of information about how other lawyers conduct civil litigation; do not confine your answers to observations you have made in the cases in which you have been directly involved.

57. This question was not well phrased. Its structure probably encouraged some attorneys to assume that the two identified factors were the only possible explanations and that they were mutually exclusive, i.e., that the sum of the two figures sought had to be 100 percent. Moreover, the wording of the question does not make clear whether the first of the two possible causes was intended to embrace only unintentionally inadequate discovery by opposing counsel or such failures plus discovery efforts that economic pressures forced opponents to leave incomplete. Given these ambiguities, the percentages the lawyers offered in response to this question are reliable only for the purpose of comparing the relative roles of privileges, on the one hand, and, on the other, unexplained limitations in opponents' discovery. 
ing attorneys, 132 indicated that when an adversary failed to discover something of arguable consequence, the reason most of the time was some limitation in his discovery effort and only rarely the protection afforded by a privilege. Even most of the predominantly big case litigators endorsed this view, a fact of some significance because, as will be discussed in a subsequent section, ${ }^{58}$ privileges reportedly play more prominent roles in big cases than in smaller litigation.

Responses to a question posed to only about one-third of the attorneys in the sample reinforce the inference that intervention of privilege is not the most common explanation for one party's failure to discover evidence from another. ${ }^{59}$ The interviewers asked 58 of the 154 attorneys who said they had settled at least one case suspecting that another party still had relevant but undisclosed information what "the most common reasons [were] for your not having discovered the information." The reason most often mentioned (by 21 of the 58 lawyers) was failure by an opponent to comply with discovery requests. In addition, 5 lawyers said that sometimes they simply decided not to pursue some evidence. Nineteen litigators mentioned cost or early settlement as a factor, and an identical number mentioned privilege, the work-product doctrine, or some statutory protection of information.

The median size case $(\$ 750,000)$ of the 19 attorneys who mentioned privilege as a reason they had not discovered some evidence was much higher than the median size case $(\$ 200,000)$ of the 21 lawyers who blamed their opponents' noncompliance with their discovery requests. That fact is consistent with other data ${ }^{60}$ that suggest that assertions of privilege are much more likely to generate friction between adversaries in large case litigation than in smaller matters.

Comments and observations made by many different attorneys also support the conclusion that, except perhaps in the biggest cases, the factors that most often account for failures to discover significant evidence are sloppy lawyering, economic constraints, and opposing counsel's adroitness at evasion. By far the most commonly volunteered explanation for nondisclosure was opponents' failures to "follow up." Several lawyers cited examples of opposing counsel failing to discover important evidence either because they were not sufficiently tenacious in specific discovery events (especially in depositions, where failure to follow "obvious leads" apparently is not uncommon) or because they failed to refine and repeat discovery probes near the end of a long pretrial period of intermittent case development. ${ }^{61}$ One litigator estimated that $30-40$ percent of his

58. See pp. 840-43 infra.

59. Time constraints prevented the interviewers from asking the entire sample this question.

60. See pp. 840-43 infra.

61. One of our respondents reported a deposition practice that may help account for this kind of failure. In this lawyer's words, "the other side is afraid to ask questions they don't know the answer to." 
opponents "don't do their discovery and that hurts these attorneys." A defense lawyer commented that "most plaintiffs' attorneys are satisfied with a simple chronological document production [and] don't follow up-so frequently don't pursue intracompany memos." And a lawyer whose cases typically involved substantial sums of money candidly admitted that in response to the "first wave of discovery we don't produce information that could be discovered by follow-up discovery." He argued that "attorneys could get all the information if they were diligent."

As the preceding paragraphs show, when asked directly why potentially important evidence often remains undiscovered, most attorneys focused on limitations in the lawyering skills and habits of opponents. As the discussions that follow demonstrate, however, there are additional forces at work in the discovery process that contribute significantly to the system's frequent failure to distribute the relevant information evenly among the parties.

\section{Principal Problems with and Abuses of the DisCOVERY SYSTEM}

"Courts want nothing to do with discovery and never use sanctions. Rule 37 is really Rule Zero."

$$
\text { -a Chicago litigator }
$$

"Discovery is too much of a game to see how much you can hide."

-a Chicago litigator

What do litigators perceive as the principal problems with the discovery system? About which kinds of abuses are lawyers most concerned? To try to answer these questions, we asked the attorneys if they felt there were "any problems with the current system" and to identify "the most troublesome kinds of discovery abuse, if any." Responses to these open-end questions, plus complaints attorneys volunteered at other times during the interviews, identify the aspects of the system's operation about which lawyers in the sample were most disturbed. Figure 14 shows the percentages of attorneys in the sample who complained about each of the nine most frequently mentioned problems with or abuses of discovery.

As figure 14 indicates, lawyers volunteered more complaints about the role of the judiciary than about any other problem in the discovery system. Seventy-one percent of the attorneys in the sample made unsolicited negative comments about how the behavior of judges or magistrates adversely affects the discovery process. Because an earlier article detailed the content of these complaints, ${ }^{62}$ it is sufficient for present purposes to 


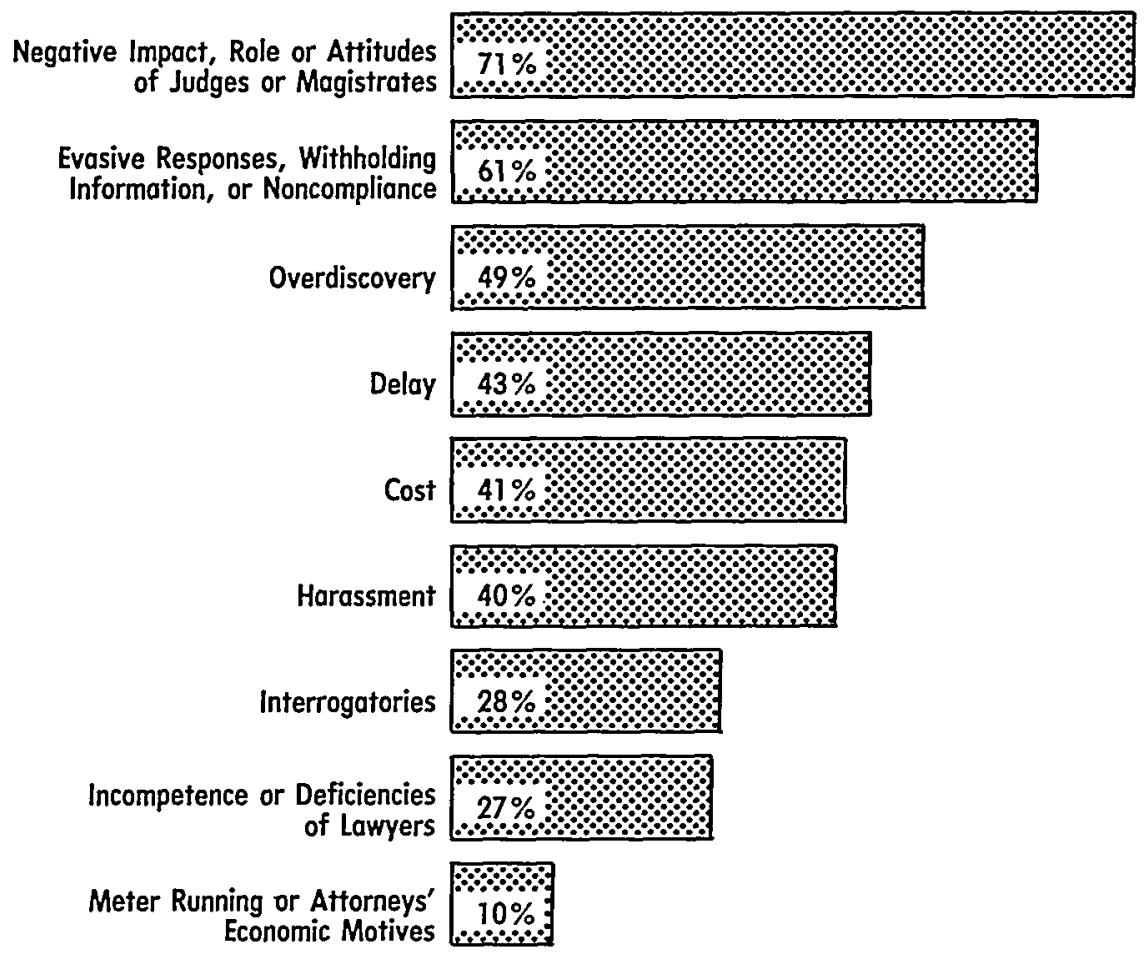

Fig. 14. Most frequently mentioned problems or abuses by percentages of attorneys who complained about each $(N=177)$.

note that they emphasized the court's inhospitability to hearing discovery disputes, the poor quality of decisions about discovery matters by trial judges and magistrates, and the underuse and ineffectiveness of sanctions.

A substantial percentage of the attorneys in every subgroup complained about the courts' negative impact on discovery. Nonetheless, the percentage of litigators who voiced these criticisms was substantially higher in the subgroups of lawyers who tended to handle larger and more complex litigation than it was in the subgroups whose cases typically were smaller and less involved. Figure 15 compares four sets of subgroups in terms of the percentages of attorneys who identified the judiciary as a source of difficulty in the discovery system.

The subgroup with the highest percentage of attorneys who complained about the judiciary was composed of the lawyers who spent 80 percent or more of their time on matters filed in federal courts. It would not be fair, however, to leap from that fact to the conclusion that the judges and magistrates in the United States District Court for the Northern District of Illinois do a worse job of handling discovery than their counterparts in the state courts in Cook County. While many attorneys 


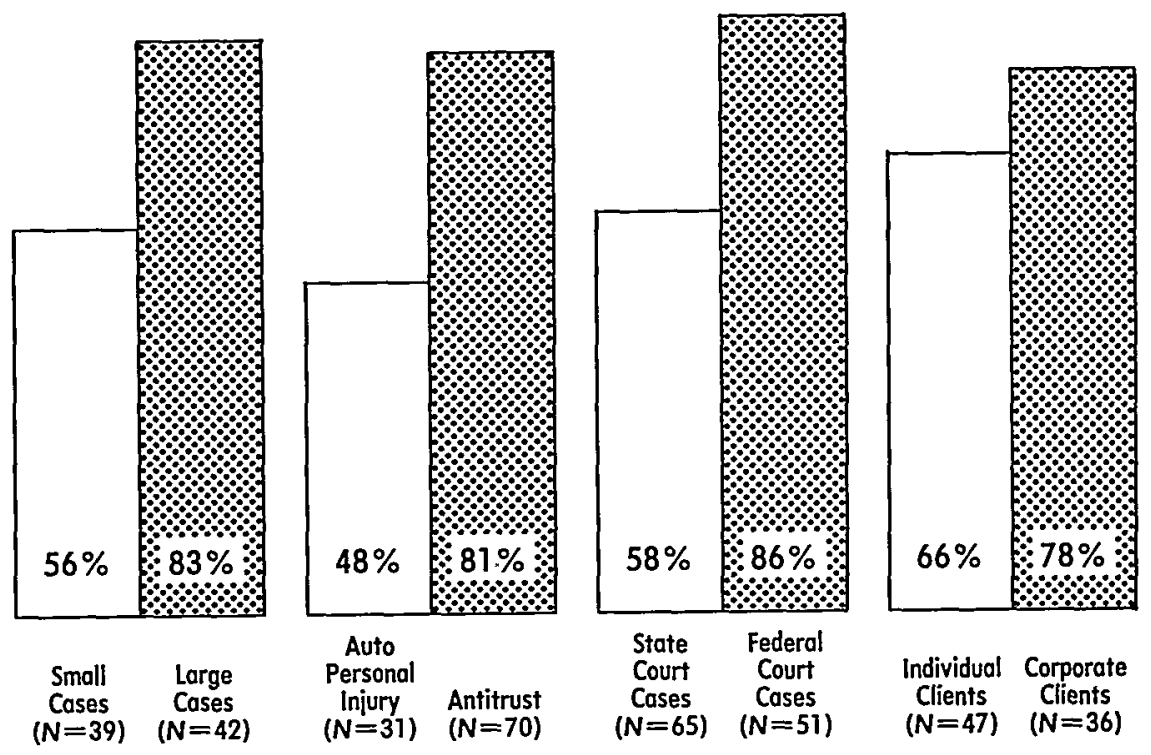

Fig. 15. Percentages of attorneys who volunteered complaints about the judiciary by subgroup set.

criticized the attitudes of some federal judges toward discovery disputes (e.g., arrogant, condescending, and impatient), the sample as a whole seemed to have a higher regard for the quality of decision making and case management of the federal bench than of the judges in the law division of the state courts. ${ }^{63}$

That a substantially higher percentage of the predominantly federal court lawyers than of the predominantly state court subgroup criticized some aspect of judicial behavior probably is in large measure a function of the fact that the median size case for the federal court subgroup $(\$ 1,000,000)$ was so much higher than the median size case for the state court subgroup $(\$ 36,000)$. Assuming that the volume of discovery activity bears some relationship to the amount of money at stake, it is reasonable to hypothesize that the lawyers in the federal court subgroup used the discovery system more than the lawyers in the state court subgroup and, therefore, were likely to encounter more discovery-related problems, which, in turn, would force them into more interaction with the courts, resulting in greater dependency and more opportunities to feel dissatisfied. This is not to argue that there could be no differences between federal and state judges or procedures that would provoke greater criticism of the federal courts' impact on discovery. Instead, it is to sug-

63. Interestingly, several lawyers praised (and none condemned) the performance of the judges in the state court's equity division, which appears to be less overburdened than the much criticized law division. The equity division also assigns one judge to each matter from initial filing through trial, unlike the law division, which sends all discovery disputes to motion judges. 
gest that until such differences are identified (a task we did not undertake), they should not be assumed to exist.

The other frequently mentioned problem with discovery that directly implicates the role of the courts is "delay." Of the 177 attorneys in the sample, 76 (43 percent) volunteered complaints about delay. Complaints about delay tended to emphasize two characteristics of the system that several attorneys insisted were closely related: (1) the long wait for a trial date (reportedly often five years in the state courts in Cook County and two years in the federal District Court for the Northern District of Illinois) and (2) opponents' dilatoriness or extended tardiness in responding to discovery requests. ${ }^{64}$ Because the interviews did not ask attorneys who complained about delay which aspect of the problem troubled them most, tabulations of these volunteered criticisms indicate lawyers' concern only with the general phenomenon. The next section of this article contains data specifically about the severity of the problem of tardy responses to discovery requests.

Perhaps the most noteworthy fact about the complaints about delay is that they were voiced by higher percentages of attorneys in the subgroups in which smaller and less complex cases were the norm than in the subgroups in which the typical lawsuits involved large sums of money and more information. Indeed, of all the major problems with discovery, delay is the only one about which small case lawyers consistently complained more often than their large case counterparts. For example, while 54 percent of the attorneys whose median size case was $\$ 25,000$ or less identified delay as one of the discovery system's principal problems, the comparable figure for the lawyers whose median size case was $\$ 1,000,000$ or more was 29 percent. Similarly, among the lawyers who practiced primarily in federal court, 35 percent mentioned delay problems, whereas among the attorneys who practiced primarily in state court that percentage was 46 percent (a figure not as high as one might expect, given the five-year backlog for civil trials in the law division in Cook County).

Another problem about which many lawyers complained was the cost of conducting and responding to discovery. ${ }^{65}$ Surprisingly, the litigators who voiced this complaint most often were the lawyers who tended to have the clients with the deepest pockets and the cases with the most at stake. ${ }^{66}$ The subgroup in which the highest percentage of lawyers complained about cost was composed of attorneys who worked 50 percent or more of the time for large corporate clients. While 67 percent of those

64. See Brazil, supra note 3, at 226-29.

65. The next section of this article includes data about the extent to which cost inhibits attorneys in conducting discovery.

66. There were notable exceptions to this generalization. One lawyer, for example, claimed that "Small inventors are harassed by large corporations with endless and costly discovery. . . . The system is its own worst enemy in terms of cost because you are allowed to discover everything." 
lawyers identified cost as a problem, only 38 percent of the attorneys who worked primarily for individuals expressed concern about the expense of discovery. Though not as extreme, the differences within other sets of subgroups cut in the same direction (e.g., 51 percent of the lawyers whose work included antitrust actions but only 32 percent of attorneys who handled auto accident cases complained about the expense of discovery).

The big case litigators also were more inclined to elaborate the dimensions of the cost problem. For example, several emphasized (with remarkable intensity) that in addition to its very substantial direct costs (such as fees for attorneys and experts and charges for reproducing massive documents), discovery very often imposes on clients a less visible but by no means less painful expense in the form of business disruption. Some lawyers went further, arguing that business disruption expenses are so great in large commercial litigation that they dramatically increase the total social cost of discovery (the cost is passed on to consumers) and should be the focus of special study. It would not be reasonable to infer from the greater number and intensity of complaints about cost by larger case litigators, however, that the expense of discovery has less impact on smaller cases. Smaller case lawyers reported turning away cases because of the foreseeable cost of discovery far more often than big case attorneys did. ${ }^{67}$ And data discussed in the next section of this article clearly indicate that economic constraints more often limit the discovery efforts of small case than of large case attorneys. ${ }^{68}$ It is fair to infer, however, that in larger cases, where more discovery is conducted, both its direct and its less visible costs are a source of great concern to many clients and lawyers.

A glance at figure 14 (supra) reveals that according to the attorneys in the sample, lawyers and methods of lawyering are sources of many of the discovery system's principal problems. Among the lawyering practices targeted for blame, none commanded more negative attention than the

67. The interviewers asked 154 attorneys if their "prediction of the cost of discovery ever caused [them] to decide not to accept a civil case." Sixty percent (93 lawyers) said yes. That percentage was substantially higher in the subgroups of attorneys whose cases tended to be smaller and less complicated, e.g., it was 79 percent for the subgroup of lawyers who handled tort actions arising out of auto accidents.

Time constraints permitted the interviewers to pose the follow-up question to only 69 of the 93 lawyers who said the cost of discovery had led them to turn away one or more cases. That question asked the lawyers to estimate the number of cases, during the preceding five years, they had "declined in large measure because of how expensive [they] predicted discovery would be." Not surprisingly, the numbers consistently were much larger for the smaller case litigators than for lawyers whose typical cases were large. The median number for the subgroup who did auto personal injury work, e.g., was 50, while for the lawyers whose principal cases included antitrust matters the figure was only 5 . Moreover, the mean figures for the smaller case subgroups were dramatically larger than the medians, reflecting the fact that among smaller case attorneys, some turned away many more cases than others because of the foreseeable cost of discovery. In the group who handled tort cases arising out of auto accidents, e.g., while the median number of cases declined on this ground was 50, the mean was 133 .

68. See pp. 839-41 infra. 
redoubtable art of evasion. As the data reported here and in the next two sections suggest, it would be difficult to exaggerate the pervasiveness of evasive practices or their adverse impact on the efficiency and effectiveness (for information distribution) of civil discovery. Evasion infects every kind of litigation and frustrates lawyers in every kind of practice. With the possible exception of the role of the courts, no aspect of the discovery process stands in greater need of extensive critical scrutiny.

The term "evasion" as used here is incapable of precise definition but embraces several kinds of reportedly widespread practices. The most obvious is the habit of manipulating the definitions of opponents' words, interpreting their interrogatories, document demands, or deposition questions as narrowly, broadly, or selectively as possible for the purpose of serving a client's adversarial interests (e.g., in order to rationalize providing as little information as possible or asserting an objection to a request). As one litigator gingerly phrased it, "where you get an ambiguous request or a broad request you hope you can be permitted to withhold the information artfully and fairly under the rules."

The term "evasion" also refers to more direct forms of resistance to disclosure, for example, refusing to respond in any way to discovery probes or intentionally withholding some evidence that is clearly sought and discoverable (both variations on the "stonewalling" theme). ${ }^{69}$ The words of one perhaps atypically cynical or at least blunt lawyer capture the spirit of the problem: "The purpose of discovery," he declared, "is to give as little as possible so [your opponents] will have to come back and back and maybe will go away or give up."

Sixty-one percent of the lawyers interviewed complained about some form of evasion. Moreover, the percentage of attorneys who voiced such complaints varied remarkably little between the two extremes in every set of subgroups, less than for any other frequently mentioned problem. Nor were large case lawyers more likely than small case attorneys to mention this problem, a fact well illustrated by noting that the subgroups with both the highest and the lowest percentages of litigators who targeted evasion as a problem were composed primarily of big case attorneys: the highest percentage (67 percent) was among the lawyers who primarily represented large corporations, while the lowest (54 percent) was among the attorneys practicing in firms of 120 or more lawyers.

Lawyers commonly associated the problem of evasion with interrogatories, ${ }^{70}$ the only one of the rule-created instruments of discovery that a sizable number of attorneys ( 50 of $177 ; 28$ percent) identified by name as a principal source of difficulty. Of course, evasive replies were not the

69. A few lawyers reported a closely related type of conduct that they probably would not classify or define as evasion. It consists of an attorney pressuring witnesses whose testimony will hurt his client to be unavailable for depositions.

70. See Brazil, supra note 3, at 233. 
only problems litigators associated with interrogatories. Some lawyers complained, for example, about "blanket interrogatories," mass produced, lengthy lists of poorly focused, untailored questions, which were said to be almost valueless except as vehicles for fishing expeditions or harassment. Others reported that opponents rarely answered interrogatories punctually. Some lawyers also complained that adversaries tried to use interrogatories to manipulate them into doing investigative work that should have been done by the propounding litigator. Most of the expressions of discontent, however, focused on the difficulty of getting opposing parties and counsel to respond to interrogatories in straightforward and useful ways. Lending credibility to such complaints, several lawyers openly admitted that they tried to be evasive when they drafted answers to interrogatories. One litigator declared, for example, that his approach was to provide "only the information that is absolutely required and [to] take advantage of the many attorneys who ask sloppy questions or use [the] wrong word." Another reported: "I always have the client put the interrogatory answer in the worst light, and I will jazz it up somewhat if I can do so. This is my job and the other side does this to me."

Not all of the lawyers who mentioned interrogatories, however, spoke in negative tones. A few attorneys (noticeably members of the plaintiffs' bar) argued that properly used interrogatories were the most economical and efficient means of acquiring certain kinds of information. Some also pointed out that because interrogatories are the least expensive discovery tool, their availability is crucial to poor litigants and important to plaintiffs generally. Two attorneys intimated that the effort to limit, by rule, the number of interrogatories parties can serve without judicial permission is the product of a defense lawyers' conspiracy whose purpose is to cripple plaintiffs' capacity to conduct meaningful discovery.

Another litigator argued that limiting the number of interrogatories parties can serve without judicial permission encourages lawyers to draft broader questions than they otherwise would-out of fear that permission to serve additional questions might be denied. The same lawyer insisted that broader questions are more likely than precise ones to yield evasive, noncommital answers (in part because broad questions can be prohibitively expensive to answer and in part because they often are so vague that they invite responses in kind). And despite the substantial number of complaints about interrogatory abuse, only half of the 28 lawyers who volunteered comments about limiting the number of interrogatories parties can serve of right favored the idea. Thus while it is unlikely that many lawyers would deny that interrogatories can be abused, it is not clear that there is a consensus about whether that potential for abuse warrants imposing formal restraints on their use.

Two other words that appeared repeatedly in responses to the openend questions about problems and abuses were "overdiscovery" and 
"harassment," the latter being a broader, less precise category of behavior in which some attorneys would include the former. ${ }^{71}$

Eighty-seven of the attorneys in the sample as a whole (49 percent) cited overdiscovery as a problem; 70 lawyers (40 percent) mentioned some form of harassment. By substantial margins, lawyers whose typical cases were likely to be large and complex complained more often about these forms of discovery abuse than lawyers whose typical cases were likely to be smaller (in dollar value) and less complicated. Figure 16 shows the frequency of complaints about overdiscovery and harassment among the lawyers in four sets of subgroups.

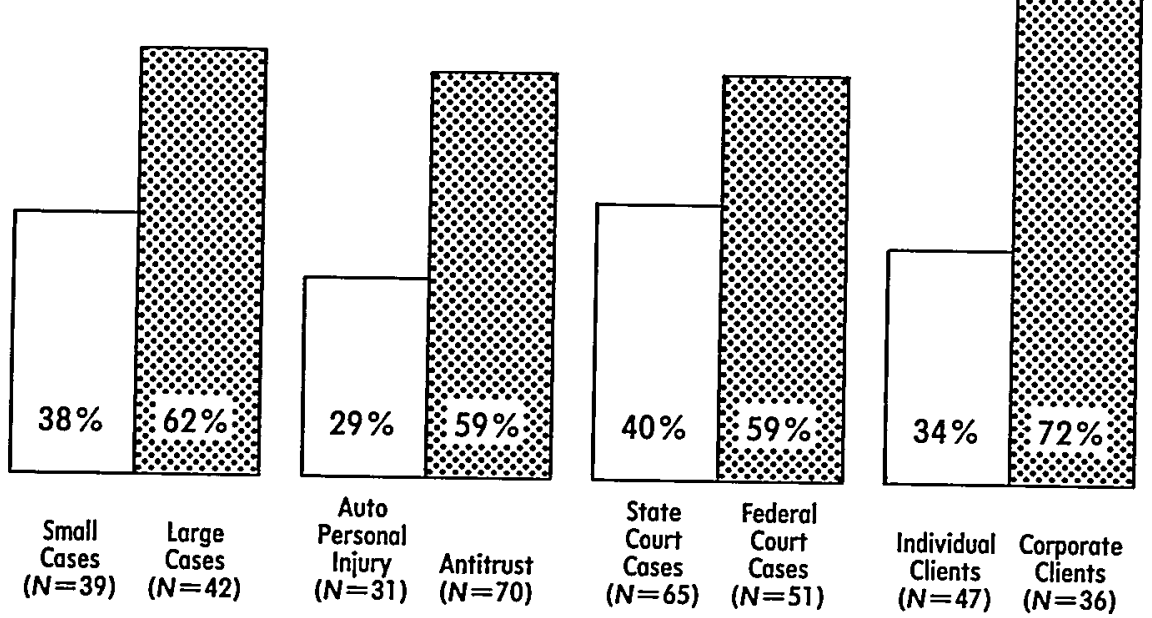

A. Attorneys Who Complained About Overdiscovery
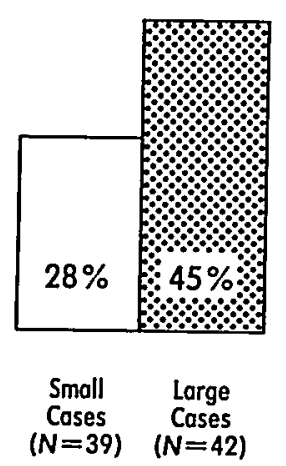

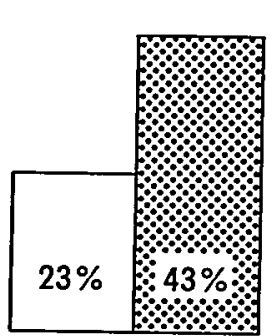

Auto

Personal

Injury Antitrust

$(N=31) \quad(N=70)$
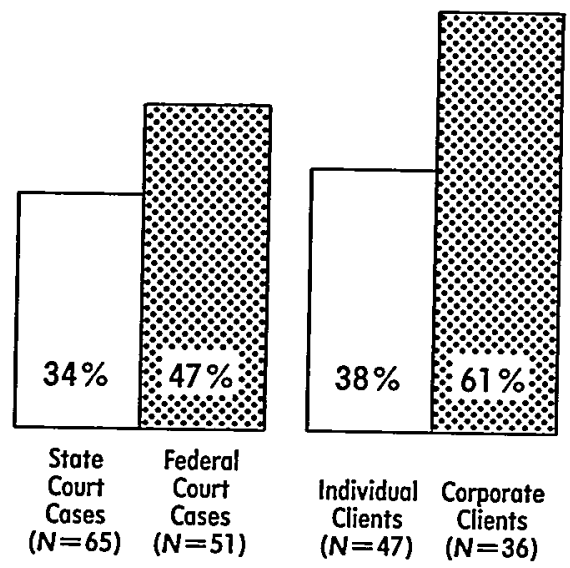

B. Attorneys Who Complained About Harassment

Fig. 16. Percentages of attorneys who complained about $(A)$ overdiscovery or $(B)$ harassment.

71. For purposes of calculating the number of complaints about major problems, however, we 
Defense attorneys expressed concern about overdiscovery much more often than plaintiffs' attorneys (57 percent in the defendants group; 38 percent in the plaintiff'). Comparing situational profiles of the litigators in other sets of subgroups exposes a similar pattern of differences: the percentage of litigators who complained about overdiscovery was consistently higher in the subgroups of attorneys who committed most of their time to defendants' matters than in the subgroups of lawyers who did more plaintiffs' work. This perhaps predictable difference between the defense bar and plaintiffs' bar in level of concern about overdiscovery stands in sharp contrast to the uniformity in the pattern of complaints about evasion: 54 percent or more of the attorneys in every subgroup expressed concern about the impact of evasive practices on the discovery process.

An appreciable number ( 47 of $177 ; 27$ percent) of attorneys mentioned one other problem in the discovery system: incompetent or obviously deficient lawyering. Because an earlier essay ${ }^{72}$ described the forms of incompetence the lawyers mentioned most often and some of the ways it afflicts the discovery process, little need be added here except to report that while the percentage of attorneys in different subgroups who mentioned this problem ranged from 17 to 36 percent, the data do not suggest that lawyers in any one practice situation were more likely than others to perceive incompetence as a serious problem.

\section{The Major Obstacles to Conducting Discovery \\ "Never be candid and never helpful and make [your] op- ponent fight for everything."}

-a Chicago litigator

One important objective of this project was to ascertain what kinds of things litigators perceived to be the most troublesome obstacles to their discovery efforts. Another goal was to explore whether the major impediments to effective discovery varied among different types of practices. Drawing on the literature in the field,,$^{73}$ suggestions made during pretest

treated overdiscovery as a distinct phenomenon. We added to the harassment column (in addition to the lawyers who explicitly used that word) the attorneys who complained about overproduction of documents in response to discovery requests or about opponents who used discovery to "spend [them] into submission" or otherwise intentionally to impose pressures on them.

72. See Brazil, supra note 3 , at 235-45.

73. There is a substantial body of material about civil discovery. The results of an early major effort to examine the operation of the discovery system are reported in William A. Glaser, Pretrial Discovery and the Adversary System (New York: Russell Sage Foundation, 1968). More recently, the Federal Judicial Center has sponsored additional empirical studies of some aspects of discovery. See, e.g., Paul R. Connolly, Edith A. Holleman, \& Michael J. Kuhlman, Judicial Controls and the Civil Litigative Process: Discovery (Washington, D.C.: Federal Judicial Center, 1978). The Federal Judicial Center also has published a useful survey of recent literature about discovery: Daniel Segal, Survey of the Literature on Discovery from 1970 to the Present: Expressed Dissatisfactions and Proposed Reforms (Washington, D.C.: Federal Judicial Center, 1978). 
interviews, and the author's experience, we identified seven "factors which, in any given case, could make [an attorney's] discovery more difficult or could account for [an attorney] not discovering or not pursuing some information." With respect to each such factor the interviewers asked the lawyers whether it ever had made their discovery more difficult or caused them not to uncover or pursue information and, if so, in approximately what percentage of their civil cases during the preceding five years the factor in question had been an obstacle.

An overview of the responses to these questions will facilitate the more detailed examination of the data that follow. Figure 17 provides such an overview by comparing the responses of three groups: (1) the sample as a whole, (2) the attorneys whose median size case was $\$ 25,000$ or less, and (3) the attorneys whose median size case was $\$ 1,000,000$ or more. The

Evasive or incomplete responses

Dilatory responses

Cost of pursuing information

Attorney-client privilege

Other privileges or statutory protections (including work product doctrine)

Attorneys' own tactical considerations

Dishonesty by opposing party and/or attorney (lack of candor or bad faith)

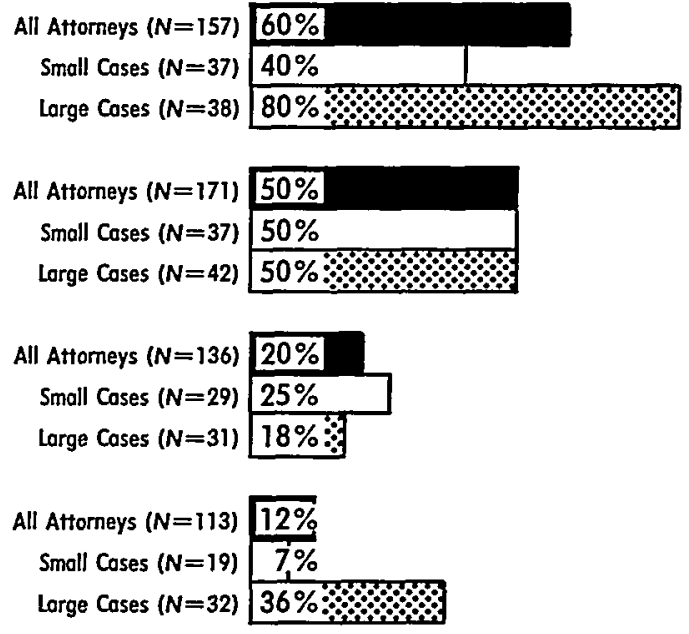

\begin{tabular}{r|r} 
All Attomeys $(N=158)$ & $10 \%$ \\
Small Coses $(N=33)$ & $7 \%$ \\
& \\
Lorge Cases $(N=39)$ & $50 \%$
\end{tabular}

\begin{tabular}{r|l|} 
All Attorneys $(N=152)$ & $15 \%$ \\
Small Coses $(N=35)$ & $10 \%$ \\
Large Coses $(N=36)$ & $20 \% \%$
\end{tabular}

All Attomeys $(N=159) \quad 74 \%$

Small Cases $(N=36) 10 \%$

Large Coses $(N=40) 18 \%$ 
bars show the percentages ${ }^{74}$ of each group's cases in which each of seven different types of obstacles reportedly impaired (at least temporarily) the lawyers' discovery efforts. ${ }^{75}$ For example, evasive or incomplete responses to discovery probes impeded discovery by smaller case attorneys in about 40 percent of their cases. In sharp contrast, the large case lawyers (as a group) reported that evasive or incomplete responses made their discovery more difficult in 80 percent of the lawsuits on which they worked. Some of the other contrasts depicted in figure 17 are equally striking.

The acculturation phenomenon described above caused particularly obvious communications problems during this portion of the interviews. The standard against which we expected lawyers to compare their experiences was an essentially frictionless system of sharing information in which responding parties made good faith efforts to understand and satisfy the requests of propounding parties. Since the lawyers were answering these questions from the perspective of "propounding parties," we expected them to consider their own requests "reasonable" (or not to count as "obstacles" reasonable objections to their clearly unreasonable requests). In this hypothetical system only "real" (good faith) misunderstandings between parties and the time required for reasonable efforts to locate requested information would encumber the process. It is probable that some lawyers did not use this standard in formulating their answers since the interviewers did not make this standard explicit for many of the attorneys who were interviewed during the earlier stages of the project. When the interviewers clarified the standard, some litigators raised their estimates of how often certain types of obstacles impeded their discovery. Such "corrections" were necessary because some "professionally acculturated" lawyers failed to consider as "obstacles" or "sources of difficulty" many phenomena (e.g., dilatoriness by opposing counsel) or types of responses to discovery requests (e.g., vague, noncommittal answers to interrogatories) that would not occur in the frictionless hypothetical system. Because of this communication problem, the data reported in this section probably understate the frequency with which at least some kinds of obstacles burden the information exchange process.

The attorneys' responses are instructive measures of the relative levels of frustration urban litigators feel about the various sources of difficulty on which the questions focused. In part because the answers to these

74. Fig. 17 reports the medians of the percentages for each group; the means frequently were higher.

75. The interviewers also asked the attorneys about an eighth potential obstacle: "Insufficient information or technical expertise to frame all the necessary questions or requests." The responses indicated, however, that this kind of difficulty rarely was significant. Only 49 percent of the lawyers in the sample said this factor ever had impeded their discovery. And the litigators who composed that 49 percent reported that "insufficient information or technical expertise" had been a source of difficulty in only 10 percent (median) to 19 percent (mean) of their cases. 
questions are consistent with responses to others, it is safe to conclude, for example that big case lawyers believe that evasive or incomplete responses to their requests more frequently impede their discovery than any other source of difficulty (the possible exception is the behavior of the judiciary-a factor about which we did not ask in this sequence of questions).

The questions about evasion produced some of the project's most dramatic results. Perhaps none is more striking than the fact that not a single lawyer said that evasive or incomplete responses had never impeded his discovery; 100 percent of the 157 lawyers asked said they had been frustrated in one or more cases by this problem. Coming from a group with as wide a range of age, experience, and types of practice as the attorneys in the sample, that unanimity bespeaks a widespread problem. While answers to the follow-up question about how often evasion impedes discovery confirm that the problem is not confined to any one kind of litigation, they also indicate that lawyers who tend to have larger and more complex cases are likely to encounter this source of frustration in a much higher percentage of their cases than are smaller case litigators. ${ }^{76}$ Figure 18 compares the experience with evasion of four sets of subgroups. As noted earlier, within each of these sets one subgroup was

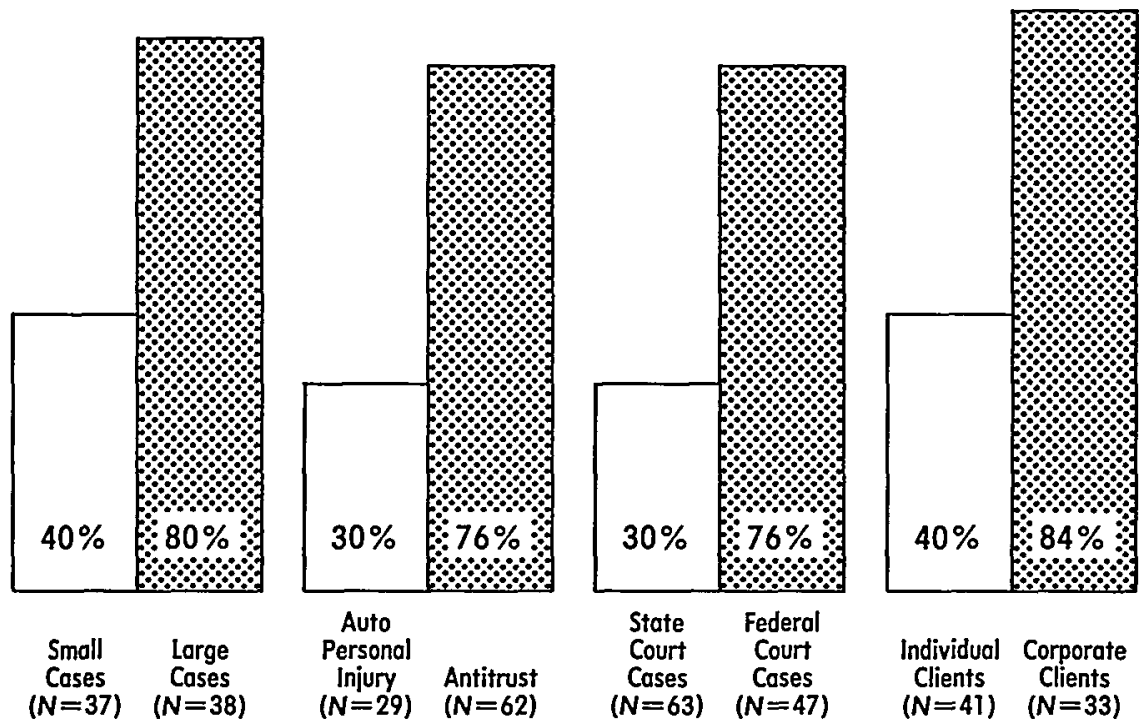

Fig. 18. Median percentages of cases in which evasive or incomplete responses impeded the attorney's discovery by subgroup set.

76. This difference between smaller and larger case litigation is consistent with and may be a function of the fact that tactical maneuvering reportedly plays a larger role in bigger lawsuits. See section VI infra. 
composed of lawyers likely to be involved in larger cases, while the attorneys in the contrasting subgroup were more likely to litigate smaller matters. The graphs show the medians of the attorneys' estimates of the percentages of their cases (over the preceding five years) in which opponents responded to their discovery with evasive or incomplete answers. As the figures indicate, lawyers in the larger case subgroups reported that these kinds of responses made their discovery more difficult in four of every five cases.

Observations lawyers made during the interviews offer some insights into why evasive practices are so widespread. Evasion can serve innumerable purposes. ${ }^{77}$ Undoubtedly foremost among these is the ubiquitous desire to avoid disclosing any information that might be damaging to a client. In the words of one litigator, it is the "attorney's duty to provide as little information as possible within the limits of the law." Specific considerations can supplement this general desire "to provide as little information as possible." One lawyer declared that evasion often reflects an attorney's effort to capitalize on an opponent's laziness. According to this view, defense attorneys are especially prone to niggardliness in responding to discovery requests because they commonly believe that most plaintiffs' lawyers are too lazy to follow up after receiving only partial answers. Another reportedly common reason for resorting to evasive practices is to "buy time," for example, for a client who temporarily is in difficult straits or for counsel to learn more about a matter or to define the strategy through which she will approach it. ${ }^{78}$ Evasive responses also can be employed as part of a larger scheme to make victory for an opponent as time consuming and costly as possible, for example, in order to discourage the filing of additional suits against a client. One attorney suggested another, less cynical explanation for evasion by corporate defendants: manufacturers, he claimed, sometimes resent the fact that plaintiffs' counsel do not know enough about the product or business to frame intelligent questions. That resentment, according to this theory, can lead such parties to resist complying even with an opponent's wellphrased discovery requests. Acute sensitivity about disclosure of proprietary information was a much more commonly cited explanation for responses that were not wholly responsive. Interestingly, a few lawyers suggested that their own fear that they would not always perceive the proprietary value of informaton (e.g., because they did not understand some of the subtleties of competition in some industry) exacerbated the evasion problem by increasing their cautiousness about supplying data to opponents.

77. See Brazil, supra note 37, at 1311-31.

78. Speaking generally, one attorney admitted that "for tactical reasons you [sometimes] . . . hold something good or bad back till the last minute." 
Cautious instincts are important ingredients in another set of closely related considerations that can inspire evasive maneuvers. One lawyer reported coaching his clients to be as evasive as possible during their depositions in order to reduce the possibility that their testimony could be used later to impeach them. Another attorney said that his practice of providing "minimum information" (except when he wanted to impress opponents with the strength of his case) was attributable to his fear of being "tied" too early to a theory, or to one theory to the exclusion of others, or to one "answer." Echoing these concerns, yet another litigator expressed his belief that "too much precision may come back to haunt me. I don't want to foreclose later theories by specific answers."

The desire to use the discovery process to set up cases for settlement negotiations also can encourage litigators to husband the evidence their investigations have developed. Many attorneys reported that a great deal of what they do during the discovery stage is geared toward settlement. One particularly candid lawyer from a large firm declared, for example, that he tried to "structure the sequence of discovery so as to shape the case for settlement." He explained that his goal was to keep damaging evidence about his client out of the discovery record while supplying as much favorable information as possible. Then, on the strength of the case presented by the evidence produced up to that point he would initiate settlement discussions. In a similar (if less elaborate) vein, another lawyer stated that he and his colleagues delay "responses to discovery so we don't have to reveal things prior to settlement."

Reports like these suggest the ironic possibility that two of the primary purposes the discovery system was designed to promote are mutually exclusive. Although discovery is supposed both to encourage settlement and to assure "[m]utual knowledge of all the relevant facts gathered by both parties," "79 as the likelihood of settlement increases so may the pressure on attorneys to block access by opponents to evidence. If lawyers expected every case to go to trial, presumably they also would expect each opponent eventually to conduct the thorough discovery that would force them to disclose even most of the evidence damaging to their clients. That expectation, in turn, would reduce their incentives to try to avoid responding to discovery requests at all and, failing that, to submit answers that give up as little as possible. Under the current system, by contrast, the probability that cases will be settled (and usually before discovery is as complete as it would be for trial) and the desire to enter settlement negotiations with only "high" cards showing can serve as powerful inducements to attorneys to be both dilatory and evasive.

After posing the questions about evasion the interviewers turned to a

79. Hickman v. Taylor, 329 U.S. 495, 507 (1947). 
closely related problem. They asked the lawyers whether "lack of candor or bad faith by opposing party or attorney" ever had impeded the litigators' discovery and, if so, in what percentage of their cases during the preceding five years. After several interviews (too late to change the printed questionnaire) it became clear that the phrase "lack of candor" confused some lawyers. Did it include "evasive or incomplete" responses? In later interviews we explained that "lack of candor" was intended to refer to a form of "bad faith," namely "dishonesty," and instructed the lawyers to include in this category only those instances in which they felt that opposing counsel (or parties) had crossed the line separating "aggressive advocacy" from unethical conduct. Although this line is not easy to draw, most lawyers in the sample clearly felt that it existed, that they could locate it with a modicum of precision, and that most of the behavior that so regularly frustrated their discovery fell on the aggressive advocacy side.$^{80}$ According to the lawyers in the sample as a whole, while evasion impeded discovery in 60 percent of their cases, bad faith or dishonesty was a problem in only 14 percent of their lawsuits. Nor did the larger case lawyers claim to have suffered from dishonesty in a substantially higher percentage of their cases than the lawyers in the entire sample. ${ }^{81}$ While the lawyers in the subgroups associated with larger cases generally reported a higher per case incidence of bad faith than the lawyers in the other subgroups, the highest median figure indicated that opponents responded to discovery in bad faith in only 18 percent of the cases. ${ }^{82}$

The sizable differences between the reported frequency of evasive responses, on the one hand, and dishonesty, on the other, suggest that most attorneys in the sample did not consider the former to be culpable conduct. Comments volunteered by some lawyers reinforce this inference. Several attorneys made it clear that evasion, at least in the form of seeking out and taking advantage of ambiguities, oversights, or other errors in the way opponents phrased discovery probes, was, so far from being unethical, a clear duty of the responsible advocate. The reported frequency of evasive practices suggests that this view of professional responsibility is widespread indeed.

After evasion, the obstacle that the attorneys said impeded their dis-

80. Some lawyers did complain about conduct they clearly would place on the "dishonesty" side of the line, e.g., coaching clients to say they "don't recall" damaging information that they do recall, concealing the whereabouts of witnesses, shredding or hiding documents, and manufacturing documents. One lawyer went so far as to assert that "manufacturing evidence for parties is so common it would shock the average person."

81. The experience of at least one lawyer clearly belies this generalization. According to this respondent, whose work primarily involved antitrust and securities matters, there is a "direct linear relationship between the amount of money at stake and the difficulty of discovery. There is a dollar threshold above which many attorneys feel it is permissible to lie."

82. Six of 159 responding lawyers reported that their opponents responded in "bad faith" in 80 percent or more of their cases. 
covery most often was dilatoriness by opponents. To explore this problem the interviewers asked the lawyers if they ever had experienced "extended delays in responding to [their] discovery requests." Because the phrase "extended delay" was not self-defining, the interviewers explained that it did not include either the routine phone call (or letter) that sought the first 30-day extension or any amount of time that would be consumed by a reasonably diligent effort to gather the requested material. Beyond the routine 30-day extension, however, any delays not justifiable by the demands of the task of securing the data were to be considered extended.

With the question so defined, 172 of 177 attorneys (97 percent) said that extended delay in responding to their requests had made their discovery more difficult in one or more of their cases. Responses to the follow-up question about how often this obstacle arose indicate that the smaller case lawyers who primarily handle state court matters are somewhat more likely to feel frustrated by dilatory responses than are the attorneys whose practices revolve around larger cases and the federal courts. The median percentage of cases in which dilatoriness was reported to have impeded discovery was approximately 50 percent for all of the subgroups save two: the lawyers who handled tort cases arising out of automobile accidents (for whom the median was 75 percent) and the attorneys who committed 80 percent or more of their time to matters filed in state court (for whom the median was 60 percent). The higher percentages for these two groups may be attributable in part to the fact that the backlog in the civil trial docket in the state courts sitting in Cook County is substantially more severe than it is in the federal District Court for the Northern District of Illinois. (This difference in backlog may more than counterbalance the greater negative effect on punctuality one would expect from the greater volume of information sought through discovery in larger cases.) Because an earlier article examined in some detail causes and consequences of the complex problem of delay, ${ }^{83}$ we can turn to another impediment to conducting discovery: its cost.

When asking whether cost had ever deterred additional discovery, the interviewers pointed out that in any given case the expense of pursuing certain information might be "excessive relative to size of case, resources of client or probable value of undiscovered information." With the question thus explained, 141 of the 174 responding attorneys ( 81 percent) said they had decided in one or more cases not to pursue some information that, but for the cost factor, they would have pursued. The next question asked the lawyers to estimate the percentage of their cases during the preceding five years in which this had occurred. The median response for the sample as a whole was a surprisingly low 20 percent (the mean was 30 percent). The median percentage was not dramatically higher for any of

83. See Brazil, supra note 3, at 226-29. 
the subgroups. Even the lawyers who reportedly were the most likely to be deterred by the expense of conducting discovery (attorneys whose cases included "commercial contracts" litigation) indicated that this obstacle was likely to have arisen in only three of every ten cases. Comparing the figures for various subgroups creates the impression, also surprising, that attorneys who tended to handle smaller cases were only slightly more likely than large case litigators to limit their discovery because of its expense. For example, the lawyers whose median size case was $\$ 25,000$ or less indicated that cost impeded their discovery in 25 percent of their cases, whereas the comparable figure for attorneys whose median size case was $\$ 1,000,000$ or more was 18 percent.

The fact that small case lawyers reported being deterred from conducting discovery by cost pressures in such a modest percentage of their cases and only slightly more often than litigators involved in larger cases may be attributable in part to the fact that smaller case lawyers decline large numbers of cases because the foreseeable cost of discovery and trial is disproportionate to the value of the matter to the prospective client and, in contingent fee cases, to the lawyer. ${ }^{84}$ Thus smaller case lawyers apparently screen out many cases in which financial constraints would impede discovery. Moreover, case development costs are likely to be considerably lower in less complex litigation, because, among other things, the kind of evidence that is likely to be discoverable is more predictable (requiring fewer costly exploratory probes) and the volume of that information is likely to be much smaller than it would be in large lawsuits. Another factor, suggested by data explored in detail in the next section, may be that there is substantially more tactical jockeying (which presumably increases expenses for both sides) in suits in which more money is at stake.

Finally, it is worth noting a psychological phenomenon that may help explain why attorneys reported that the expense of pursuing information deterred them in such a modest percentage of their cases. When asked whether cost pressures ever impaired their discovery efforts some attorneys seemed to take offense-to feel that to admit to failing to pursue relevant evidence out of concern for "mere money" would be to admit to serious professional irresponsibility and, perhaps, to malpractice. Some lawyers adamantly asserted that if they believed information that might help a client remained discoverable, they would never permit cost considerations to interfere with the hunt. It is not clear how widespread such views were. Nor is it clear that they affected the quantifiable answers to the questions about cost. It is reasonable to assume, however, that a lawyer who viewed cost-based decisions to forgo discovery as professional "bad form" would be tempted to understate their frequency in his practice.

84. See note 67 supra. 
Privileges (especially attorney-client) and the work-product doctrine are additional potential "obstacles" to discovery that we attempted to explore. Figure 17 (supra) reports how three groups of attorneys responded when asked in what percentage of their cases (during the preceding five years), first, the attorney-client privilege, then, separately, any other privilege or doctrinal protection of information "made their discovery more difficult or accounted for them not discovering or not pursuing some information." The vast majority of the lawyers in the sample did not respond to the literal terms of these questions (privileges would protect some information in virtually every case). ${ }^{85}$ Instead, most lawyers sensibly construed the questions as asking how often privileges caused visible friction between opponents during the discovery stage of litigation. Several attorneys, for example, commented that the attorney-client privilege was a source of difficulty only infrequently because in their field the rules fixing the scope of that privilege are relatively clear. The percentage of their cases in which these attorneys thought this privilege was an obstacle or impediment during discovery was relatively low. The fact that a substantial number of lawyers ( 43 of 157,27 percent) said that the attorney-client privilege had never impeded their discovery also indicates that the questions being answered were about friction, not about the mere existence of protected communications.

Thus the responses to the questions about privileges as "obstacles" suggest how often privilege claims cause conflicts during discovery and illuminate differences between different types of practices (or cases) with

85. In virtually every case both the attorney-client privilege and the work-product doctrine "account for [an attorney] not discovering or not pursuing some information." In almost every case clients discuss matters in confidence with their lawyers and lawyers prepare some documents that could qualify as work product. Opposing counsel probably would like to know what lawyer and client say to one another in confidence about the case and probably would like to have copies of whatever documents the lawyer drafts while preparing the case for possible trial. Neither these conversations nor these documents, however, are discoverable. And it is the attorney-client privilege and the work-product doctrine that account for this kind of information either not being discovered or not being pursued.

Comments provoked by the questions about privileges elucidate this fact of civil litigation life. Some attorneys pointed out that formal assertions of privilege rarely were necessary in their practice because the lawyers usually understood what kinds of communications or documents the privileges protected and, therefore, rarely asked for undiscoverable material. In a similar vein, other litigators indicated that they never tried to discover what was in a statement opposing counsel had secured from his client, even though they would have liked to have known the contents of such documents. Such observations show that the mere existence of the privileges blocked, tacitly and invisibly, the exchange of information between parties.

It follows that if all the attorneys in the sample had responded to the literal phraseology of the questions that asked them to estimate the percentage of their cases in which privilege had "accounted for [them] not discovering or pursuing some information," all (or virtually all) of the answers would have been " 100 percent." A few lawyers may have taken the words of the questions literally. Ten of 113 responding attorneys reported that the attorney-client privilege impeded their discovery in 100 percent of their cases. Similarly, 8 of 158 respondents said some other doctrinal protection of information was an obstacle to discovery in 100 percent of their cases. The substantially smaller percentages offered by the vast majority of the litigators, however, indicate that they were not strict constructionists. 
respect to levels of tension privileges generate between adversaries. ${ }^{86}$ In brief, the data suggest that privileges are substantially less likely to be sources of conflict and frustration in smaller, less complex litigation than in lawsuits involving large amounts of money and information. As figure 17 indicates, for example, small case lawyers, as a group, reported that the attorney-client privilege was likely to have impaired their discovery efforts in only 7 percent of their cases; the comparable figure for large case litigators was 36 percent. And while the median percentages for other subgroups of attorneys who tended to be involved in bigger cases fell to 18-20 percent, the figures for subgroups of lawyers who generally handled smaller cases were lower still (7-13 percent).

This pattern is consistent with comments lawyers volunteered. Several antitrust attorneys complained that fights about privilege claims were perennial and time consuming. This problem may be a function in part of efforts by sophisticated corporate employees to sheathe foreseeably sensitive documents with the protection of privilege by routinely circulating them to house counsel or to some officer who also is a lawyer. Some big case litigators also suggested, however, that a major reason the attorneyclient privilege provokes clashes in large lawsuits is that the courts have not consistently and precisely defined the doctrine's reach within corporate parties. By contrast, some smaller case personal injury lawyers observed that one reason conflicts centering around privilege were relatively rare in their practices was that the courts had fixed pretty clearly the scope of the attorney-client privilege as it affected their clients.

The data also indicate that the work-product doctrine and privileges other than the attorney-client privilege generated conflicts in substantially higher percentages of large cases than of smaller suits. Figure 17 (supra) illustrates this point by comparing the percentages of cases in which doctrinal protections of information other than the attorney-client privilege reportedly impeded the discovery efforts of large case lawyers and of small case lawyers. Comparisons within other sets of subgroups reveal a similiar pattern of differences: the groups in which the lawyers' cases were likely to involve more money and more evidence consistently reported higher percentages of cases in which other privileges had generated friction between parties. ${ }^{87}$

One reason disputes about doctrinal protections occur in higher percentages of larger cases than of smaller ones undoubtedly is that in

86. The fact that a few lawyers apparently responded to the literal phrasing of the question (and indicated that privileges accounted for the inaccessibility of information in 100 percent of their cases) skews (upward) the median and mean percentages. The number of lawyers who so construed these questions was small enough, however, not to invalidate the data, at least for the purpose of making comparisons between differently situated litigatorș.

87. The median percentages for the other "large case subgroups," however, ranged between 20 and 40 percent, measurably lower than the 50 percent figure for the attorneys whose median size case was $\$ 1$ million or more. 
larger lawsuits attorneys seek more information and are involved in more interchanges with opponents. It is highly unlikely, however, that that fact fully explains the substantial difference between the two contrasting types of litigation. Responses to a follow-up question asking lawyers to identify which doctrine other than attorney-client privilege had most often been a source of difficulty revealed that, other than work product, "trade secrets" were cited most often. Moreover, the attorneys who cited this doctrine were larger case lawyers. Thus it appears that differences between small and large cases in levels of friction provoked by protective doctrines result not only from the fact that in large cases there is more information to fight about but also from the fact that there is at least one major additional doctrine about which to do battle. And, of course, the economic incentives to engage in the combat are stronger in suits in which more is at stake.

It is important to emphasize that responses to questions about how often privileges made discovery more difficult cannot be interpreted as expressions of hostility toward privileges per se. Many lawyers went to great lengths to assure the interviewer that they believed very much in the concept of privileges, especially attorney-client privilege, even though they sometimes felt frustrated by how adversaries used them. Such volunteered comments, as well as quantifiable data discussed in section VIII of this article, reflect a fact that emerged clearly from the interviews: most of the lawyers not only accept but are actively committed to the attorneyclient privilege. This obvious loyalty to privilege doctrine may have encouraged some attorneys to understate the frequency with which they feel frustrated by opponent's use of it.

The role of one other potential obstacle to discovery remains to be examined: tactical constraints felt by the attorney conducting the discovery. The interviewers asked the lawyers if they ever had "decided not to pursue [information] for tactical reasons." To clarify the question, the interviewers added the following examples of tactical reasons that might inspire such a decision: "desire not to educate your opponent or encourage him to prepare, desire not to expose your theories or concerns, desire to preserve business or personal relationships." So explained, the question elicited affirmative responses from 155 of the 176 responding attorneys (88 percent). The phrasing of the follow-up question for these lawyers probably resulted in underestimations of how frequently self-imposed tactical constraints deterred full discovery efforts. After posing the follow-up question in many interviews simply by asking "In approximately what percentage of your cases during the past five years has this occurred?" the interviewers learned (from attorneys being interviewed) that in responding to the question so generally phrased, lawyers were likely to overlook tactical decisions they had made during depositions not to ask 
certain questions or to pursue certain lines of inquiry. Since the interviewers did not change the wording of the follow-up question in order to encourage the remaining respondents to focus on this particular kind of tactical decision, the data produced by the question probably do not reflect a good many instances of forgone inquiries.

Absence of such instances may help account for the fact that most attorneys reported being deterred from pursuing evidence by tactical considerations relatively infrequently. For the sample as a whole, the median (15 percent) and mean ( 25 percent) responses indicate that the lawyers made tactically inspired decisions not to seek information in only about one case in five. While larger case lawyers reported making such decisions in higher percentages of their cases than smaller case lawyers did, ${ }^{88}$ the median figures even for subgroups of typically large case litigators ranged only between 18 and 25 percent. ${ }^{89}$ The "means" of the lawyers' responses were higher for all the subgroups and were between 34 and 39 percent for most of the groups of attorneys who tended to be involved in larger lawsuits. ${ }^{90}$ This significant difference between medians and means reflects the fact than even within groups of similarly situated lawyers (e.g., lawyers representing large corporate clients primarily in big cases) some litigators made tactically based decisions not to pursue information much more often than others; 9 lawyers (of the 152 responding) said they made such a decision at least once in every case. Taken as a whole, however, the data suggest that self-imposed tactical restraints interfere with the conduct of discovery (even in large cases) substantially less than such factors as evasion and dilatoriness by responding counsel and their clients.

The data produced by the questions about specific obstacles to discovery set the stage for analyzing what were intended to be broader questions about the difficulty of conducting discovery. After asking the lawyers to estimate the number of civil cases on which they had active files, the interviewers posed the following question: "Have you had difficulty discovering the information you need in any of these currently active cases?" Ninety-seven percent of the lawyers asked (170 of 175) said yes. There were no significant differences between subgroups in percentage of affirmative responses to this question; the lowest figure for any subgroup

88. E.g., the median size case for the sample as a whole was $\$ 150,000$, but that median was $\$ 501,000$ for the 38 lawyers who reported that tactical considerations induced them not to pursue some information in 33 percent or more of their cases.

89. The modest differences between the percentage figures for the larger and the smaller case attorneys might well reflect little more than the fact that since larger cases involve more discovery they also necessitate more decisions that tactics could affect.

90. The means for some of the subgroups of attorneys who tended to have larger cases were: 39 percent for lawyers whose median size case was $\$ 1$ million or more; 34 percent for lawyers whose principal cases included antitrust matters; 35 percent for lawyers whose principal cases included securites actions; 27 percent for attorneys who devoted 80 percent or more of their time to matters filed in federal court; and 37 percent for attorneys who received 50 percent or more of their work from large corporate clients. 
was 94 percent. The follow-up question asked the lawyers to estimate the percentage of their active cases in which they had had difficulty discovering the information they needed. In light of the reported frequency of evasive (or incomplete) and tardy responses to discovery requests, the figures provided in response to this question appear surprisingly low. For the sample as a whole the responses indicate that the lawyers were likely to have had difficulty acquiring needed evidence through discovery in $\mathbf{3 0}$ percent (the median for the 160 responses) to 41 percent (the mean) of their active cases. These percentages (and the sizable difference between median and mean) remained relatively constant between subgroups: the medians ranged between a low of 25 percent and a high of 40 percent, while the low and high for the means were 35 and 48 percent. Surprisingly, the modest differences between subgroups did not fall into a pattern that reflected greater difficulty in larger and more complex litigation: in fact, the subgroup composed of attorneys who handled tort actions arising out of automobile accidents reported difficulty discovering needed information in a higher percentage of cases than any other subgroup. ${ }^{91}$

What might account for the fact that the same attorneys (the entire sample) who indicated that evasive responses impeded discovery in 60 percent of their cases and that dilatory responses had that effect in 50 percent of their cases also reported having "difficulty discovering" needed information in only about one in every three cases? Several factors seem to be at work here, all suggesting that the figures for the active cases are understated. One such factor was the interviewers' failure to remind many of the lawyers to exclude, when estimating the percentage of their active cases in which they were having difficulty, those cases in which they had conducted little or no discovery. The phenomenon of professional acculturation described above may have affected many responses. ${ }^{92}$ It is also possible that the wording of the question ("Have you had difficulty discovering the information you need?") encouraged some attorneys to focus on the ultimate results of their efforts, rather than on the process by which those results were achieved. ${ }^{93}$ Focusing on the results rather than the path to

91. For the auto personal injury subgroup the median was 40 percent and the mean was $\mathbf{4 8}$ percent. For most of the other subgroups the medians ranged between 26 and 33 percent while the means fell between 39 and 45 percent.

92. See pp. 792-93, 797-99, 833-34 supra.

93. There may be inferential support for this possibility in a remarkable parallel between the responses (viewed in the aggregate) to this question and to the two questions that were intended to focus on the results of the information exchange process. The question that asked the attorneys to estimate the percentage of the cases they had settled during the preceding five years believing an opponent had not discovered arguably significant information from them produced, for the sample as a whole, a median of 30 percent and a mean of 37 percent. Similarly, the question that asked for estimates of the percentage of cases they had settled suspecting another party had relevant information they had not discovered produced a median of 30 percent and a mean of 41 percent. And the question that sought estimates of the percentage of the lawyers' active cases in which they had had difficulty discovering needed information produced a median of 30 percent and a mean of 41 percent. Of course, this dramatic convergence of estimates, made in response to questions separated in 
them might have caused some lawyers to overlook "difficulties" they felt they were overcoming or had overcome.

\section{The Role of Tactics IN Discovery}

"Most attorneys still see discovery as a game and play it to the hilt to avoid disclosure."

"I use discovery to hurt my opponent and help my client; it's something that is second nature to me. I will try to make it inconvenient for [my] opponent to pursue the case."

"Tactics are the whole basis of your approach to a case." -three Chicago litigators

While the views expressed in the quotations above are not shared by all Chicago litigators, they reflect widely shared attitudes toward discovery that greatly affect the character of the system.

Before examining the quantifiable data, I will describe how two very differently situated litigators reacted to questions about their tactical uses of discovery tools. While perhaps not representative, these reactions illustrate the wide range of feelings within the litigating bar about tactical maneuvering and highlight important differences between small case and large case practices. The interviews included about a dozen questions (they will be described in detail momentarily), some more specific than others, that probed the role tactics played in the way each interviewed attorney conducted and responded to discovery. In essence, the questions asked each lawyer to describe the extent to which he used discovery tools for purposes they were not intended to serve. While these questions provoked stressful reactions in many lawyers, the character of that stress was particularly instructive in two instances.

One instance involved a seasoned solo practitioner whose high volume practice revolved around personal injury and family law matters. This lawyer became more and more agitated as he tried to respond to a series of questions about how often various specified tactical purposes had affected his use of discovery tools. His answer to each question was essentially the same: not very often. Finally, at the end of this sequence, his agitation broke into an emotional explanation. Obviously embarrassed by the fact that his answers showed that his handling of discovery did not in-

the interviews by many other inquiries, could be merely fortuitous. That possibility, however, does not reduce the temptation to infer that the virtually identical aggregate answers to these three questions reflect what is, in fact, the likelihood in any given case that the discovery system will distribute the significant information evenly among the parties. If these lawyers' estimates are to be believed, the system leaves at least one party at an informational disadvantage in about one case in every three. And in high stakes litigation that result is likely in every other case. 
clude substantial tactical jockeying, he insisted that his cases were too small and his practice too hectic to permit him to develop strategic plans. He went on to confess that his inability to seek advantages through tactical devices made him feel that he was not giving his clients " 100 percent" representation.

The stress that the questions about tactics caused the second lawyer seemed to have a very different source. As a partner in a sizable firm, this lawyer handled larger cases, many of which were class actions in which he defended manufacturing companies. During the first half of the interview, which focused on problems other lawyers created, this attorney was cheerful and animated. When the focus of the questions shifted to his own use of tactics, however, he became noticeably more sober, tense, and reflective. His answers indicated that tactical considerations affected how he conducted discovery in virtually every case. The questions, which seemed to surprise him, made him step back from the intensity of day-today decision making. They forced him to look systematically at the kinds of things he was absorbed in thinking about and doing every day. Apparently he was not altogether comfortable with what he saw. His transformation from cheerfulness to gravity seemed directly attributable to the results of his examination of his motivations and conduct in litigation. At the end of the interview he seemed emotionally drained when he said, without humor, "I feel like I've just been deposed."

The accounts of these interviews depict, in brief, a small case lawyer who was ashamed that he could not be more tactical and a large case lawyer who had lost sight of tactics, as such, because they had become so deeply ingrained in his everyday work. As the quantifiable data show, these pictures tell a great deal about the place of tactics in civil discovery.

While this project was not designed to produce a complete delineation of either the pervasiveness or the effects of tactical considerations, it did explore how often such considerations affect lawyers' decisions during discovery. The interviews asked the lawyers to consider the word "tactical" to embrace "every purpose other than simply to acquire information you need to prepare your case." Using this broad definition, the interviewers asked the lawyers to consider "all of the possible tactical uses of discovery tools," then to estimate the percentage of their cases during the preceding five years in which "at least one tactical purpose" had affected their "use of discovery tools." Amplifying the question orally, the interviewers asked the lawyers also to include in their answers cases in which tactics had affected how they had responded to discovery. For the sample as a whole the median of the responses was 99.5 percent

94. By casting a wide net, this definition prevented time-consuming semantic sparring and reduced the odds that differences of opinion about how to characterize various purposes would result in an understatement of the scope of the general phenomenon. 
and the mean was 82 percent. Of the 164 lawyers who answered this question, 87 said that tactics had affected some aspect of how they had conducted or responded to discovery in every case. Another 41 litigators reported that tactics had affected their behavior in discovery in 75 percent or more of their cases. Of course, these figures do not indicate the percentage of all discovery decisions affected by tactical purposes. Nonetheless, the lawyers' responses strongly suggest that at least in Chicago it is a rare case in which tactics play no role during the discovery stage.

A comparison of subgroups shows that the likelihood of some aspect of the discovery process being affected by tactics was somewhat higher in larger cases than in smaller ones. Even lawyers who typically handled small cases in state court indicated, however, that one or more tactical purposes affected their discovery in an overwhelming majority of their cases. Figure 19 illustrates these results by comparing eight subgroups; it

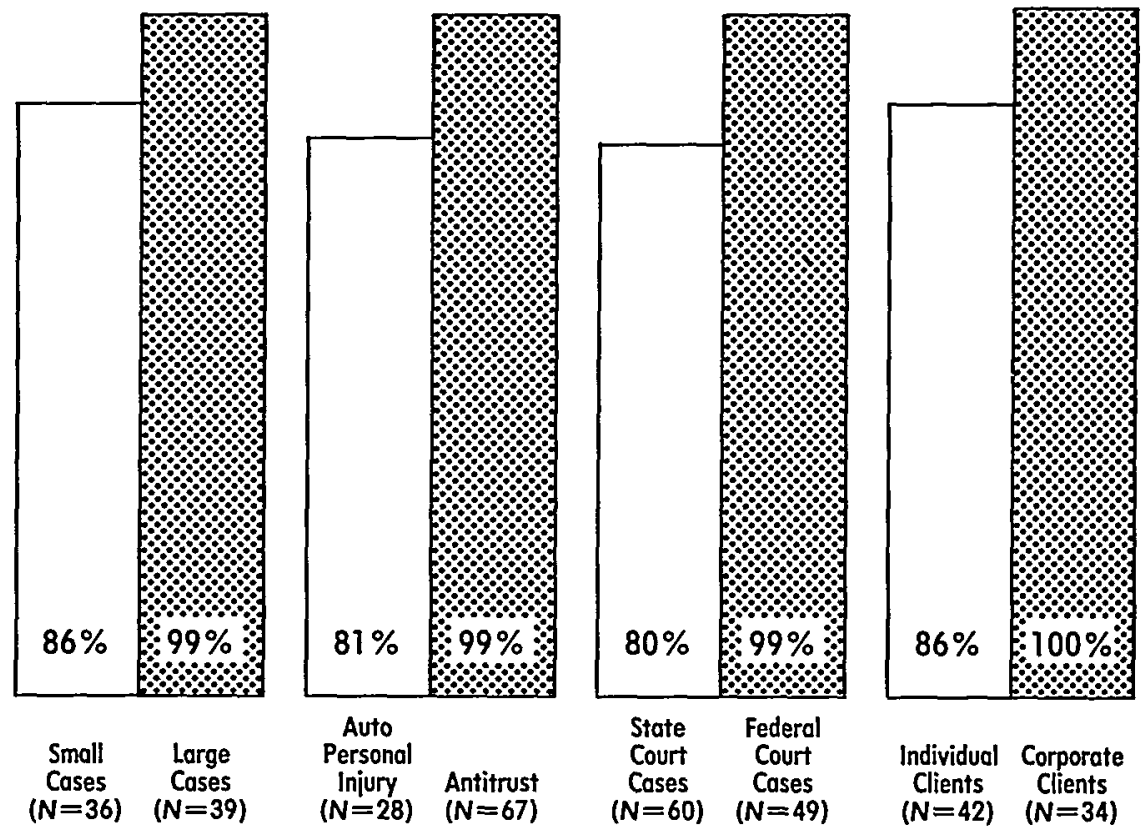

Fig. 19. Median percentages of cases in which one or more tactical purposes affected the attorney's discovery by subgroup set.

shows the median percentage of cases in which the lawyers in each subgroup said one or more tactical purposes had affected their discovery.

Answers to questions about the timing of discovery events also suggest that tactical considerations play a prominent role in lawyers' approaches to discovery. When asked whether "any tactical purpose ever [has] been a factor affecting how you have timed or scheduled discovery events," 167 of the 169 responding attorneys (99 percent) said yes. ${ }^{95}$ Obviously, 
the percentage of attorneys who answered this question in the affirmative was very high in every subgroup (the lowest percentage for a subgroup was 97 percent). Moreover, most of the lawyers in the sample indicated that tactics had affected some aspect of their timing or sequencing of discovery in a high percentage of their cases. Viewed as a whole, the lawyers in the sample reported that tactical purposes had affected their timing or scheduling of discovery events in 75 percent of their cases. ${ }^{96}$ The percentage of cases in which tactics affected the timing of discovery was measurably higher for the large case litigators than for the lawyers who typically handled smaller matters. Figure 20 illustrates this point by comparing four sets of subgroups.

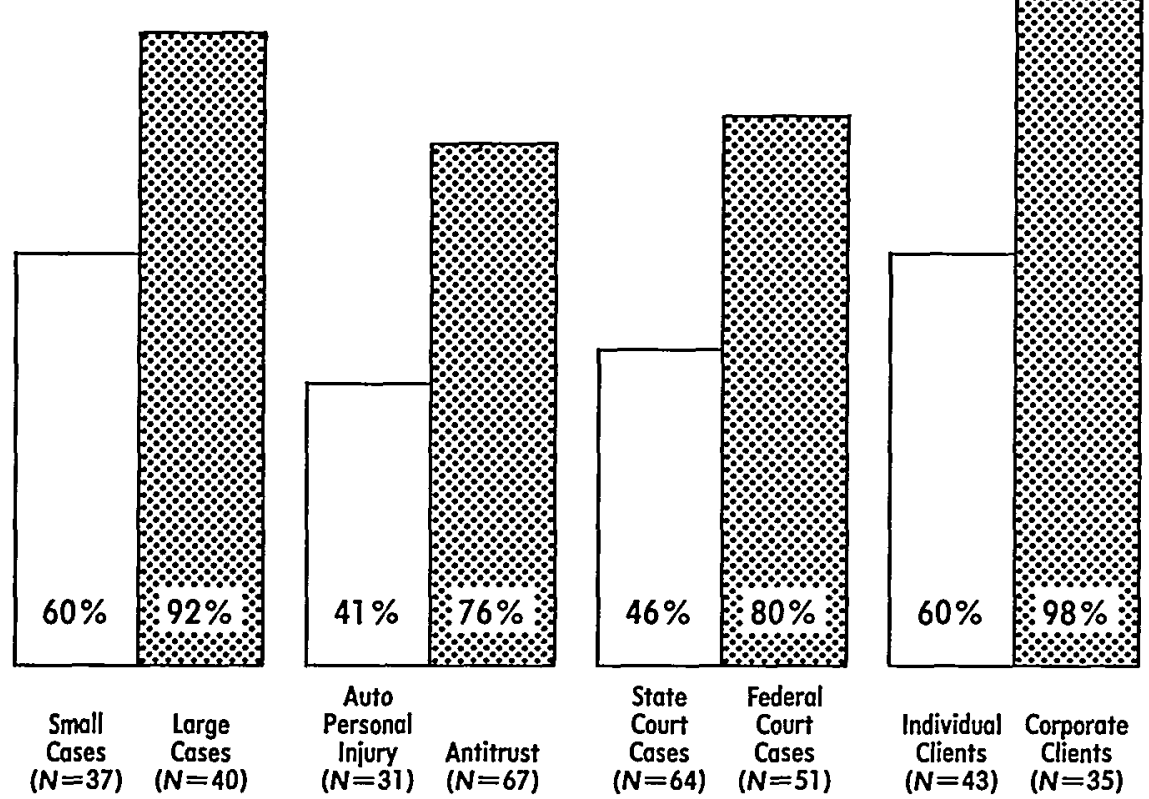

Fig. 20. Percentages of cases in which tactics affected the attorney's timing of discovery by subgroup set.

95. A few attorneys asked whether the desire to acquire information in a logical and efficient sequence qualified as a "tactical purpose" as that phrase was used in the question. The interviewers told these lawyers not to consider such an objective tactical.

96. In addition to jockeying for the most desirable position in a sequence of depositions of experts or clients (the usual objective being to depose an opponent's people before he deposes yours), our respondents offered some interesting examples of scheduling for tactical purposes. One attorney said that in more than one case he had intentionally postponed most of the important depositions, then "telescope" scheduled them (all in a very brief time span) right before the close of the discovery period in order to create an excuse to postpone a trial he did not want to proceed as originally set. Other lawyers admitted that on occasion they had intentionally noticed depositions at times they knew were extremely inconvenient for opposing counsel-either to create leverage to bargain for some favor or in the hope that the firm representing the opposing party would have to send a lawyer to the deposition who was inexperienced and unfamiliar with the case and who, therefore,.would be less capable of preventing the taking of inadmissible testimony in an "evidence" deposition (see note 6 supra). 
Similar patterns can be seen in the lawyers' responses when they were asked for their "impression about how often tactical purposes affect the way other attorneys time or schedule discovery events." Given four alternative responses from which to choose ("never," "seldom," "moderately often," or "quite frequently"), 103 of the 166 responding lawyers (62 percent) selected "quite frequently." While another 30 percent chose "moderately often," only 8 percent selected "seldom," and no one said "never." The pattern of responses among the subgroups also assumed a common form: as figure 21 illustrates, substantially higher percentages of

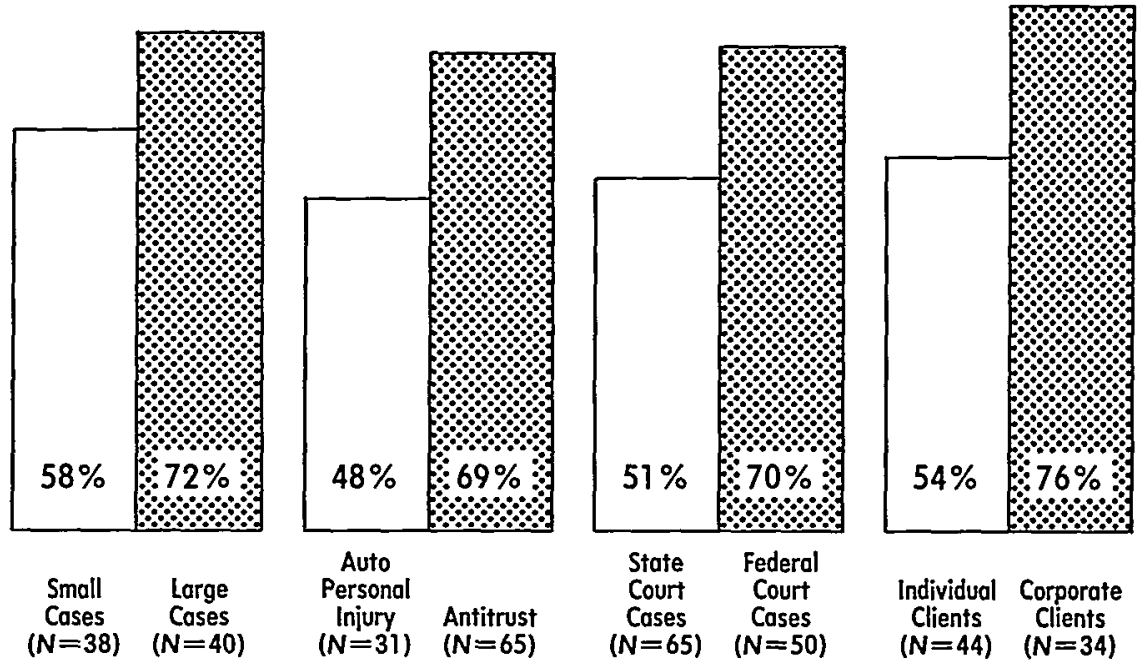

Fig. 21. Percentages of attorneys who said that tactics "quite frequently" affected other lawyers' timing of discovery by subgroup set.

lawyers in the larger case subgroups than in the smaller case groups opined that tactics "quite frequently" affect the way other lawyers time their discovery.

The fact that larger case lawyers reported scheduling discovery probes with tactical purposes in view in a higher percentage of their cases than smaller case litigators did may be attributable in part to the fact that larger cases generally involve more discovery events and, therefore, more opportunities to seek tactical advantages. It is unlikely, however, that the greater number of discovery events in bigger cases completely explains the differences. For one thing, as the paragraphs that follow show, larger case lawyers consistently reported being motivated by tactical considerations or engaging in tactical conduct in higher percentages of their cases with respect to every tactical purpose and every type of tactical behavior about which questions were posed. ${ }^{97}$ The answers to these questions

97. See also the discussions of evasion and of deposition preparation at pp. 833-38, 850-58. 
about how often other lawyers behave tactically also suggest that there is more to the differences between large and small case lawyering than merely volume of discovery per case. The questions about the tactical behavior of other lawyers were not couched in terms of percentages of cases; instead, these questions simply asked "how often" other lawyers appeared to be motivated by various types of tactical objectives. This phraseology presumably encouraged the responding lawyers to focus not on the percentage of cases in which they observed the tactical conduct in question but on the percentage of discovery events. Even with the question so phrased the pattern of differences in the responses by smaller and larger case lawyers remained constant: the larger case litigators consistently asserted greater likelihoods that other attorneys would be motivated by tactical considerations.

Numerous unquantifiable comments by interviewed attorneys also reinforce the suggestion that tactics are likely to play a larger role in the day-to-day discovery practices of big case attorneys than of their smaller case counterparts. In the aggregate, such comments create the hardly surprising impression that the bigger and more complex cases tend to be harder fought and to offer substantially greater opportunities for tactical maneuvering than the smaller matters. In the larger lawsuits the incentives to win are greater, as are the resources to commit to the effort. The clients tend to be more sophisticated and to make more sophisticated demands of the lawyers they hire. The lawyers can justify committing more time to more subtle aspects of the litigation process and can tailor different strategies for different cases. And because the law tends to be more complex and the evidence much more voluminous, there is more room for tactical jockeying. Large cases, for example, frequently involve at least one corporate party, and the adversaries of a corporation are less likely (than the oppponents of a natural person) to know who in the corporation made relevant decisions, how the corporation's documents are organized, and what kinds of things they might contain. Such uncertainty invites adversarial exploitation. Smaller case lawyers, in sharp contrast, reported that their litigation presented fewer opportunities and incentives for tactical inventiveness: the resources were too spare, the amount of information was too small, and the issues and the evidence were too predictable. ${ }^{98}$ Thus the lawyers' characterizations of their own practice styles strongly support the conclusion that tactical considerations color discovery decisions much more often in larger litigation than in smaller cases.

98. One lawyer whose practice primarily involved small cases but who occasionally litigated more substantial matters reported that he used discovery relatively little (and then only in a simple, straightforward manner) in his small cases, but that he was very conscious of tactics and aggressive with discovery in his larger cases. As an example of his style in the larger cases he said he tried to use "evidence depositions" to "sneak up" on his opponents-by scheduling them at strange times and very early in the litigation, before his opponents understood the cases or took them seriously. 
In addition to the broader questions discussed above, the interviews probed the extent to which three specific kinds of tactical purposes affected discovery decisions: (1) "gaining time or slowing down part or all of an action," (2) "imposing work burdens or economic pressure on another party or attorney," and (3) "distracting another party's [or attorney's] attention from or obscuring the existence of information." Not surprisingly, questions about how often they had been animated by these purposes seemed to make many attorneys uncomfortable. There is no way of knowing to what extent, if any, that discomfort inspired lawyers to hedge their responses or to lie. Because some attorneys seemed to view positive answers to these questions as unflattering or even as admissions of some form of culpability, however, there is a distinct possibility that this data understates how often these purposes affected decisions about discovery matters.

When asked if "the purpose of gaining time or slowing down part or all of an action" ever had "been a factor affecting" their use of discovery tools, ${ }^{99} 141$ of the 176 responding attorneys (80 percent) said yes. The responses to the follow-up question by the 141 lawyers left in the sample indicate that this purpose was likely to have affected how any given lawyer conducted (or, perhaps, responded to) discovery in one of every three or four of his cases. ${ }^{100}$ Since there are virtually always at least two lawyers in a case, the likelihood in any given matter that this purpose will affect the discovery process is substantially higher.

The desire to delay part or all of an action reportedly affected discovery decisions by large case lawyers in a higher percentage of their cases than of smaller case litigators' cases. For example, the subgroup of attorneys who spent 50 percent or more of their time representing large corporate clients indicated that (in the aggregate) they were likely to have used discovery to "gain time" in 30 percent (median) to 46 percent (mean) of their cases. The subgroup of lawyers who got 50 percent or more of their work from individual clients, by comparison, indicated that

99. Lawyers provided the following examples, among others, of the ways they had used discovery tools for purposes of delay: (1) filing, or asserting in depositions, countless technical objections and refusing on grounds of vagueness to comply with discovery requests, (2) serving unnecessarily lengthy sets of interrogatories or document production demands that consumed opponents' time or provoked disputes, and (3) asking for documents or testimony that an opponent was known to be especially sensitive about and, therefore, likely to resist disclosing. One attorney described this last tactic simply when he said: "To slow things down you ask for things that will create arguments."

100. The median of the responses was 25 percent; the mean was 34 percent.

Some of the attorneys in the sample pointed out that the backlog in the civil trial docket of the law division of the state courts in Chicago was so severe (about five years) that there was less temptation to use discovery to "slow things down" than there might be in a system in which trial dates were more pressing. This observation may help account for the fact that big case lawyers admitted using discovery for purposes of delay more often than their smaller case counterparts. Big case attorneys tended to spend a substantially higher percentage of their time (than small case attorneys did) on matters filed in federal court, where trial dates were available much earlier than in the state court system. See appendix D. 
they were likely to have used discovery for purposes of delay in only 10 percent (median) to 26 percent (mean) of their cases. Similarly, the figures for attorneys whose median size case was $\$ 1,000,000$ or more were 34 percent (median) and 40 percent (mean), while for the lawyers whose median size case was $\$ 25,000$ or less they were 20 percent (median) and 28 percent (mean). ${ }^{101}$ These differences between subgroups may be attributable, at least in part, to the fact that attorneys who had smaller median size cases and who tended to represent individuals also tended to represent plaintiffs more often than did attorneys who had larger median size cases and who tended to represent large corporations. ${ }^{102}$ The data suggest that defense counsel are more likely than plaintiffs' lawyers to use discovery tools for purposes of delay. As a group, attorneys who committed 75 percent or more of their time to defendants' matters indicated that the desire to "gain time" had affected their discovery in 28 percent (median) to 39 percent (mean) of their cases; those figures were 15 percent (median) and 27 percent (mean) for the group of predominantly plaintiffs' lawyers. This difference probably is not attributable primarily to the relatively modest differences between these two subgroups in median size cases or in principal types of cases. ${ }^{103}$ It is likely that defense attorneys use discovery to slow things down more often than plaintiffs' attorneys do because postponing judgment or settlement generally is more likely to be to a defendant's advantage and a plaintiff's detriment. ${ }^{104}$

The data also suggest that defense counsel were somewhat more likely than plaintiffs' lawyers to use discovery tools for purposes of delay. As a group, attorneys who committed 75 percent or more of their time to defendants' matters indicated that the desire to "gain time" had affected their discovery in 28 percent (median) to 39 percent (mean) of their cases; those figures were 15 percent (median) and 27 percent (mean) for the group of predominantly plaintiffs' lawyers. This difference probably is not attributable solely to differences between these two subgroups in median size case or in principal types of cases; as noted earlier, the differ-

101. The consistently higher "means" reflect the fact that wide ranges of responses were reported within subgroups; the desire to slow things down affected discovery decisions for some attorneys in a much higher percentage of their cases than for others, even though the lawyers were by some measures similarly situated.

The big case lawyers, in the aggregate, also thought that "other lawyers" used discovery to "gain time" or to delay an action more often than the smaller case lawyers thought they did. For example, of the attorneys whose median size case was $\$ 25,000$ or less, 29 percent thought that "other attorneys" "seldom" used discovery to slow things down; 34 percent of this group thought other lawyers used discovery for that purpose "moderately often," and 37 percent thought that others were so motivated "quite frequently." Among the attorneys whose median size case was $\$ 1,000,000$ or more, the comparable estimates of how often other attorneys used discovery to delay an action were respectively, 10,46 , and 44 percent.

102. See table D1.

103. Id.

104. See Brazil, supra note 3, at 228-29. 
ences between these subgroups with respect to typical size and types of cases were not large.

A short set of questions designed to explore the role of another tactical purpose began with this inquiry: "Has the purpose of distracting another party's attention from or obscuring the existence of information ever affected the way you have shaped your responses to another party's discovery?" The interviewers offered the following examples to the lawyers who appeared not to understand the question stated in the abstract: "e.g., incomplete responses to interrogatories, overproduction of documents [or] unnecessarily long lists of people with knowledge of certain matters." Several lawyers in the sample amplified these examples or provided others. One lawyer expounded: "Discovery is trial by avalanche of documents. [An] unprepared attorney should be surprised if you can. This is contra to discovery but I view it this way. I bombard opponents with mounds of information and see if they will wade through it. They usually already have access to the information they ask for anyway." Another lawyer reported responding to an interrogatory that asked for the names of witnesses by identifying six people but intentionally omitting the one who had the key information. Yet another litigator said he coached his clients to go off on harmless and time-consuming tangents during their depositions-both to lead opponents astray and to increase their costs. Several lawyers admitted framing answers to try to prevent an adversary who was pursuing one track from discovering other bases for liability or damages. And two attorneys reported going on the offensive with discovery to distract opponents: one saying he designed questions "to throw the fox off the course" and the other proudly recounting his efforts "to mislead [the] other party and cause [him] to meet this argument when you aren't even going to use this argument. This is pure joy."

While the last quotation expresses a conscious attitude that probably is not representative, it also reflects an instinct that, in more muted tones, many lawyers apparently feel. The important question is: How often does that instinct affect behavior? While the data produced by the interviews offer no definitive answer, they do provide instructive clues. Of the 175 lawyers asked, 150 (86 percent) said that on one or more occasions the "purpose of distracting another party's attention from or obscuring the existence of information" had affected their responses to another party's discovery. When asked to estimate the percentage of their cases in which this had occurred, however, 89 of the 146 responding lawyers (61 percent) provided figures of 33 percent or less. For the sample as a whole the median figure was 20 percent and the mean was 34 percent.

These percentages are surprisingly low if the lawyers included in their answers every aspect of responding to discovery that might be considered evasive. Recall that the attorneys in the sample as a whole estimated that 
"evasive or incomplete" responses impeded discovery in 60 percent of their cases. Comments by some of the interviewed litigators suggest that the substantial difference between these two figures is attributable not merely to reluctance to admit to evasive practices but also to ambiguity in the question. Some lawyers pointed out that they were not sure where to draw the line (for purposes of answering this question) between aggressive efforts to distract an opponent, on the one hand, and the responsibility they felt, on the other, to interpret every discovery request as favorably to their clients as possible and to provide damaging information only when the precision of the probe and the absence of privilege left no alternative short of lying. ${ }^{105}$ It is probable that the figures that suggest how often the lawyers shaped responses to discovery probes with the intention of "distracting" an opponent do not include many instances of aggressively partisan but not outright dishonest readings of discovery requests.

In conformity with the patterns of responses to other questions about tactics, the data indicate that big case lawyers try to distract opponents in a higher percentage of their cases than do smaller case litigators. The median percentage of cases in which the purpose of distracting an opponent or obscuring evidence affected responses to discovery was a consistent 40 percent for the subgroups of attorneys who tended to handle large and involved lawsuits. By contrast, that figure was only about 12 percent for the subgroups of lawyers with predominantly smaller cases. For all of the subgroups, however, the means of these percentages were consistently higher, often by an appreciable margin, indicating that some lawyers in each subgroup admitted trying to distract opponents in a substantially higher percentage of their cases than other lawyers in the same subgroups admitted. Figure 22 compares the median and mean percentages for four sets of subgroups.

The interviewers also asked the litigators for their impression about how often the desire to distract opponents or obscure evidence "affects the way other attorneys shape their responses to discovery." Predictably, the bigger case lawyers thought other attorneys were so motivated more often than smaller case lawyers thought they were. The most dramatic differences between the impressions of small case and large case lawyers appear in the percentages of attorneys in the subgroups who said that other lawyers "quite often" shaped their responses to discovery in order

105. A few attorneys even admitted having chosen this course. One said, e.g., that he and a client simply decided not to acknowledge the existence of clearly discoverable information because to do so would have been disastrous for the client's case and might have exposed the client to criminal liability. The lawyer did not invoke his client's Fifth Amendment privilege against self-incrimination; it is not clear whether he even considered its applicability. Another attorney intimated that it was not beyond the pale "even [to] lie about temporarily losing a document." 

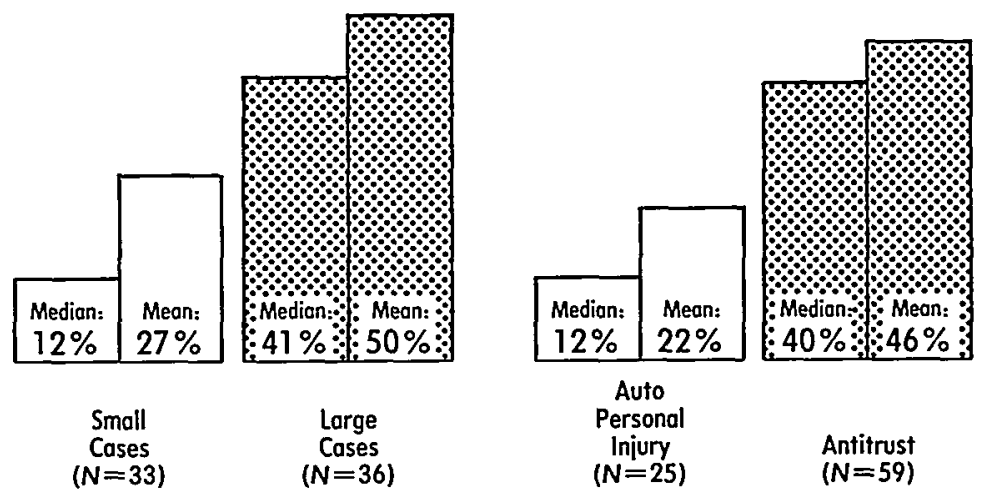

Auto
Personal
Injury
$(N=25)$

Antitrust

$(N=59)$

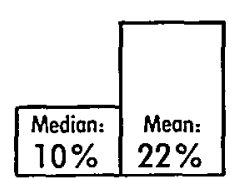

State
Court
Cases
$(N=56)$

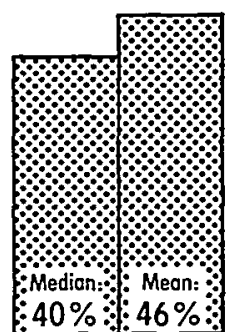

Federal

Court

Cases
$(N=41)$

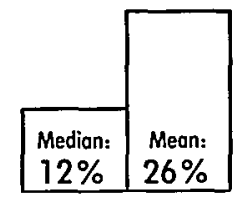

Individual
Clients

$(N=34)$

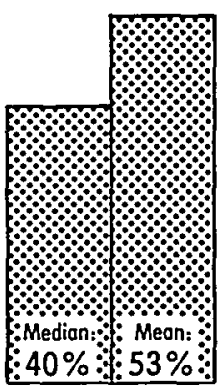

Corporate

Clients

$(N=33)$

Fig. 22. Median and mean percentages of cases in which a desire to distract an opponent affected how attorneys responded to discovery by subgroup set.

to distract opponents or obscure evidence. Figure 23 compares these percentages for eight subgroups.

The interviewers asked the lawyers about one other type of tactical purpose: the desire to impose "work burdens or economic pressure on another party or attorney." Prompted by the interviewers' questions, several attorneys offered examples of how they had used discovery weapons to burden opponents. These included (1) initiating unnecessary and demanding discovery probes (especially through interrogatories, depositions, and document production demands), (2) noticing depositions for remote (expensive to reach) places, (3) producing great quantities of peripheral or irrelevant documents, and (4) repeatedly asserting technical objections in order to obstruct discovery efforts by opposing counsel. With respect to the last mentioned "technique" one lawyer claimed that "by being an obstructionist you can avoid providing about 80 percent of the information because it's expensive for [an] opponent to go to court to compel discovery." Another lawyer articulated, in atypically blunt terms, the core of the instinct that seems to inspire pressure tactics: "You want 

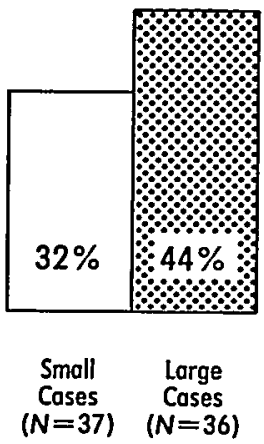

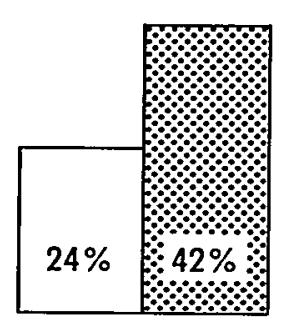

Auto

Personal

Injury
$(N=25)$
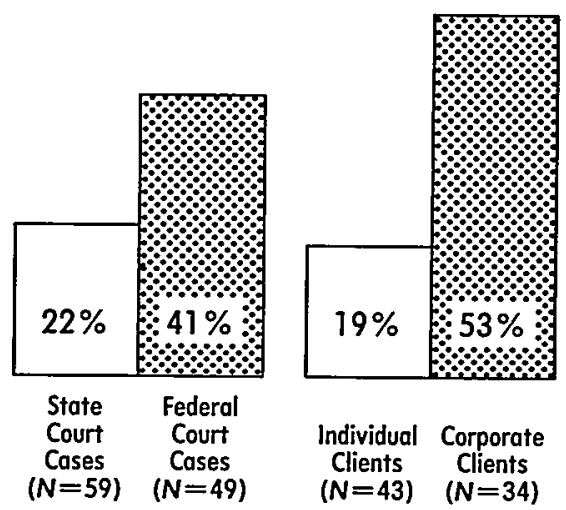

Fig. 23. Percentages of attorneys who said desire to distract opponents "quite often" affected how other lawyers responded to discovery by subgroup set.

to win," he said, "so if breaking a guy will enable you to win you will do it." Observing that "discovery gives incredible leverage to parties and firms with big resources," one attorney said he would "use this power to penalize opponents whenever" he could. Another lawyer put the matter more gently when he remarked: "It sometimes enters my mind that if I initiate a lot of discovery my opponent will throw up his hands and want to get rid of the case."

Again the key question is: How often do lawyers who feel such impulses translate them into action? When asked whether "the purpose of imposing work burdens or economic pressure on another party or attorney ever [had] been a factor affecting" their "use of discovery tools," 136 of the 176 responding lawyers (77 percent) said yes. The percentages of attorneys in the subgroups of predominantly smaller case lawyers who answered this question in the affirmative were noticeably smaller than they were in the subgroups comprised primarily of larger case litigators: while the figures fell between 65 and 77 percent for the small case subgroups, they ranged between 80 and 92 percent for the large case lawyers.

The follow-up question asked the lawyers to estimate the percentage of their cases during the preceding five years in which the desire to burden an opponent had affected their discovery practices. For the sample as a whole this question produced a median response of 18 percent and a mean of 28 percent, suggesting that this tactical objective was likely to have affected the discovery behavior of any given attorney in the sample in roughly one of every four or five of his cases. Again there were significant differences between the small case and the big case subgroups. For example, attorneys who handled tort actions arising out of automobile accidents estimated, as a group, that the desire to impose financial or work pressures on an opponent affected their discovery in only 7 (median) to 12 percent (mean) of their cases. Lawyers whose principal kinds 
of cases included antitrust matters, by comparison, estimated (again, in the aggregate) that such purposes affected how they conducted or responded to discovery in 30 (median) to 38 percent (mean) of their cases. The differences within the sets of subgroups defined by median size case, percent of time in state and federal court, and dominant client type were comparable but not quite as large.

Lawyers in the small case and in the large case subgroups also disagreed sharply about how often the desire to burden an opponent affected discovery by "other attorneys." Lawyers in the large case subgroups believed that this purpose affected the discovery practices of other attorneys much more often than litigators in the smaller case subgroups believed it did. The differences between attorneys who handled automobile accident cases and those who did antitrust work again are instructive (and, again, slightly greater than the similar differences within the other three sets of subgroups). Among the auto personal injury lawyers, 42 percent estimated that other attorneys "seldom" used discovery to impose burdens, and only 6 percent had the impression that other attorneys were "quite frequently" so motivated. Among the antitrust lawyers, by comparison, only 11 percent believed that other attorneys "seldom" tried to use discovery to burden opponents, while 32 percent declared that other litigators "quite frequently" used discovery for that purpose.

Of course, desires to delay, distract, or pressure an opponent are by no means the only tactical objectives for which lawyers could use discovery. ${ }^{106}$ To try to identify other commonly pursued tactical goals the interviewers asked many of the attoneys to provide "one or two examples of such other tactical purposes." The following were among the more frequently mentioned. Several lawyers reported using discovery to try to "move" cases toward settlement. For some attorneys this meant little more than trying to pick a propitious moment to serve a major discovery request, hoping that an opponent would rather settle than respond. For others it meant asking for information about which they knew opposing parties were particularly sensitive or using a deposition to "educate" an opponent about the weaknesses of his case or the cost of litigation. Several lawyers, however, claimed that they had used depositions not only to take the measure of an opposing party (i.e., to probe the strengths and weaknesses of his testimony and to assay his demeanor as a witness) but also to try to frighten, embarrass, or abuse him into submission. Lawyers reported pursuing such ends not only by probing personally sensitive subjects (e.g., triangular relationships, unreported income, or "gifts" to well-placed officials), but also by adopting harshly aggressive styles of

106. There is some support for this proposition in that when asked whether any tactical purposes "other than . . . gaining time or imposing work burdens on opponents" had affected how they had used discovery devices, 108 of the 112 responding attorneys (96 percent) said yes. 
questioning designed to make the opposing party decide he never wanted to repeat such an experience. As one litigator phrased it, he used depositions to put hostile witnesses or opposing parties "through the wringer, through the mud, [so that] they are frightened to be a witness and . . . are a much worse witness." Another lawyer reported using depositions of officers of corporate opponents "to test their will-[to] see if you can make them mad or pull their chain." And several attorneys told of noticing the deposition of a particular person because they knew their opponent did not want that person "dragged in" or otherwise bothered by the litigation.

Attorneys also offered examples of more "passive" tactics-devices used primarily to try to conceal information or to encourage opposing counsel to underestimate the quality of the responding attorney's evidence or the level of his preparedness. Some of these "devices" were nothing more than violations of the rules of discovery; for example, one lawyer admitted that when he did not want an opponent to have certain information he simply did not answer interrogatories that would force him to disclose it. Another attorney said he routinely did not answer interrogatories "unless I get a letter asking me where the hell [the answers] are." Nor were interrogatories the only instrument of discovery so abused; requests for documents also were vulnerable to "passive" tactics. One litigator stated: "I provide nonresponsive documents when I feel it would be advantageous." Another asserted: "I decline to be of any assistance to a plaintiff on discovery. If he asks for documents he gets them in a pile." Somewhat more subtly, other attorneys took steps to assure that they did not have information opponents were likely to seek, for example, by not taking statements from interviewed witnesses, by not retaining experts, or by instructing retained experts not to form opinions or prepare reports until just before trial. Finally, a few lawyers said that they made it a practice to conduct as little discovery as possible-on the theory that opponents often prepared their cases only as they were compelled to do so by the other party's discovery.

Taken together, comments by the lawyers and their quantifiable responses to questions indicate that while pursuit of no single tactical objective dominates the discovery process there are a great many tactical ends to which the instruments of discovery can be and often are committed.

\section{Some Clues About the Roles of Clients}

While the primary purpose of this project was to explore lawyers' views about and behavior in the discovery system, the interviews also produced some interesting information about roles played by clients. For example, a few attorneys described how clients pressured them to conduct more 
discovery (or to conduct it more formally) than the lawyers thought necessary. Two litigators also reported that clients who believed that opposing parties had abused the process reacted by trying to force their lawyers to use discovery as a weapon for retaliatory harassment. Most of the lawyers' complaints about their clients' behavior, however, focused on resistance to discovery initiated by opposing counsel. Complaints about such resistance were not confined to one type of client. Lawyers recounted problems with corporate officers, units of government, small businesses, and poor people. Attorneys also described many different reasons for this phenomenon: some clients could not understand (or accept) the breadth of permissible discovery, some were especially protective of certain kinds of information (e.g., what they considered purely personal matters, including sources and size of income or proprietary data and trade secrets), some entered the litigation process expecting chicanery by their own lawyers, ${ }^{107}$ and some simply did not want to spend the time and money to comply. A few lawyers reported dramatic forms of resistance by their clients, for example, bold lying during depositions or blunt offers to destroy or to manufacture key documents. Judging from attorneys' comments, however, such behavior does not appear to be common.

Nor does it appear from the quantifiable data that clients very often aggressively pressure their attorneys to resist disclosing properly sought information. While most of the lawyers ( 82 percent of the 177 respondents) said that at least once a client had "attempted to influence or pressure [them] not to produce information sought through discovery," most also indicated that they had felt such pressure from a client in less than one case in every five. As a group, the lawyers in the sample reported that clients were likely to have resisted disclosure in 10 (median) to 20 percent (mean) of their cases during the preceding five years. Lawyers who tended to handle small cases and whose clients usually were individuals experienced this problem even less often. The subgroup comprised of attorneys whose median size case was $\$ 25,000$ or less, for example, indicated that their clients were likely to have pressured them not to comply fully with discovery in only 7 (median) to 13 percent (mean) of their cases. Not surprisingly, clients in cases where there was more money at stake were more likely to exert such pressures on their lawyers. The litigators whose median size case was $\$ 1,000,000$ or more reported that this problem was likely to have arisen in 20 (median) to 32 percent (mean) of their cases. The substantial difference between the median and mean percentages for the large case lawyers reflects the fact that some lawyers in this subgroup claimed that clients exerted pressure on them to resist dis-

107. One attorney asserted that clients "take a dim view of discovery and want their attorneys to spring something on opponents." 
closure in a high percentage of their cases (10 of the 29 responding lawyers in this group reported a figure of 50 percent or more).

The data described above relate to attempts by clients to pressure their lawyers not to disclose sensitive information. The interviews also included two questions about how often such attempts were successful. When asked if a client ever had "succeeded in persuading [them] to take a position against disclosure of information when [they] initially were inclined to produce" it, 65 percent of the responding attorneys (85 of 130) said yes. Their responses to the follow-up question, however, suggest that even powerful clients in big cases were not likely to enjoy this kind of success often. The lawyers in the sample as a whole reported that over the preceding five-year period clients were likely to have persuaded them to resist disclosing information they considered discoverable in only 7 (median) to 9 percent (mean) of their cases. While large corporate clients in substantial litigation succeeded in such efforts in a higher percentage of cases than individual clients in smaller lawsuits did, even the highest reported success rates were modest; for example, the lawyers who spent 50 percent or more of their time representing large corporations reported, as a group, that their clients had prevailed upon them to resist disclosure in only 8 (median) to 16 percent (mean) of their cases. ${ }^{108}$

During pretest interviews lawyers suggested an additional question about how clients react to discovery. Promped by this suggestion, the interviewers asked: "Has desire to avoid being exposed to expanded discovery probes ever led a client of yours to decide not to raise some issue during litigation or not to assert some claim or defense?" Seventy-five percent of the responding lawyers (121 of 162) said yes. Because the attorneys were not pressed for explanations, the relative importance of various possible motivations for such decisions is unclear. Comments volunteered by some lawyers, however, suggest that two common grounds are (1) the desire to preserve the confidentiality of sensitive information and (2) concern about the expense of responding to additional discovery. A few litigators also reported that fear of antitrust counterclaims discouraged their clients from pursuing patent infringement actions.

However motivated, fear of expanded discovery probes seems to induce clients not to raise issues or assert defenses in a relatively small percentage of cases. The lawyers in the sample estimated that clients were likely to have made such decisions in only 10 (median) to 15 percent

108. Some of these successes apparently consisted of a client "educating" a lawyer who was unfamiliar with an industry so that he could perceive the proprietary value and trade secret status of certain information.

There is reason to suspect that the percentages reported in this paragraph understate how often clients persuade their lawyers to resist disclosure. Some attorneys intimated that admitting that their clients could pressure them into taking questionable positions would reflect badly on their professional ethics and on their capacity to control the professional dimensions of the attorney-client relationship. 
(mean) of their cases. The figures were modestly higher for the groups of attorneys who primarily handled large cases on behalf of corporate clients. For the subgroup of litigators who represented large corporations 50 percent or more of the time, for example, the median was 15 percent and the mean was 22 percent. The patent and copyright lawyers reported the greatest frequency of client decisions to forgo claims or defenses because of concern about discovery, but even for this subgroup the median ( 20 percent) and the mean ( 22 percent) indicate that clients made such decisions in only about one case in five.

Viewed as a whole, the quantifiable data and the lawyers' comments create the impression that of the three major participants in discovery (lawyers, judges, and clients), clients, while by no means always a benign influence, are, nonetheless, the source of the fewest problems.

\section{Lawyers' Attitudes Toward Possible Changes in the ROLES OF COURTS AND THE SCOPE OF Discovery}

"Unless judges take a strong stand no one will quit playing games because you know you can get away with it."

-a Chicago litigator

Are Chicago litigators satisfied with the help they receive from the courts during the discovery stage of litigation? Would attorneys favor greater judicial activism in the pretrial period? How would the litigation bar react to more frequent imposition of sanctions for discovery abuse? Should the scope of permissible discovery or of the attorney-client privilege be changed? The lawyers' responses to these questions produced some of the most dramatic results of this project.

As the lawyers' observations about the discovery system's principal problems made abundantly clear, ${ }^{109}$ there is a great deal of discontent within the litigating bar about the roles the courts play during the discovery stage of litigation. As the data discussed in the following paragraphs suggest, however, that discontent is by no means evenly distributed throughout the litigation community. Nor is there a consensus about whether it would be desirable to have the judiciary more thoroughly involved in discovery matters; instead, attitudes vary with types of practices. There is little disagreement, however, about what the courts should do with their power to sanction for discovery abuse. Moreover, the attorneys in at least one major segment of the litigating bar call in clear, loud, and remarkably united voices for more help from the courts in controlling what to many big case lawyers seems to be a runaway system.

To the question, Do lawyers "feel that [they] get adequate and efficient help from the courts in resolving discovery disputes and problems?" 
the questionnaire offered three possible answers: "yes," "no," and "sometimes." Since attorneys with a penchant for logical exactitude who had received "adequate and efficient help" from the courts with discovery problems rarely (or only once) might have been tempted to choose "sometimes" as the proper response to this question, the interviewers encouraged the lawyers to select that answer only if they could not say whether more often than not they were either satisfied or dissatisfied with the assistance the courts provided. Of the 167 lawyers who responded to this question, 27 (16 percent) apparently felt that their experiences with the courts in discovery matters had been neither predominantly positive nor predominantly negative and, therefore, selected "sometimes" as their answer. Of the remaining attorneys, 97 (69 percent) said they did not receive "adequate and efficient help from the courts in resolving discovery disputes and problems."

The percentage of lawyers who were dissatisfied with the quality of judicial assistance during discovery varied considerably between groups of differently situated litigators. While about half of the lawyers whose cases were predominantly smaller and filed in state court were unhappy with the courts' contributions to resolving discovery disputes, ${ }^{110}$ almost 90 percent of the lawyers who primarily handled larger cases said that the judiciary's assistance with discovery problems was inadequate. Figure 24 shows the percentage of lawyers in each of eight subgroups who were displeased with the quality of the courts' service in discovery matters.

Since most of the attorneys in the sample are dissatisifed with the help they get from the bench, would they like to see "greater judicial involvement in the discovery stage of litigation?" "111 of the 176 attorneys who answered this question, 102 (59 percent) said yes; 61 (35 percent) said no. The others equivocated or could not decide. Interestingly, one reason a few lawyers cited for opposing greater judicial involvement was their belief that the judges currently on the bench are, for the most part, incompetent. These lawyers declared that they would favor an expanded role for the courts only if the quality of judges improved substantially-a development they would welcome but did not anticipate.

110. As fig. 24 shows, there is one subgroup of predominantly smaller case attorneys to which this generalization does not apply. Seventy-one percent of the lawyers who received 50 percent or more of their work from individuals said they did not receive adequate help during discovery from the courts. It is not clear why the attorneys in this subgroup were more unhappy with the courts than were the attorneys in the other subgroups of predominantly smaller case lawyers. The known characteristics of the lawyers in this subgroup do not seem to differ substantially enough from the characteristics of the attorneys in the other three subgroups to account for this measurably higher level of disaffection.

111. If the lawyers appeared not to understand this question the interviewers offered an example of one of the forms such involvement might take: "a judicially conducted discovery conference early in the litigation." The Supreme Court's recent amendments to the Federal Rules of Civil Procedure provide, in paragraph (f) of Rule 26, for a "discovery conference" for which parties may move "any time after commencement of an action." The amendments that included this provision took effect on Aug. 1, 1980. 


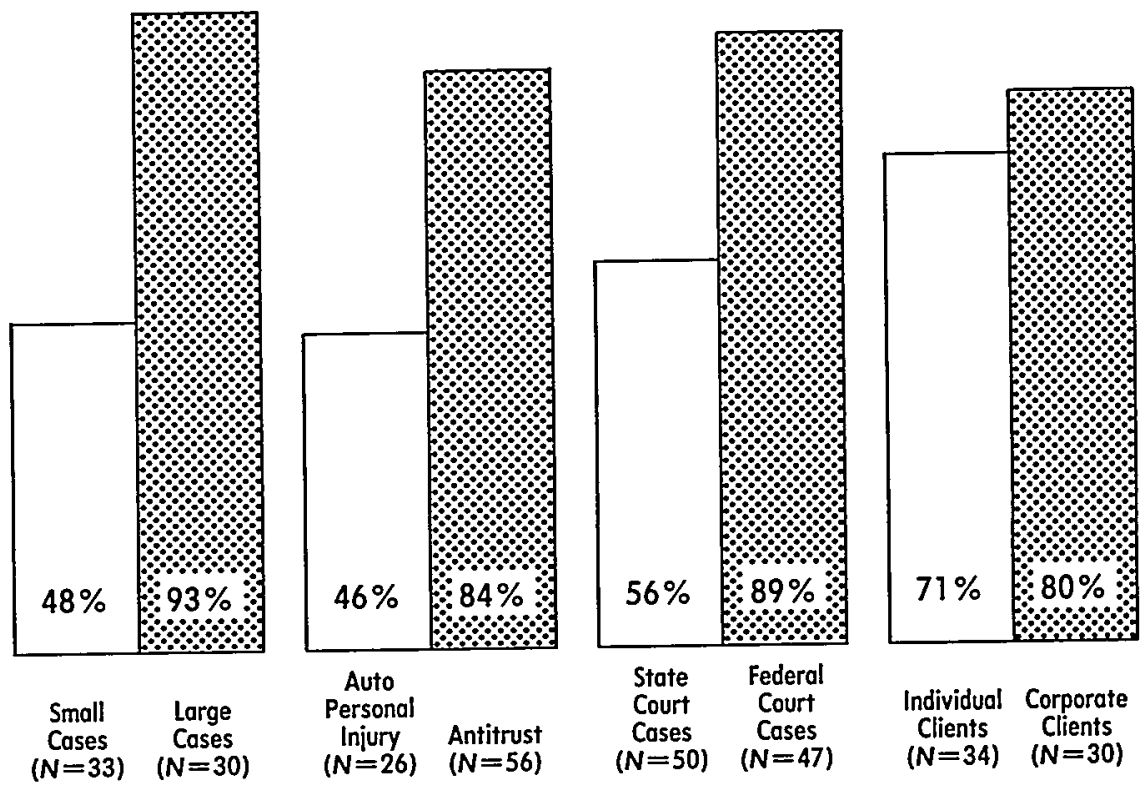

Fig. 24. Percentages of attorneys who said they did not receive adequate help from courts in resolving discovery problems by subgroup set. (Data on a few attorneys in each subgroup who said they "sometimes" received adequate help from the courts are excluded from the percentages in this figure.)

Again there were substantial differences of opinion between differently situated lawyers. Approximately 80 percent of the attorneys whose typical cases were large and complex favored a more active role in discovery for the judiciary. In the subgroups of attorneys whose cases tended to be smaller and more straightforward, however, the percentages of attorneys who wanted more judicial involvement were substantially lower, ranging from a high of approximately 50 percent to a low of 30 percent. Figure 25 presents these percentages for four sets of subgroups.

Compared to the sample as a whole, the 61 attorneys who opposed greater judicial involvement in discovery tended to have smaller cases, to work in smaller law firms, and to commit substantially higher percentages of their time to matters filed in state court. While the median size case for the entire sample was $\$ 150,000$, it was just $\$ 100,000$ for the attorneys who did not want the courts to be more active during the discovery stage. Similarly, the median size law firm for the whole sample was 20 attorneys, whereas for the 61 opponents of more pretrial judicial activism it was only 8. The most striking difference between the sample as a whole and the opponents of greater judicial involvement in discovery, however, was in the percentage of their time the lawyer spent in state court: the median for the entire sample was 50 percent, but for the lawyers who opposed expanding the courts' role it was an overwhelming 90 percent. 


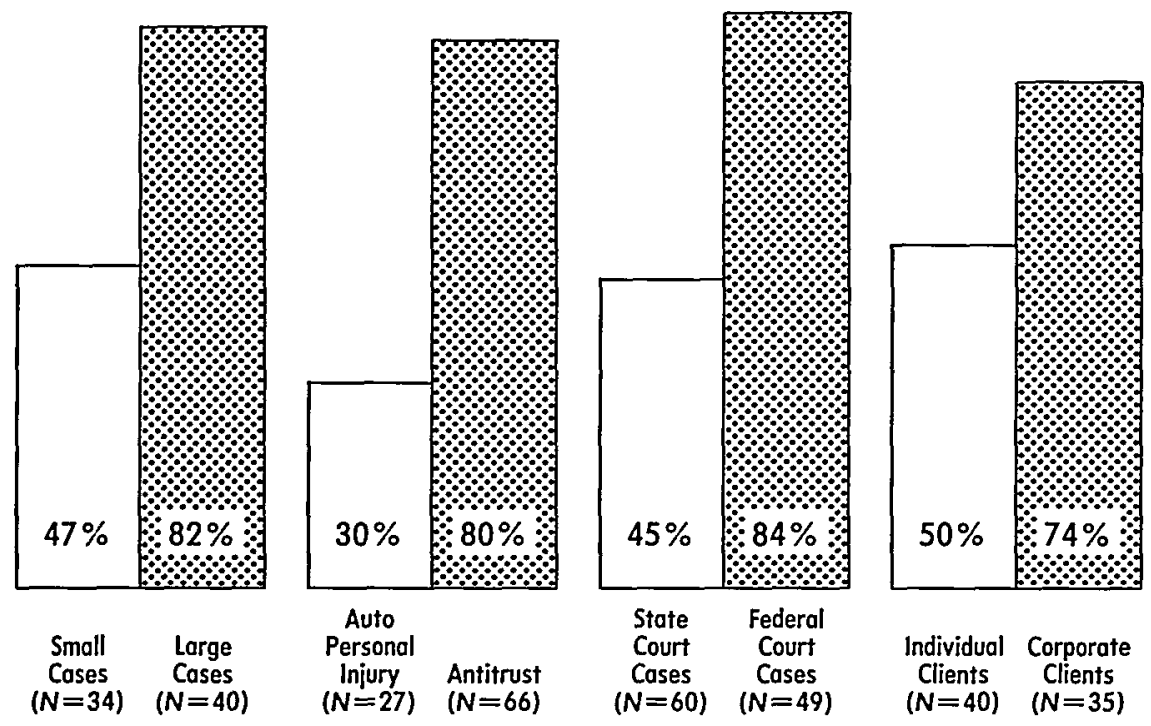

Fig. 25. Percentages of attorneys who favored greater judicial involvement in discovery by subgroup set.

These comparisons, as well as those presented in figure 25 , indicate that it is primarily smaller case litigators who practice in state court who oppose greater judicial involvement in the discovery stage of litigation, although even among them 30-50 percent would welcome a more active judiciary. Apparently a sizable number of smaller case lawyers believe they can handle by themselves most of the problems that arise in their generally less intense, less intricate, and less voluminous discovery. Not so for the large case litigators, of whom some 80 percent want the courts to play a more assertive role in controlling the discovery process. The vast majority of big case lawyers believe that the bar simply cannot exercise effective control over discovery in large lawsuits and that only aggressive judicial intervention can curb the excesses that, according to some, create a risk that the system will collapse under its own rapidly increasing economic weight.

When asked if they would "favor or oppose more frequent use of sanctions for discovery abuse" 90 percent ${ }^{112}$ of the lawyers whose median size case was $\$ 1,000,000$ or more favored more frequent use of sanctions. As figure 26 shows, the percentage of favorable responses to this proposal was almost as high in the other subgroups of attorneys who tended to handle larger and more complex matters. Moreover, such positive reactions to the possibility of more vigorous enforcement of the discovery rules were not confined to the big case lawyers. Just under 80 percent of

112. Thirty-six of $\mathbf{4 0}$ who responded favored more frequent use of sanctions. 


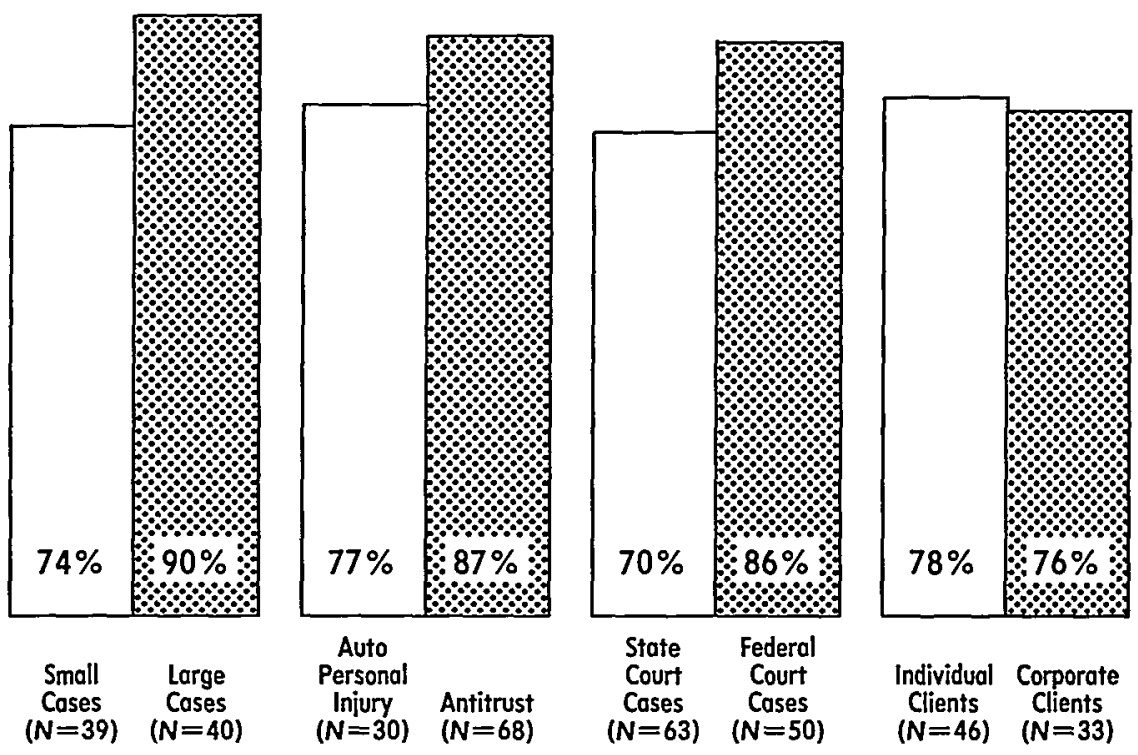

Fig. 26. Percentages of attorneys who favor more frequent use of sanctions by subgroup set

all the lawyers asked (136 of 174) said they would welcome more aggressive use of the sanctioning power. The sharp division of feelings among predominantly smaller case attorneys about a general expansion of judicial involvement in discovery was replaced by a clear vote of approval for "more frequent use of sanctions for discovery abuse." Approximately three of every four lawyers whose typical cases were small and filed in state court said they would like to see the courts impose sanctions more often. Figure 26 shows the percentages of attorneys in eight subgroups who shared this view.

The 31 lawyers who opposed more frequent imposition of sanctions tended to be involved in modest sized cases (their median size case was $\$ 175,000$, compared to $\$ 150,000$ for the sample as a whole), to practice in small law firms (the median size firm in which these attorneys worked was 7 , while for the entire sample it was 20), and to spend most of their time on matters filed in state court (the median percent of time consumed by state court matters for the $\mathbf{3 1}$ opponents of increased use of the sanctioning power was 85 percent, while for all lawyers it was 50 percent).

Several of the attorneys who opposed more frequent use of sanctions volunteered reasons for their positions. Some thought that the process for imposing sanctions too often is arbitrary and unpredictable, sometimes imposing penalties where none are deserved and, on a regular basis, punishing only the unlucky few who are caught committing practices in which large numbers of attorneys routinely engage. Increasing the frequency of sanctions would extend the reach of a process these lawyers do 
not respect. Some litigators also contended that it would be unfair to invigorate enforcement of the discovery rules because for a long time some forms of abuse have been widespread and tolerated, by court and counsel alike, under the "unwritten rules" of the system. Finally, a few lawyers said they objected because they perceived sanctions as ineffectual devices for curbing abuse; these lawyers simply did not believe that more vigorous enforcement would substantially deter violators of the rules. The vast majority of their fellow litigators, however, were not prepared to give up without a fight; most lawyers want the courts to get tougher with abusers of the system.

The substantive portions of the interviews ended with two questions that probed how the lawyers would feel about changing the scope of civil discovery or of the attorney-client privilege. Most lawyers said they did not want the scope of either discovery or the attorney-client privilege changed. There was, however, a greater division of feeling among the lawyers about the desirability of changing the scope of permissible discovery than there was about rearranging the reach of the privilege.

The first of the two questions was phrased: "Would you favor the scope of civil discovery being (1) left as it is, (2) narrowed [or] (3) broadened?" In the sample as a whole, 60 percent of the lawyers (104 of 172) chose "left as it is." 113 Thirty percent (51 lawyers) declared that the scope of discovery should be narrowed, while only 10 percent (17 lawyers) thought it should be broadened. Figure 27 presents these results graphically. Comparing subgroups reveals that there was more support for narrowing the scope of discovery among attorneys whose cases tended to be larger and more complex than there was among smaller case litigators, but that a majority of the lawyers in every group wanted no change. Figure 27 illustrates the differences in the views of smaller and larger case lawyers by comparing the responses of the attorneys whose principal types of cases included antitrust matters to those of the lawyers whose work included tort actions arising out of automobile accidents.

Not surprisingly, there was more sentiment for narrowing the scope of discovery among predominantly defense lawyers and among attorneys whose typical clients were large corporations than there was among plaintiffs' attorneys and lawyers who primarily represented individuals. ${ }^{114}$ In all of these subgroups, however, more votes were cast to leave the scope of discovery as it is than for any other option.

113. Four lawyers refused to select one of the three options, instead offering observations that could not be categorized. These responses were excluded in calculating the percentages reported in the text.

114. Thirty-eight percent of the defendants' attorneys and 42 percent of the attorneys who primarily represented large corporations favored narrowing the scope of discovery, while among the plaintiffs' lawyers and the attorneys who primarily represented individuals the figures were 23 and 22 percent, respectively. 


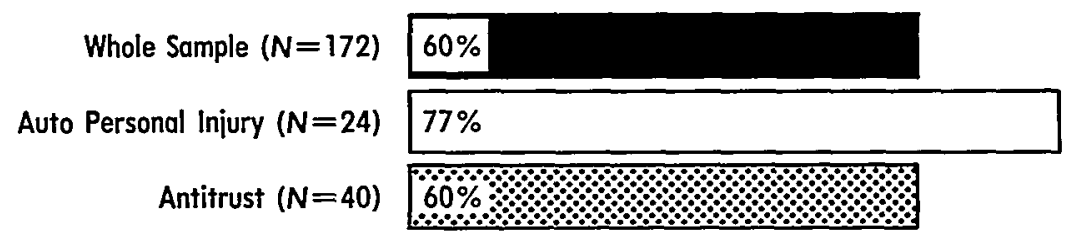

A. Leave Scope as It is

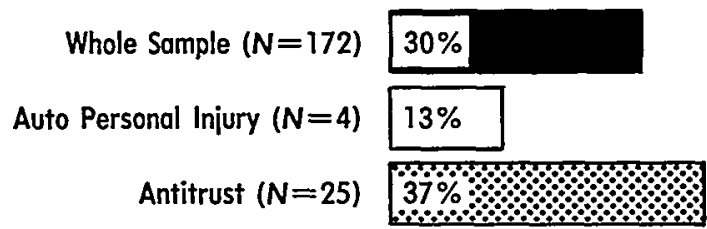

B. Narrow It

$$
\begin{array}{rr}
\text { Whole Sample }(N=172) & 10 \% \\
\text { Auto Personal Injury }(N=3) & 10 \% \\
\text { Antitrust }(N=2) & 3 \% \\
\text { C. Broaden It }
\end{array}
$$

Fig 27. Attorneys' opinions of the proper scope of discovery: whole sample $(N=172)$, attorneys handling auto personal injury cases $(N=31)$, and attorneys handling antitrust cases $(N=67)$.

One other feature of the responses to the questions about the scope of discovery warrants comment. The subgroup in which the highest percentage of lawyers favored narrowing the scope of discovery was composed of the attorneys who had been in practice for 25 years or more. Among these lawyers the division of opinion about the proper scope of discovery was quite close: while 51 percent favored leaving it as it is, 46 percent favored narrowing it. It may not be a good sign that the question was this close among the attorneys who had had the most experience with the system.

The question about the proper scope of the attorney-client privilege, by contrast, produced no close votes. Among all the subgroups, the lowest percentage of attorneys who favored leaving the scope of this privilege where it is was 70 percent, and in that subgroup (the lawyers with 25 years or more experience) another 24 percent favored broadening the privilege. In the sample as a whole, 75 percent of the lawyers (126 of 
$167)^{115}$ wanted no change in the scope of the privilege, 16 percent (26 attorneys) wanted it broadened, and only 9 percent (15 lawyers) voted to narrow it. Figure 28 describes these results. The only subgroup in which

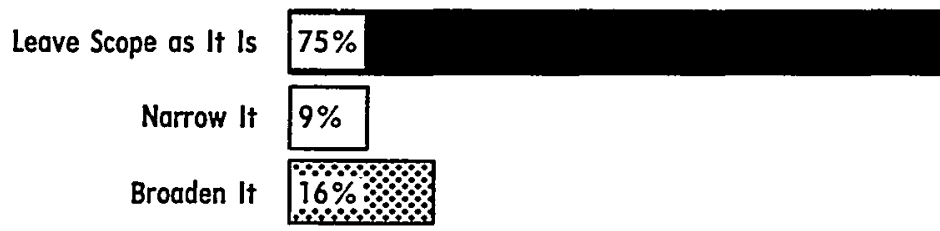

Fig 28. Attorneys' opinions of the proper scope of the attorney-client privilege $(N=167)$

the responses differed to a significant degree from those of the sample as a whole was composed of the lawyers whose principal types of cases included tort actions arising out of automobile accidents. That difference, however, consisted only of a more resounding endorsement of the current status of the privilege: 90 percent of these predominantly smaller case lawyers said the scope of the attorney-client privilege should be "left as it is."

Thus while most of the lawyers in the sample want the level of judicial involvement in and control over discovery to increase, most do not want changes in the two major doctrines that fix the theoretical boundaries of discovery.

\section{Conclusion}

"Pointing at judges alone won't solve the problems; we need to look at the system as a whole."

\section{-a Chicago litigator}

The data discussed in the preceding sections describe two very different systems of discovery. These two systems are not set apart from one another by differences in formal rules. Rather, the two systems are distinguished by the size and complexity of the cases to which the rules are applied. Since large, complicated cases tend to be litigated in federal courts and to involve corporate clients, and since smaller, simpler cases tend to be litigated in state courts and to involve individuals as clients, the graphs presented in the preceding pages create the impression that the two systems also are distinguishable by the types of clients being served and the jurisdiction in which a suit is pending. We strongly suspect, however, that the primary determinants of the character of the discovery process and the problems infecting it are the size and complexity of cases and that 
the impressions created by the data about the roles of client type and jurisdiction are attributable primarily to the fact that the four factors tend to cluster. Thus while size and complexity of case tend to vary with client type and court system (federal or state), we do not believe that the latter two factors are important, independent sources or causes of distinguishing characteristics of discovery systems. ${ }^{116}$

Since the two systems of discovery the data describe are so different, the principal characteristics of each should be reviewed separately.

If the experiences and attitudes of attorneys in the sample are any indication, discovery in large case litigation is in serious trouble. While almost half of the big case attorneys expressed unequivocally critical, aggressively negative assessments of the overall effectiveness of the discovery system, only about one in ten such lawyers offered essentially unqualified endorsements of it. During the interviews a great many big case lawyers vented intense feelings of anger and frustration toward the discovery process. Even lawyers who admitted that conducting and complying with discovery was making them wealthy complained that the system was grossly inefficient, often failed to achieve its primary purposes, and was unfairly expensive to clients.

The picture painted by the large case lawyers' responses to specific questions shows a system characterized by high costs, vulnerability to abuse, and failure to distribute relevant information evenly among the parties. In half of the large cases that are settled at least one side believes it has an informational advantage because its opponent has failed to discover from it some arguably significant evidence. At least one side believes it has a similar advantage in about one in every three big cases that is tried to completion. Nor are such failures in the distribution of information primarily attributable to the intervention of privilege. Most of the evidence that remains undisclosed is discoverable under the rules; it is not uncovered because its holder is skilled in the art of evasion, its seeker is not sufficiently tenacious or perceptive, or the cost of pursuing it is prohibitive.

Several characteristics of how lawyers handle discovery in major litigation provoked repeated complaints. In response to open-end questions

116. This belief has several bases. One is the fact that several interviewed attorneys expressed this view. Another is the reportedly modest role clients play in determining what happens during the discovery stage of litigation. It also seems significant that the rules of discovery that apply in Illinois courts and those that apply in the federal District Court for the Northern District of Illinois contain no differences that would make discovery more onerous or difficult in the federal system. Finally, we subjected some of the data to a modest cross-tabulation analysis that focused on the relative importance of two factors: (1) the size of cases (dollar value) and (2) the court system in which suits were litigated. While the analysis we conducted cannot "prove" which of these two factors plays the larger causal role, its results suggest that size of case is a more reliable predictor of problems with discovery. The cross-tabulations show, for example, that big case lawyers who worked primarily on federal court matters did not consistently report more difficulty with discovery or more tactical use of discovery tools than did big case lawyers whose practices involved substantial work in state courts. 
that contained no suggestions or examples, more than 60 percent of the big case lawyers complained that overdiscovery and evasive practices constituted troublesome abuses of the system. More than 50 percent of these attorneys similarly volunteered complaints about various forms of harassment through discovery devices. Responses to another kind of question exposed even more graphically the pervasive and pernicious role played by evasion in big cases. Large case lawyers reported that an opposing counsel's evasive or incomplete responses to discovery requests impeded their discovery or completely blocked their access to discoverable information in four of every five cases. Big case litigators also reported that in one of every two cases their discovery efforts were impeded by their adversaries' dilatoriness.

Tactical maneuvering and use of discovery tools for tactical purposes also pervade the discovery stage of major litigation. Large case lawyers reported that one or more tactical considerations affected how they conducted or responded to discovery in virtually every case ( 99 percent) and that tactics affected how they timed discovery events in more than 80 percent of their lawsuits. And even though there are innumerable different kinds of tactical purposes that can motivate how attorneys act in the discovery arena, big case attorneys admitted that the desire to distract an opponent or to obscure the existence of information affected how they responded to discovery probes in almost one of every two cases and that the desire to impose work burdens or economic pressure on an adversary affected their use of discovery tools in almost one case in every three.

As a group, large case attorneys also are very angry about the impact on the discovery process they attribute to the courts. Many of these attorneys believe that most judges have hostile, impatient, and unrealistic attitudes toward discovery disputes. More than 85 percent of big case litigators feel they do not receive adequate help from the courts with discovery problems. Many believe that the judiciary's inhospitality to discovery disputes and its incompetence in handling them, coupled with the courts' underuse of sanctions for discovery abuse, are the principal causes of the serious problems that afflict the system in large lawsuits. Among this study's most dramatic results is the virtual unanimity among big case attorneys about how the judiciary should respond to the current state of discovery affairs: about 85 percent of these lawyers want the courts to impose sanctions more often for discovery abuse, and about 80 percent believe the courts should become more actively involved generally in the discovery stage of litigation.

The discovery system provokes fewer complaints by smaller case litigators and in some respects appears to function better in smaller, less complicated lawsuits. Among smaller case lawyers more than 30 percent are very happy with how the discovery system serves them, and only about 20 percent expressed clearly negative overall assessments of the system. The 
percentage of less complex cases that are settled with at least one party believing another has failed to discover something arguably consequential is only about 25 percent (as compared to about 50 percent for larger matters), and the percentage of smaller cases that are tried to judgment in that condition is only about 10 percent. Overdiscovery and harassment provoke complaints from substantially lower percentages of smaller case litigators than from their larger case counterparts. And while lawyers who primarily handle smaller suits report that evasive or incomplete responses impede their discovery in about 35 percent of their cases, that figure is less than half of the percentage reported by big case litigators. Attorneys conducting discovery in lawsuits where less money is involved and less information must be exchanged also appear to take actions based on tactical considerations less often than attorneys in high stakes litigation. The only major discovery-related problem that seems to be as large (or larger than) in smaller suits as in larger cases is delay: a higher percentage of predominantly smaller case lawyers (50-55 percent) volunteered complaints about delay than did big case litigators ( $30-40$ percent) and smaller case lawyers reported that dilatoriness by opponents impedes their discovery efforts in a slightly higher percentage of their cases than that reported by large case attorneys (for both groups the median is close to 50 percent). As argued in an earlier article, ${ }^{117}$ the magnitude of delayrelated problems reported in smaller cases seems to be attributable in large measure to the almost five-year backlog in the civil trial docket of the law division of the state courts sitting in Cook County.

Apparently because they feel more in control of the discovery process as it operates in their litigation, a majority (albeit slight) of smaller case lawyers believe the courts provide adequate help with discovery problems and oppose a general expansion of the judiciary's role in the discovery stage. Even among small case litigators, however, concern about the level of discovery abuse remains high: more than 70 percent want the court to impose sanctions more often.

Several factors help account for these major differences between discovery in small cases and in large lawsuits. In big cases much more information must be processed and exchanged. Moreover, what kinds of data an opponent will produce and retain, how he will organize it, and why he will be sensitive about its disclosure are much less predictable in major litigation than, for example, in routine tort matters. Furthermore, as an attorney's theory of liability or damages becomes more sophisticated or complex, she may need to secure more evidence or to pursue unusual kinds of information-thus both complicating her task and increasing the likelihood that an opposing party will resist disclosure (out of misunder-

117. See Brazil, supra note 3, at 226-29. 
standing or well-placed sensitivities). And as the volume of information to be processed and the subtlety of the legal theories to be developed increase so does the room for uncertainty, confusion, and error.

In big cases, by definition, the stakes are high. High stakes generate strong incentives (and, usually, ample resources) both to use discovery to gain advantages (informational or other kinds) and to obstruct or complicate an opponent's access to potentially damaging evidence These temptations (some would call them responsibilities) are strongest, and the resources to convert them into action are most ample, in the kinds of lawsuits that, because they involve more information, more complexity, and more uncertainty, also present attorneys with the most opportunities for tactical jockeying and other efforts to exploit opponents' weaknesses.

Thus in big cases attorneys not only need and rely on discovery more than in little cases but also are more likely to be subjected to manipulations of the process. The large case lawyer is more dependent on discovery to develop his case and, therefore, must enter litigation with greater expectations and demands of the discovery system. That greater dependence is accompanied by greater vulnerability to abuse. The product of this dynamic between dependence and vulnerability often is intense frustration. And the target on which many big case litigators vent that frustration is the judiciary. Unfortunately, the ability of the courts, as presently funded and staffed, to provide fair and firm guidelines for the conduct of discovery and to resolve discovery disputes promptly and intelligently appears to decrease directly as the need increases. The more involved the case is, and the more incentives and opportunities it creates for abuse, the less the courts are able to monitor effectively the discovery process. Thus the current discovery rules, coupled with current limitations on the judiciary's capacity to understand and to guide the pretrial development of major lawsuits, result in a system that is inefficient, ineffective, and appears to be virtually out of control. In short, the discovery system as it operates in big cases needs a major overhaul.

It is not at all clear that the kinds of changes that would benefit large case discovery would be appropriate for smaller litigation. The great differences between the characteristics of discovery in smaller cases and in large lawsuits strongly suggest that it would be wise to tailor different sets of discovery rules and procedures for the unique demands and problems of each of the two very different kinds of civil litigation. Since many of the problems that beset discovery in smaller cases are related to trial docket backlogs and dilatory practices, and since there generally is less evidence to be discovered in less complex matters, it might well be appropriate to establish a separate, streamlined discovery track for this kind of litigation, a track featuring early trial dates, limitations on how much discovery (e.g., how many depositions and interrogatories) parties could 
conduct without judicial permission, and firm deadlines to expedite exchanges of information. ${ }^{118}$ Such a tracking system also might be designed to free some judicial resources for the larger cases, where more active involvement by the courts seems necessary.

While the data generated by this project do not spell out the refinements of new discovery rules and procedures, they do indicate that there is a pressing need for a major effort to reform the process through which parties exchange information before trial.

118. Experiments with such "tracks" for smaller cases are being sponsored by the Colorado Supreme Court and by the American Bar Association's Action Commission to Reduce Court Costs and Delay. 


\section{APPENDIX A}

QUESTIONNAIRE

COVER SHEET AND INTRODUCTION

RESPONDENT INFO.

NAME: INTERVIEW NO.

FIRM HAME: SIZE

ADDRESS :

PHONE:

DATE OF INTERVIEW: TIME OF INTERVIEW:

LOCATION OF INTERVIEW:

(only if different from above address)

[Reep your introductory remarks as brief as possible]

I. Introduce Self

II. Describe the PURPOSES of the Study:
1) To gather information about How eivil discovery is WORKING
and
2) To COMPARE uses of DISCOVERY by lawyers in DIFFERENT KINDS OF CIVIL PRACTICE

We are Interested only in your civil Iitigation experience please do not Include your experience in criminal iftigation in your answers.

III. Explain the TOPICAL PROGRESSION the interview will follow:

A. A few questions about your professional experience.

B. Questions about hos well the tools of discovery have sarfisfed your needs.

c. Questions about how successfully opposing counsel have used discovery to gather information from you and your clients.

D. A few questions about how you would view different possible changes in the discovery system.

IV. We would prefer that you not identify cases a clients by name and we have structured our questions so that no such Identifications are necessary.

Your responses will be kept STRICTLY CONFIDENTIAL.

v. If you DOA'T UNDERSTAID any parts of any questions please Interrupt me and ask te to explain what I mean.

VI. DURIMG the interview we will pose some QUESTTONS that ASK you to ESTIMATE the PERCEITAGE of your civil cases in which different things occur.

Precise answers to these questions are 1mpossible. Please just try to provide us with rough, ball park figures. 
I. PRELIMINARY PROFESSIONAL BACKGROUND QS. (I)

A. During the past five years, about what $z$ of your professfonal time has been committed to civil Iitfgation? (Please do not include any work you have done in criminal matters).

B. In your practice in civil litigation during the past five years, what are the princfpal kinds of cases you have handled?

1. Have you specialized in any particular kinds of cases?

c. During the past five years approx. what $\bar{z}$ of your time in civil litigation has been consumed by matcers filed in federal court?

$z$ and what $z$ has been consumed by matters filed in

state court? z.

D. Approximately how many clvil cases have you tried over the course of your career? (Include both bench and fury trials, but do not include summary proceedings, e.g. motions for sumbary judgment or for temporary restraining orders, unless they have been pxeceded by (number) substantial discovery)

E. During the past five years, what $z$ of your time in civil litigation have you committed to plaintiff's matters?

\% and what \% to defendant's matters? \%

[Preface to $F$ : Some attorneys find the next question difficult to answer because of the wide range of cases they handle. An answer that represents a very rough approximation is all that we need.]

F. During the past five years, approx. what is the median or typlcal stze (measured by amount of judgment or settlement or amount realistically in dispute) of the cases on which you have worked?

$\$$ 
PRELIMINARY BACKGROUND QS (2)

c. Focusing on your work in clvil litigation over the past two years, has any one type of cllent or institution been the Bource of more than $10 z$ of your litfgation work during that period?

No [Skip to Section III]

YES [Hand respondent the list of types of clients and ask Q. $1 \&$ Q. 2]

\section{Principal Types of Clients - Civil Litigation}

1. Individuals (non-professionals)

2. Professionals (doctors, lawyers, architects, engineers, etc.)

3. Governmental bodies or Agencies (local, state or federal)

4. Community or Non-Governmental Political organizations

5. Hospitals, CIInics, Schools, Training Institutions (publicly or privately owned).

6. Religlous, Cultural or Charitable Institutions or Organizations (e.g. museums, churches)

7. Untons

8. Smaller, Privately-Owned Businesses or Corporations

9. Larger Manufacturing or Retaling Corporations

10. Transportation or Utility Corporations

11. Banks

12. Insurance Companies

13. Other Commercial Services Corporations (e.g. maintenance, business consulting)

14. Diversiffed or Conglomerate Corporations

1. Would you please Identify the client types.

2. What $z$ of your work has each client type produced?

1. client type

2. $\%$ of work produced 
II. INTRODUCTORY GENERAL QUESTIONS

EXPLAIN: WE WILL BEGIN WITH A FEW GENERAL QUESTIONS ABOUT DISCOVERY, THESE FIRST FEW QUESTIONS HAVE BEEN PHRASED INTENTIONALLY IN AN OPEN-ENDED FORM IN ORDER TO GIVE YOJ THE WIDEST POSSIBLE LATTITUDE IN RESPONDING. THE REMAINDER OF OUR QUESTIONS WILL BE MORE PRECISELY FOCUSED.

A. What is your general impression about how well the current system of discovery is working?

B. Do you feel there are any problems with the current system?

c. What are the most troublesome kinds of discovery abuse, if any? 
III. SEQUENCE I (1)

FOCUS: HOW DISCOVERY HAS WORKED FOR YOU IN YOUR CIVIL LITIGATION.

Prellninary general 1nstruction about time frame for answers: when answering the remaining questions posed in this interview please consider only the past five years of your experience unless the question asks you explicitly to consider a different tire frame (for example, some questions ask if certain things have ever occurred in your practice).

A. I an going to read to you a list of different types of factors which, In any given case, could make your discovery more difficult or could account for your not discovering or not pursuing some Information.

With respect to each such type of factor would you please indicate:

1. Whether it ever has made your discovery more difficult or accounted for your not discovering or not pursuing some information.

and, 1f so:

2. In approximately what \% of your civil cases during the past five years the factor in question has made your discovery rore difficult or accounted for your not discovering or pursuing some information?

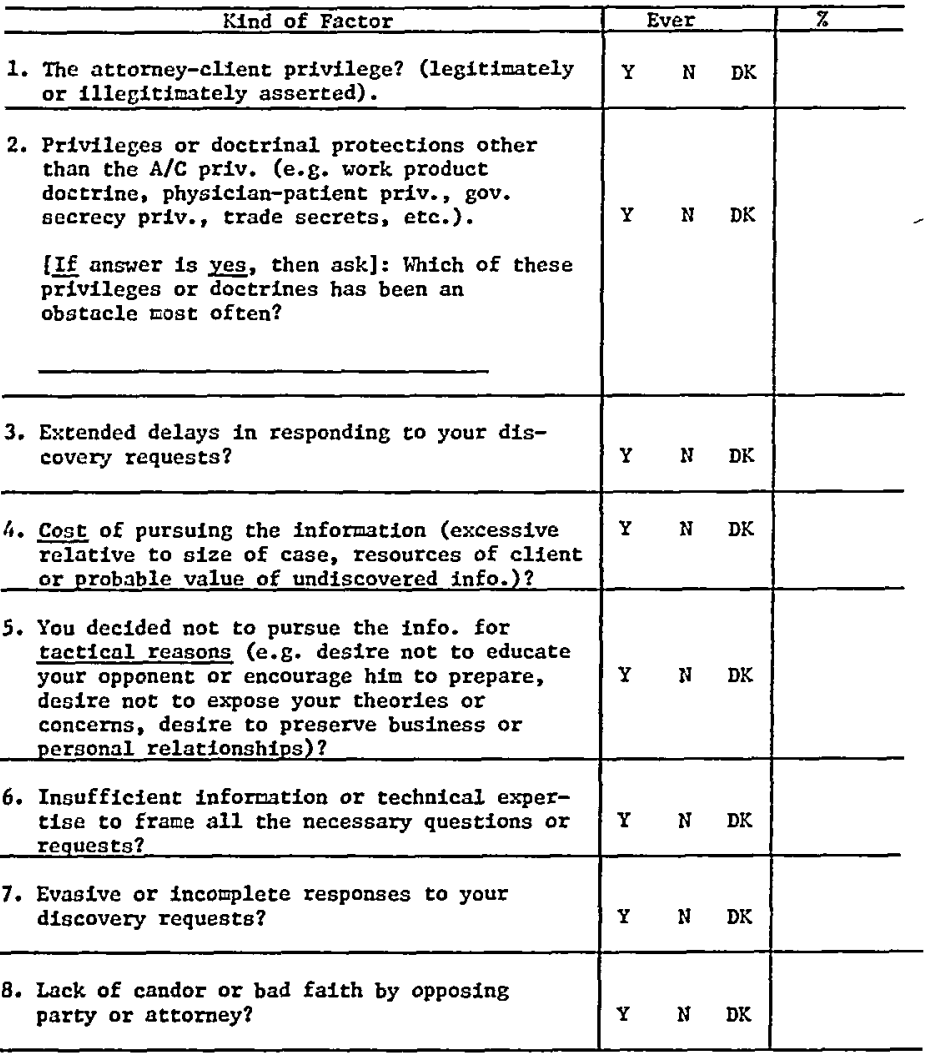


B. Has your prediction of the cost of discovery ever caused you to decide not to accept a civil case?

No [SkIp to C.]

Yes [Ask Q. 1]

1. During the past five years approxtmately how many cases have you declined in large measure because of how expenstve you predicted discovery would be?

(number of cases)

c. Have you ever suspected, when you settled a case, that another party had relevant information (including information legitimately protected by privilege or other rules) that you had not discovered?

No [Skip to D]

Yes [Ask Q. 1 and Q. 2]

1. During the past five years in approximately what $z$ of the civil cases you have settled have you had that feeiling?

\section{\%}

2. In those cases in which you suspected that another party had relevant Information that you had not discovered, what were the most comon reasons for your not having discovered the information?

D. Have you had more difficulty discovering information from certain kinds of party opponents than from others?

No [Skip to $E$ ]

Yes [Hand respondent the list of types of clients, then ask $Q$. I and record the types he identifies].

Principal Types of Clients - Civil Litigation

1. Individuals (non-professionals)

2. Professionals (doctors, lawyers, architects, engineers, etc.)

3. Governmental Bodies or Agencles (local, state or federal)

4. Communtry or Non-Governmental Political organizations

5. Hospitals, Clinics, Schools, Training Insticutions (publicly or privately owned)

6. Religious, Cultural or Charitable Institutions or Organizations (e.g. museums, churches)

7. Unions

8. Smaller, Privately-Owned Businesses or Corporations

9. Larger Manufacturing or Retailing Corporations

10. Transportation or Utility Corporations

11. Banks

12. Insurance Companies

13. Other Conmercial Services Corporations (e.g. maintenance, business consulting)

14. Diversified or Conglomerate Corporations

1. From what kinds of party opponents has discovery been most difficult? 
E. Have you had more difficulty making discovery from parties represented by certain kinds of law firms than from parties represented by other kinds of lay firms?

[Offer examples of categories of law firms only if respondent does not understand the question; e.g. by size of firm, nature of of the firm's work or princtpal types of clients the firm serves].

No [SkIP to F]

Yes [Ask Q. 1]

1. From what kinds of $1 \mathrm{kw}$ firms has discovery been most difficult for you?

F. Have there been any particular kinds of information that you have had more difficulty discovering than others?

[Offer the following examples only if respondent does not understand the question:

Information might be categorized by:

1. Issues to which it relates, e.g. damages, state of wind;

or

2. Sources from which it comes, e.g. expert consultants;

or

3. Subjects to which it relates, e.g. an opponent's financial condition or psychological history, or proprietary information like shares of markets, Ilsts of prospects or the profitability of certain products].

No [Skip to G]

Yes [Ask Q. 1]

1. What kInds of Information have been most difficult to discover?

G. Has it ever happened that something relatively slgnificant has come up at trial that had not been disclosed by another party or that you had not discovered during the discovery stage of the Iitigation?

\section{No [SkIp to H]}

Yes [Ask Q. 1]

1. During the past five years in approximately what $z$ of the civil cases you have tried has this occurred? 
SEQUENCE I (4)

TRANSITION: CURRENT CASES. At this point we would like to pose a few questions about cases on which you are currentiy working. Please do not identify the casea or parties by name.

H. On approximately how many civil cases are you working actively at this time (include cases in which you share significant responsibility either as a supervising attorney or as an associate)?

(number of cases)

[If respondent has difficulty answering ask: Do you keep a list of current cases that would help refresh your recollection?]

1. Have you had difficulty discovering the information you need in any of these currently active cases?

No [Skip to I]

Yes [Ask Q. 2]

2. Would you estimate for me the $\%$ of your currently active cases in which you have had or are having difficulty discovering the information you need? $\%$

TRANSITION: THE STRATEGY AND TACTICS OF DISCOVERY

INTRODUCTION: The next several questions have two components:

(1) in the first we ask if a particular strategtc or tactical purpose has ever been a factor affecting your use of discovery tools; and

(2) In the second we ask what your impression is about how frequently, if at all, the particular purpose under discussion is a factor affecting the way other attorneys use discovery tools.

In giving us your impressions about other attorneys please draw upon all of your sources of information about how other lawyers conduct civil litigation; do not confine your answers to observations you have made in the cases in which you have been directly involved.

I. Has the purpose of gaining time or slowing down part or all of an action ever been a factor affecting your use of discovery tools? [Only offer examples if respondent does not understand the question;

e.g. serving document production requests or interrogatories in part because you want some time and you know it will take your opponent time to respond to your discoveryl.

No [Skip to r. 2]

Yes [Ask Q. 1 and Q. 2]

1. During the past five years in approximately what $\%$ of your cases has this purpose been a factor affecting your use of discovery tools?

\section{$\%$}

2. What is your impression about how often the purpose of gaining time or slowing part or all of an action is a factor affecting the way other attorneys use discovery tools?

Never Seldom Moderately Often Quite Frequently 
SEQUENCE I (5)

J. Has the purpose of 1mposing work burdens or economic pressure on another party or attorney ever been a factor affecting your use of discovery tools?

[Only provide an example if respondent does not understand the question; e.g. making discovery demands that will be expensive or time consuming to satisfy].

No [Sk1p to J. 2]

Yes [Ask Q. I and Q. 2]

1. During the past five years in approximately what $\%$ of your cases has this purpose been a factor affecting your use of discovery tools?

$\%$

2. What is your 1mpression about how often the purpose of Imposing work burdens or economic pressure on another party or attorney is a factor affecting the way other attorneys use discovery tools?

Never Seldom Moderately often Quite Frequently

In the next few questions we use the word "tactical" to describe some of the possible purposes of discovery. By "tactical" we mean every purpose other than simply to acquire information you need to prepare your case.

K. Has ony tactical purpose ever been a factor affecting how you have timed or scheduled discovery events?

Coffer an example only if respondent does not understand the question; e.8.trylng to make the opposing party's deposition the first taken in order to better prepare for your client's deposition or trying to make your expert's deposition the last taken in order to prepare better for $1 t]$. No [Sk1p to R. 2] Yes [Ask Q. I and Q. 2]

1. In approximately what $z$ of your cases during the past five years have any tactical purposes affected how you have timed or scheduled discovery events? \%

2. What is your impression about how often tactical purposes affect the way other attorneys time or schedule discovery events? 
SEQUENCE I

L. Other than the purposes of gaining tfme and Imposing work burdens on opponents, are there other tactical purposes which have affected how you have used the tools of discovery?

toffer an example only if respondent does not understand the question;

e.g. to pin down an opponent early in the case or to set up an opponent for sumary judgment].

No [Skfp to $\mathrm{M}$ ]

Yes [Ask Q. 1]

1. Would you give us one or two examples of such other tactical purposes?

M. Not focusing on any one particular tactical purpose, but considering all of the possible tactical uses of discovery tools, In roughly what $x$ of your civil cases during the past five years has your use of discovery tools been affected by at least one tactical purpose?

\section{$\%$}

N. Has desire to avoid being exposed to expanded discovery probes ever led a client of yours to decide not to ralse some Issue during Iitigation or not to assert some clafm or defense?

No [SkIp to 0]

Yes [Ask Q. 1]

1. During the past five years in approximately what $z$ of your civil cases has a client's desire to avoid being exposed to additional discovery led to this kind of decision? \%

0. Has desire to avold being exposed to discovery probes ever led a client of yours to decide not to initlate a lawsuit?

No [SkIp to Section IV]

Yes [Ask Q. 1]

1. Hould you estimate for us the number of times over the course of your career that a client of yours has decided not to file a lawsult because of its desire to avold leing the object of discovery?

(number) 


\section{SBQUEATE II (1)}

FOCDS: BON SUCCESSFOLLY OTHER ATTORAETS HAVE USED DISCOVERY TO ACQUIRE ITFORYATION FROY YOD AND HOW YOU HAVE RESPONDED TO DISCOVERY PROBES.

A. Has it ever happened that after you have setitled a case (as distinguished from trying it to completion) you or your client st1ll had arguably signiflcant information (including information protected by privilege) which, to the best of your knowledge, another party had not discovered?

No [Skip to B]

Yes [Ask question 1 and 2]

1. Durfing the past 5 years, in approximately what $\%$ of the cases you have settied has this occurred?

\%

[Ask next question only if less than $80 \%$ of respondent's time has been congured by one side.]

2. During the past 5 years has this been wore likely to occur in cases in which you represented a defendant or in cases in which you represented a plaintiff?

defendant

plaintiff

B. Has it ever happened that after you have tried a case to completion (as distingulshed from settling it before or during trial) you or your cllent still had arguably significant information (including Information protected by privilege) which, to the best of your knowledge, another party had not discovered?

\section{No [SkIp to $\mathrm{C}$ ]}

Yes [Ask question 1]

1. During the past 5 years, in approximately what $\%$ of all the cases you have tried to completion has this occurred?

\section{$\%$}

[Sk1p C and D if respondent answered "no" to both A and B.]

C. During the past 5 years in roughly what \% of the cases you have closed (by settlegent, fudgment or otherwise) and in which another party had not discovered some arguably significant information from you or your clifent was the reason for that fallure by the other party:

1. Opposing counsel's fallure to ask the right questions or for the right documents or to depose the right people?

\%

2. The operation of a privilege or the W/P doctrine?<smiles>[14CH3]</smiles> 
D. Are there certain kinds of information that other parties have more frequently failed to discover from you or your clients than other kinds of information?

[Offer the following examples only if respondent does not understand the question; Information might be organized by:]

1. Issues to which it relates, e.g. damages (e.g. subsequent injurfes or medical treatment).

$\frac{\text { or }}{2 .}$ Sources from which it derives, e.g. expert consultants;

or

Subjects to which it relates, e.g. your client's financial condition or psychological history; or proprletary information like shares of markets, lists of customers or prospects or analyses of the profitablility of certain products.

No [Skip to E]

Yes (Ask Question 1)

1. What kinds of information have other parties failed to discover?

E. Has a client ever attempted to influence or pressure you not to produce information sought through dicovery?

No [skip to F]

Yes [Ask questions I through 4]

1. During the past five years in approximately what $\%$ of your civil cases has this occurred?

$$
\text { \% }
$$

2. Have there been any particular kinds of cases in which your cllents have been more Ilkely than in others to want to resist disclosure.

No

Yes

(specify kinds of cases)

3. Have there been any particular kinds of information that your clients have been more likely not to want to disclose?

No

Yes

(specify kinds of Information)

4. Has a client ever succeeded in persuading you to take a position against disclosure of information when you initially were inclined to produce the information?

No [Skip to F]

Yes [Ask question 4a]

a. During the past five years in approximately what $z$ of your clvil cases has this occurred? 


\section{SEQUEACE II (3)}

7. Have you ever Inftlated settlesent negotlations in order to try to resolve a matter before another party discovered information that could be damaging to your client (damaging either in the lawsult that you attempted to settle or in some other action or context)?

No [Skfp to F. 3]

Yes [Ask questions 1 through 3]

1. During the past five years in approximately what $\%$ of the civil cases you have settled have you inftlated settlement discussions with this purpose at least partly in view?

$\%$

2. In approximately what $\%$ of the Instances in which you have Initlated settlement with this purpose at least partly in view have you succeeded in settling the matter before another party discovered sote information that was potentially damaging to your client (again, daraging either in the setcled suit or in some other context)?

\%

3. What is your impression about how often other attorneys initfate settlement negotiations for this purpose?

never _seldom - moderately often _quite often

G. Has the purpose of distracting another party's attention from or obscuring the existence of information ever affected the way you have shaped your responses to another party's discovery?

[Offer examples only if respondent does not understand the question; e.g. Incomplete responses to interrogatories, overproduction of documents, unnecessarily long lists of people with knowledge of certain matters, etc.].

No [Skip to G.2]

Yes [Ask questions 1 and 2]

1. During the past 5 years in approximately what \% of your cases has this purpose affected the way you have shaped your responses to another party's discovery?

$\%$

2. What is your impression about how of ten this purpose affects the way other attorneys shape their responses to discovery?

never _seldom _ Eoderately of ten _quite of ten

H. Has the way you have prepared a client or witness to be deposed ever resulted in other parties not learning something of arguable gignificance from your client or witness during his deposition?

No [Skip to Section v]

Yes [Ask question 1]

1. During the past 5 years, in roughly what \% of your cases has this occurred? 


\section{POSSIBLE CEANGES (1)}

[Transition:] THE NEXT FEW QUESTIONS IN OUR SURVEY ARE DESIGNED TO EXPLORE YOUR VIEWS ABOUT THE FUTURE OF DISCOVERY.

A. Are there any changes that you would recommend being made in efther the rules of discovery or the way the courts handle the discovery stage of litigation? If you would make different recoumendations for state courts and for federal court, please indicate which changes would apply to which courts.

FEDERAL:

STATE:

B. Would you favor or oppose greater judicial involvement in the discovery stage of litigation?

[Offer an example only if respondent does not understand the question; e.g. a judicially conducted discovery conference early in the litigation?]

Favor

Oppose

Don't know

Comments:

C. Would you favor or oppose more frequent use of sanctions for discovery abuse?

Favor

Don't know

Comments:

D. Do you feel that you get adequate and efficient help from the courts in resolving discovery disputes and problems?

Yes

No

Sometimes

Comments: 
POSSIBLE CHAHGES (2)

E. Would you favor the scope of clvil discovery betng:

Left as it Is

__ Narrowed ___ Broadened?

Coments:

F. Would you favor the scope of the attorney-cllent privilege being:

Left $a 8$ it is

Narrowed

Broadened?

Coments:

G. Do you have any comments or complaints about the current system of discovery that our other questions have not permitted you to express?

\section{CONCLUDTNG BACKGROUND INFORMATION}

A. In what year were you first admitted to a bar? In which jurisdiction?

(year) (Jurisdiction)

B. Beglnning with 1970 and working forward in time would you list the firms or employers for whom you have practiced, their location and their size? We also would appreclate it if you would categorize

the nature of your practlce for each employer in one of the following broad categorles:

1. General Civil Litigation

2. General Business or Corporate Practice

3. Insurance Defense (insureds and/or coverage)

4. Criminal Defense

5. Government Service

6. Clv1I RIghts or Poverty Law

7. Labor Law

\begin{tabular}{|c|c|c|c|c|}
\hline Dates & Firm/Employer & Location & Size & Nature of Practice \\
\hline \multicolumn{5}{|c|}{$1970-$} \\
\hline & & & & \\
\hline & & & & \\
\hline & & & & \\
\hline & & & & \\
\hline & & & & \\
\hline & & & & \\
\hline & & & & \\
\hline
\end{tabular}




\section{APPENDIX B}

How the Attorneys in the Sample Were Selected

The project director and his research associate selected the 33 lawyers who were interviewed during the pretest period through a different process than they used to select the lawyers who made up the main body of respondents. The process of selecting attorneys for the pretest group began with referrals by members of the American Bar Foundation staff, by scholars affiliated with the Foundation, and by the staff of the Chicago office of the Lawyers' Committee for Civil Rights Under Law. Interviewed attorneys identified other lawyers who were added to the pretest candidates.

Because the questionnaire was being amplified and refined during the pretest period, the project director was careful to assure that the attorneys in this first group represented a wide range of practice situations. Thus the pretest included interviews with, among others, small firm (and solo) personal injury lawyers, large firm securities or antitrust lawyers, civil rights attorneys, specialists in divorce and family law matters, litigators who worked primarily for defendants, a labor lawyer, and attorneys who practiced in medium-sized firms that handled a wide range of commercial litigation or suits arising out of construction projects.

In selecting lawyers for the main study the project director and his associate sought to obtain a group of respondents who were involved in the major types of civil litigation practices and that would be as evenly balanced as possible. ${ }^{11}$ To assure that balance the project staff (relying in part on criteria developed by John P. Heinz and Edward O. Laumann) subdivided the world of civil litigation into three major groups. ${ }^{120}$ Group I was "large business litigation" and included attorneys who primarily handled big cases in the following fields: antitrust, securities, unfair competition, large commercial contracts, and products liability (defense only, of large corporations sued in class actions). Group II was "medium-sized general litigation" and included lawyers whose practices revolved around modest-sized commercial litigation, insurance defense, plaintiffs' patent and copyright matters, substantial probate litigation, and plaintiffs' class actions. Group III was labeled "personal plight" and included lawyers who devoted major portions of their time to plaintiffs' personal injury matters, civil rights actions, landlord-tenant and other aspects of "poverty law," divorce actions, and tort litigation on behalf of governmental entities or public bodies like the Chicago Transit Authority.

To identify lawyers in the kinds of practices required, the project staff acquired membership lists for the Chicago Bar Association's Antitrust Law Committee and Tort Litigation Committee as well as for the ABA's Litigation Section and Insurance Section. The staff also acquired lists of the lawyers employed by the Legal Assistance Foundation of Chicago and of the attorneys who worked with the Chicago office of the Lawyers' Committee for Civil Rights Under Law and with the Illinois Division of the American Civil Liberties Union. Names of Chicago litigators also were acquired from the Martindale-Hubbell Law Directory, Sullivan's Law Directory for the State of Illinois, the 1978-79 Organization

119. Because this project was conceived as a "pilot," its staff did not try to make the sample "representative" of the litigation bar in Chicago.

120. See, e.g., their two articles The Legal Profession: Client Interest, Professional Roles, and Social Hierarchies, 76 Mich. L. Rev. 1111 (1978), and The Organization of Lawyers' Work: Size, Intensity, and Co-Practice of the Fields of Law, 1979 A.B.F. Res. J. 217. 
Manual of the Association of Trial Lawyers of America, and the 1978 Lawyer's Register by Specialties and Fields of Law, published by the Lawyer to Lawyer Consultation Panel, Inc.

Using all of the sources described above, the project director and his associate, neither of whom had ever worked in Chicago or previously met any of the interviewed lawyers, made a random selection of attorneys from all of those listed. A letter explaining the purposes of the project and requesting an interview was sent to each attorney. Thereafter either the project director or his associate telephoned the attorneys to try to arrange convenient times to conduct the interviews. Only two or three of the selected lawyers refused to be interviewed; a few others could not be reached because they were on vacation or ill. Tables in appendix $\mathrm{C}$ describe the group of respondents this selection process produced.

\section{APPENDIX C}

\section{Profile of the Sample as a Whole}

In tables $\mathrm{Cl}$ to $\mathrm{C} 4$ the second column "Freq." lists the number of attorneys who made the response listed in the first column. For example, the first entry in the "Freq." column in table $\mathrm{Cl}$ indicates that 19 lawyers said they practiced in one-attorney law firms (i.e., by themselves).

TABLE C1

Size of Respondent's Law Firm

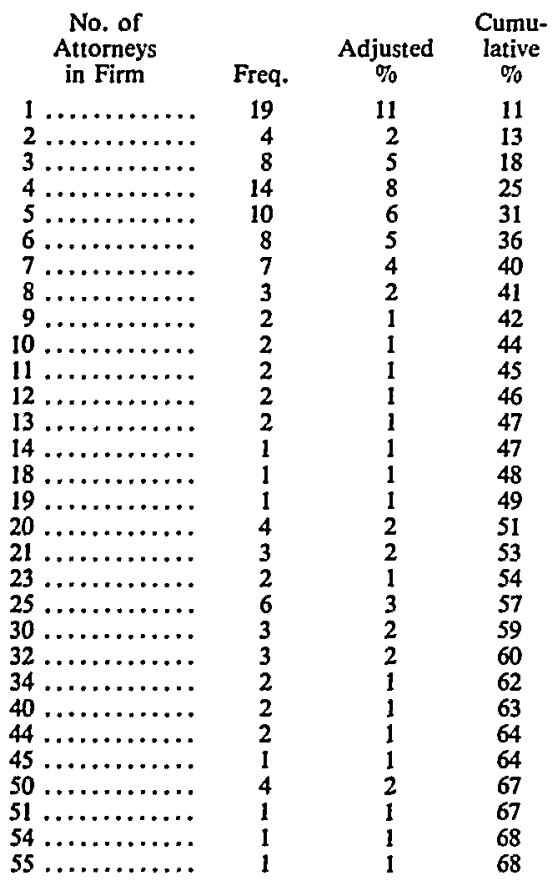

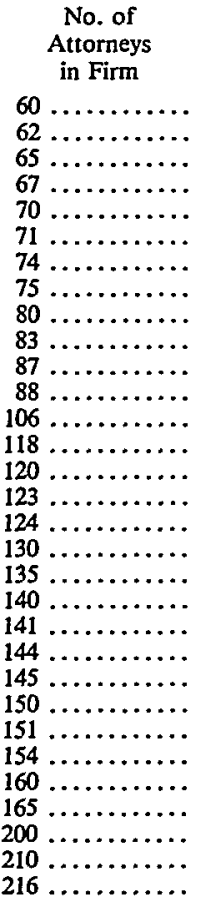

$\begin{array}{ccc}\text { Freq. } & \begin{array}{c}\text { Adjusted } \\ \%\end{array} & \begin{array}{c}\text { Cumu- } \\ \text { lative } \\ \%\end{array} \\ 1 & 1 & 69 \\ 2 & 1 & 70 \\ 1 & 1 & 71 \\ 1 & 1 & 71 \\ 3 & 2 & 73 \\ 2 & 1 & 74 \\ 1 & 1 & 75 \\ 2 & 1 & 76 \\ 1 & 1 & 76 \\ 1 & 1 & 77 \\ 1 & 1 & 77 \\ 1 & 1 & 78 \\ 3 & 2 & 80 \\ 1 & 1 & 80 \\ 1 & 1 & 81 \\ 7 & 4 & 85 \\ 4 & 2 & 87 \\ 6 & 3 & 90 \\ 1 & 1 & 91 \\ 2 & 1 & 92 \\ 1 & 1 & 93 \\ 1 & 1 & 93 \\ 1 & 1 & 94 \\ 1 & 1 & 94 \\ 1 & 1 & 95 \\ 2 & 1 & 96 \\ 1 & 1 & 97 \\ 1 & 1 & 97 \\ 3 & 2 & 99 \\ 1 & 1 & 99 \\ 1 & 1 & 100\end{array}$




\section{TABLE C2}

Percentage of Civil Litigation in Federal Court

\begin{tabular}{|c|c|c|c|}
\hline $\begin{array}{l}\% \text { Federal } \\
\text { Litigation }\end{array}$ & Freq. & $\underset{\%}{\text { Adjusted }}$ & $\begin{array}{c}\text { Cumu- } \\
\text { lative } \\
\%\end{array}$ \\
\hline 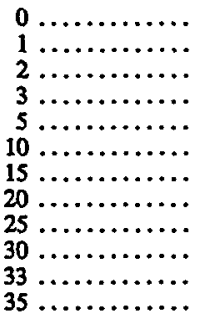 & $\begin{array}{r}8 \\
9 \\
4 \\
2 \\
18 \\
17 \\
3 \\
4 \\
5 \\
2 \\
2 \\
1\end{array}$ & $\begin{array}{r}5 \\
5 \\
2 \\
1 \\
11 \\
10 \\
2 \\
2 \\
3 \\
1 \\
1 \\
1\end{array}$ & $\begin{array}{r}5 \\
10 \\
13 \\
14 \\
25 \\
35 \\
37 \\
39 \\
42 \\
43 \\
45 \\
45\end{array}$ \\
\hline
\end{tabular}

\begin{tabular}{|c|c|c|c|}
\hline $\begin{array}{l}\% \text { Federal } \\
\text { Litigation }\end{array}$ & Freq. & $\underset{\%_{0}}{\text { Adjusted }}$ & $\begin{array}{c}\text { Cumu- } \\
\text { lative } \\
\% \%\end{array}$ \\
\hline 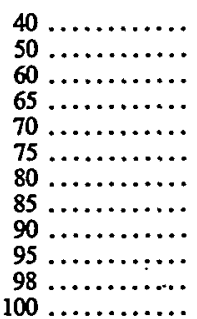 & $\begin{array}{r}5 \\
11 \\
10 \\
3 \\
4 \\
8 \\
10 \\
6 \\
10 \\
13 \\
1 \\
10\end{array}$ & $\begin{array}{l}3 \\
7 \\
6 \\
2 \\
2 \\
5 \\
6 \\
4 \\
6 \\
8 \\
1 \\
6\end{array}$ & $\begin{array}{r}48 \\
55 \\
61 \\
63 \\
65 \\
70 \\
76 \\
80 \\
86 \\
93 \\
94 \\
100\end{array}$ \\
\hline
\end{tabular}

TABLE C3

Percentage of Time on Plaintiffs' Matters

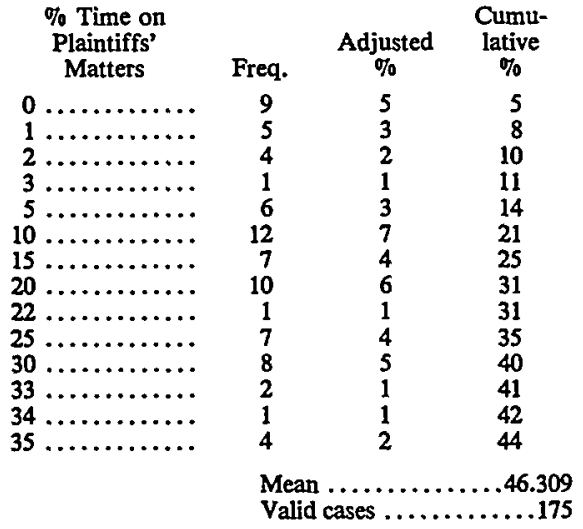

\begin{tabular}{|c|c|c|c|}
\hline $\begin{array}{l}\text { \% Time on } \\
\text { Plaintiffs' } \\
\text { Matters }\end{array}$ & Freq. & $\underset{\%}{\text { Adjusted }}$ & $\begin{array}{c}\text { Cumu- } \\
\text { lative } \\
\%\end{array}$ \\
\hline 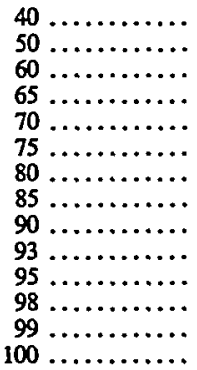 & $\begin{array}{r}7 \\
33 \\
8 \\
2 \\
1 \\
3 \\
7 \\
3 \\
5 \\
1 \\
5 \\
4 \\
4 \\
15\end{array}$ & $\begin{array}{r}4 \\
19 \\
5 \\
1 \\
1 \\
2 \\
4 \\
2 \\
3 \\
1 \\
3 \\
2 \\
2 \\
9\end{array}$ & $\begin{array}{r}48 \\
67 \\
71 \\
73 \\
73 \\
75 \\
79 \\
81 \\
83 \\
84 \\
87 \\
89 \\
91 \\
100\end{array}$ \\
\hline
\end{tabular}

TABLE C4

Median Size of Case (Thousands of Dollars)

\begin{tabular}{|c|c|c|c|c|c|c|c|}
\hline $\begin{array}{c}\text { Median } \\
\text { Case } \\
\text { Size }\end{array}$ & Freq. & $\begin{array}{l}\text { Adjusted } \\
\%\end{array}$ & $\begin{array}{c}\text { Cumu- } \\
\text { lative } \\
\%\end{array}$ & $\begin{array}{c}\text { Median } \\
\text { Case } \\
\text { Size }\end{array}$ & Freq. & $\underset{\%}{\text { Adjusted }}$ & $\begin{array}{c}\text { Cumu- } \\
\text { lative } \\
\%\end{array}$ \\
\hline 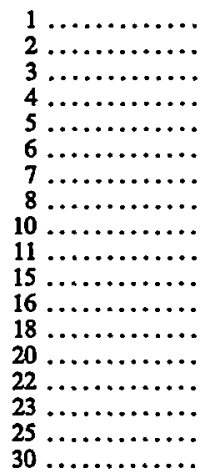 & $\begin{array}{l}1 \\
3 \\
1 \\
3 \\
3 \\
1 \\
1 \\
3 \\
3 \\
2 \\
2 \\
1 \\
2 \\
4 \\
2 \\
3 \\
4 \\
3\end{array}$ & $\begin{array}{l}1 \\
2 \\
1 \\
2 \\
2 \\
1 \\
1 \\
2 \\
2 \\
1 \\
1 \\
1 \\
1 \\
2 \\
1 \\
2 \\
2 \\
2\end{array}$ & $\begin{array}{r}1 \\
2 \\
3 \\
5 \\
7 \\
7 \\
8 \\
10 \\
12 \\
13 \\
14 \\
15 \\
16 \\
18 \\
19 \\
21 \\
24 \\
25\end{array}$ & 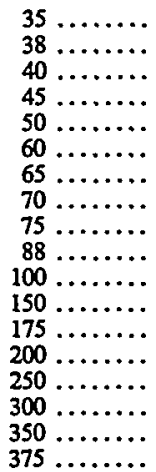 & $\begin{array}{r}2 \\
1 \\
1 \\
1 \\
7 \\
2 \\
1 \\
1 \\
1 \\
3 \\
2 \\
14 \\
6 \\
3 \\
8 \\
9 \\
4 \\
1 \\
1\end{array}$ & $\begin{array}{l}1 \\
1 \\
1 \\
1 \\
4 \\
1 \\
1 \\
1 \\
2 \\
1 \\
8 \\
4 \\
2 \\
5 \\
5 \\
2 \\
1 \\
1\end{array}$ & $\begin{array}{l}27 \\
27 \\
28 \\
28 \\
33 \\
34 \\
35 \\
35 \\
37 \\
38 \\
47 \\
50 \\
52 \\
57 \\
62 \\
65 \\
65 \\
66\end{array}$ \\
\hline
\end{tabular}


TABLE C4-Continued

\begin{tabular}{|c|c|c|c|}
\hline $\begin{array}{c}\text { Median } \\
\text { Case } \\
\text { Size }\end{array}$ & Freq. & $\underset{\%}{\text { Adjusted }}$ & $\begin{array}{c}\text { Cumu- } \\
\text { lative } \\
\%\end{array}$ \\
\hline $\begin{array}{r}400 \ldots \ldots \ldots \\
500 \ldots \ldots \ldots \\
550 \ldots \ldots \ldots \\
625 \ldots \ldots \ldots \\
650 \ldots \ldots \\
750 \ldots \ldots \\
1,000 \ldots \ldots \ldots \\
1,005 \ldots \ldots \ldots \\
1,500 \ldots \ldots \ldots \\
2,000 \ldots \ldots \ldots\end{array}$ & $\begin{array}{r}2 \\
7 \\
1 \\
1 \\
1 \\
2 \\
18 \\
1 \\
2 \\
1\end{array}$ & $\begin{array}{r}1 \\
4 \\
1 \\
1 \\
1 \\
1 \\
11 \\
1 \\
1 \\
1\end{array}$ & $\begin{array}{l}67 \\
72 \\
72 \\
73 \\
73 \\
75 \\
85 \\
86 \\
87 \\
88\end{array}$ \\
\hline
\end{tabular}

\begin{tabular}{|c|c|c|c|}
\hline $\begin{array}{c}\text { Median } \\
\text { Case } \\
\text { Size }\end{array}$ & Freq. & $\underset{\%}{\text { Adjusted }}$ & $\begin{array}{c}\text { Cumu- } \\
\text { lative } \\
\%\end{array}$ \\
\hline $\begin{array}{r}2,500 \ldots \ldots \ldots \\
2,750 \ldots \ldots \ldots \ldots \\
3,000 \ldots \ldots \ldots \\
5,000 \ldots \ldots \ldots \\
5,500 \ldots \ldots \ldots \\
10,000 \ldots \ldots \ldots \\
30,000 \ldots \ldots \ldots \\
50,000 \ldots \ldots \ldots \\
150,000 \ldots \ldots \ldots\end{array}$ & $\begin{array}{l}2 \\
1 \\
3 \\
4 \\
1 \\
6 \\
1 \\
1 \\
1\end{array}$ & $\begin{array}{l}1 \\
1 \\
2 \\
2 \\
1 \\
4 \\
1 \\
1 \\
1\end{array}$ & $\begin{array}{r}89 \\
90 \\
92 \\
94 \\
95 \\
98 \\
99 \\
99 \\
100\end{array}$ \\
\hline
\end{tabular}

TABLE C5

Year Respondent First Admitted to Bar

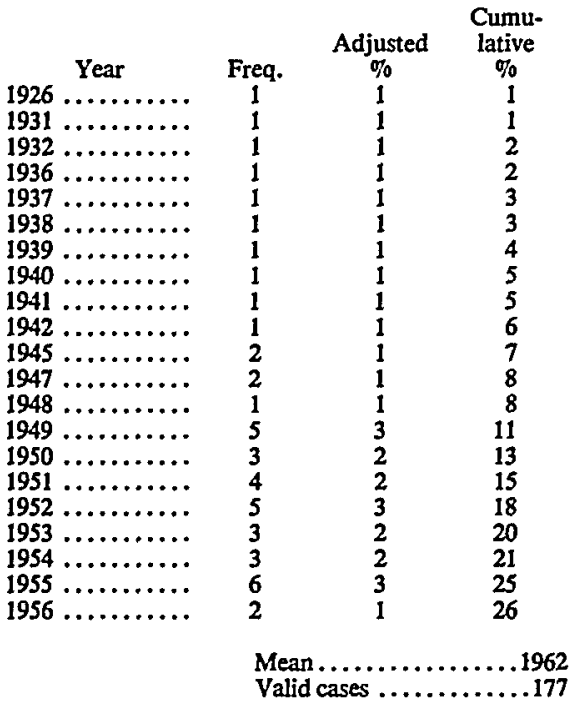

\begin{tabular}{|c|c|c|c|}
\hline Year & Freq. & $\underset{\%}{\text { Adjusted }}$ & $\begin{array}{c}\text { Cumu- } \\
\text { lative } \\
\%\end{array}$ \\
\hline $1957 \ldots \ldots \ldots \ldots$ & 3 & 2 & 28 \\
\hline 1958 .......... & 6 & 3 & 31 \\
\hline $1959 \ldots \ldots \ldots$ & 7 & 4 & 35 \\
\hline $1960 \ldots \ldots \ldots \ldots$ & $\begin{array}{l}5 \\
5\end{array}$ & 3 & $\begin{array}{l}38 \\
41\end{array}$ \\
\hline $1962 \ldots \ldots \ldots \ldots$ & 5 & 3 & 44 \\
\hline $1963 \ldots \ldots \ldots \ldots$ & 2 & 1 & 45 \\
\hline $1964 \ldots \ldots \ldots \ldots$ & 5 & 3 & 47 \\
\hline $1965 \ldots \ldots \ldots \ldots$ & 8 & 5 & 52 \\
\hline $1966 \ldots \ldots \ldots \ldots$ & 4 & 2 & 54 \\
\hline $1967 \ldots \ldots \ldots \ldots$ & 12 & 7 & 61 \\
\hline $1968 \ldots \ldots \ldots \ldots$ & 11 & 6 & 67 \\
\hline $1969 \ldots \ldots \ldots \ldots$ & 14 & 8 & 75 \\
\hline $1970 \ldots \ldots \ldots \ldots$ & 8 & 5 & 80 \\
\hline $1971 \ldots \ldots \ldots \ldots$ & 5 & 3 & 82 \\
\hline $1972 \ldots \ldots \ldots \ldots$ & 11 & 6 & 89 \\
\hline $1973 \ldots \ldots \ldots \ldots$ & 10 & 6 & 94 \\
\hline $1974 \ldots \ldots \ldots \ldots$ & 4 & 2 & 97 \\
\hline $1975 \ldots \ldots \ldots \ldots$ & 2 & 1 & 98 \\
\hline $1976 \ldots \ldots \ldots \ldots$ & 2 & 1 & 99 \\
\hline $1977 \ldots \ldots \ldots \ldots$ & 2 & 1 & 100 \\
\hline
\end{tabular}

\section{TABLE 66}

Number of Civil Cases Tried

\begin{tabular}{|c|c|c|c|c|c|c|c|}
\hline No. & Freq. & Adjusted & $\begin{array}{c}\text { Cumu- } \\
\text { Iative } \\
\%\end{array}$ & No. & Freq. & $\underset{\%}{\text { Adjusted }}$ & $\begin{array}{c}\text { Cumu- } \\
\text { lative } \\
\%_{0}\end{array}$ \\
\hline 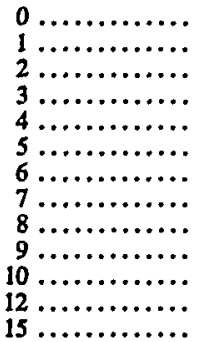 & $\begin{array}{l}5 \\
2 \\
2 \\
3 \\
2 \\
1 \\
4 \\
3 \\
3 \\
1 \\
7 \\
4 \\
4\end{array}$ & $\begin{array}{l}3 \\
1 \\
1 \\
2 \\
1 \\
1 \\
2 \\
2 \\
2 \\
1 \\
4 \\
2 \\
2\end{array}$ & $\begin{array}{r}3 \\
4 \\
5 \\
7 \\
8 \\
9 \\
12 \\
13 \\
15 \\
16 \\
20 \\
22 \\
25\end{array}$ & 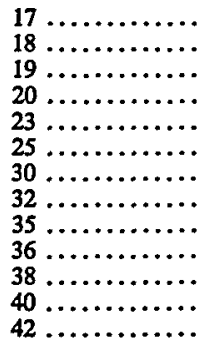 & $\begin{array}{r}1 \\
1 \\
1 \\
12 \\
1 \\
7 \\
4 \\
1 \\
4 \\
1 \\
3 \\
4 \\
1\end{array}$ & $\begin{array}{l}1 \\
1 \\
1 \\
7 \\
1 \\
4 \\
2 \\
1 \\
2 \\
1 \\
2 \\
2 \\
1\end{array}$ & $\begin{array}{l}25 \\
26 \\
27 \\
34 \\
35 \\
39 \\
41 \\
42 \\
44 \\
45 \\
47 \\
49 \\
50\end{array}$ \\
\hline
\end{tabular}




\section{TABLE C6-Continued}

\begin{tabular}{|c|c|c|c|c|c|c|c|}
\hline No. & Freq. & $\begin{array}{l}\text { Adjusted } \\
\%\end{array}$ & $\begin{array}{c}\text { Cumu- } \\
\text { lative } \\
\%_{0}\end{array}$ & No. & Freq. & $\underset{\%}{\text { Adjusted }}$ & $\begin{array}{c}\text { Cumu- } \\
\text { lative } \\
\%\end{array}$ \\
\hline 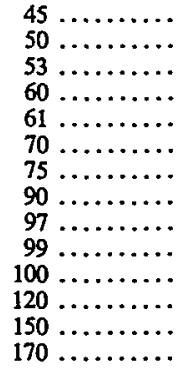 & $\begin{array}{r}2 \\
11 \\
1 \\
1 \\
1 \\
1 \\
3 \\
1 \\
1 \\
1 \\
13 \\
1 \\
6 \\
1\end{array}$ & $\begin{array}{l}1 \\
7 \\
1 \\
1 \\
1 \\
1 \\
2 \\
1 \\
1 \\
1 \\
8 \\
1 \\
4 \\
1\end{array}$ & $\begin{array}{l}51 \\
58 \\
58 \\
59 \\
59 \\
60 \\
62 \\
62 \\
63 \\
64 \\
72 \\
72 \\
76 \\
76\end{array}$ & 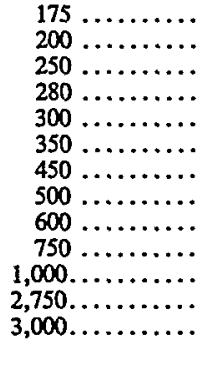 & $\begin{array}{l}1 \\
7 \\
6 \\
1 \\
5 \\
2 \\
3 \\
6 \\
1 \\
2 \\
3 \\
1 \\
1\end{array}$ & $\begin{array}{l}1 \\
4 \\
4 \\
1 \\
3 \\
1 \\
2 \\
4 \\
1 \\
1 \\
2 \\
1 \\
1\end{array}$ & $\begin{array}{r}77 \\
81 \\
85 \\
85 \\
88 \\
90 \\
92 \\
95 \\
96 \\
97 \\
99 \\
99 \\
100\end{array}$ \\
\hline & $\begin{array}{l}\text { Mea } \\
\text { Vali }\end{array}$ & ases ....... & $\begin{array}{l}\ldots 157.939 \\
\ldots \ldots .165\end{array}$ & $\begin{array}{l}\text { Median } \ldots . . . . \\
\text { Missing cases .... }\end{array}$ & .44 & & \\
\hline
\end{tabular}

\section{TABLE C7}

The Principal Types of Cases on Which the Lawyers in the Sample as a Whole Worked

Type of Case

1. Admiralty, Jones Act, seaman's injury

No. of

Attorneys

$\%$ of

2. Airline accidents

3. Antitrust, trade regulation, unfair commercial competition

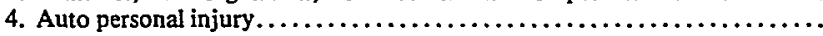

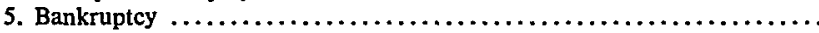

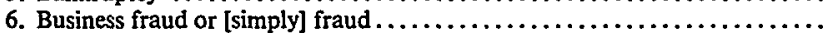

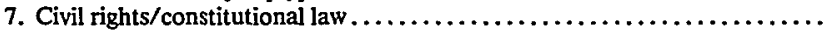

8. Commercial contracts or business contracts or [simply] contract(s) or "commercial" or "business"

9. Consumer law

or domestic relations or family law or matrimonial law ..........

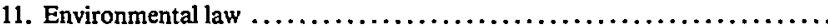

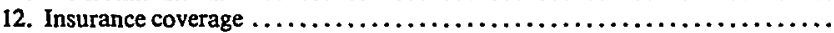

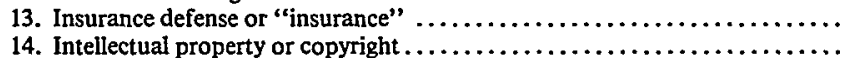

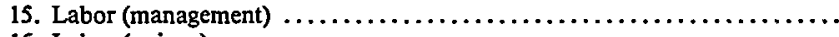

16. Labor (unions)

17. Malpractice (all types of professionals, including, but not limited to doctors, attorneys, accountants, engineers, architects, etc.) .............

18. Miscellaneous torts/personal injury: slips and falls, premises, property

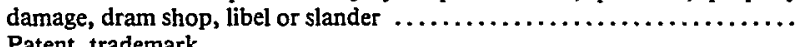

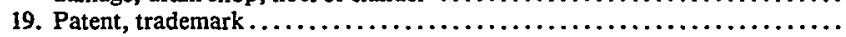

20. Personal contracts (include nonbusiness, noncommercial real estate con-

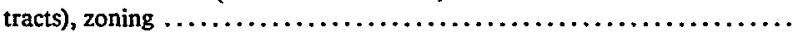

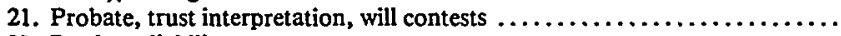

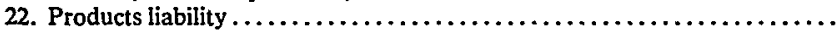

23. Real estate litigation (business or commercial) $\ldots \ldots \ldots \ldots \ldots \ldots \ldots \ldots$

24. Securities, 10b-5, stockholders' derivative actions, corporate opportunities, breach by corporate officers or directors of fiduciary obligations ..........

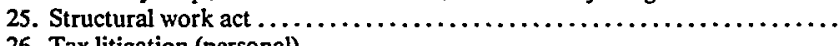

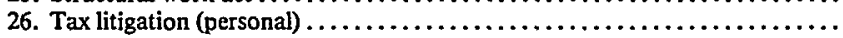

27. Tax litigation (business) .

28. Workers' compensation .

$\begin{array}{rr}2 & 1 \\ 6 & 3 \\ 70 & 40 \\ 31 & 18 \\ 3 & 2 \\ 13 & 7 \\ 29 & 16 \\ 72 & 41 \\ 2 & 1 \\ 17 & 10 \\ 7 & 4 \\ 9 & 5 \\ 11 & 6 \\ 13 & 7 \\ 4 & 2 \\ 1 & 1 \\ 36 & \\ & 20 \\ 64 & \\ 19 & 11\end{array}$




\section{APPENDIX D}

\section{Profiles OF MAJOR SUbGrouts}

The interviewers asked each attorney (1) how many lawyers worked in the firm in which she practiced and, referring to the preceding five years, to approximate (2) the percentage of her time she committed to matters filed in federal court, (3) the percentage of her time she spent representing plaintiffs, and (4) the median size (in thousands of dollars) of her cases. The interviewers also asked each attorney (5) what year she was first admitted to a bar. The table below reports the mean and the median responses to these questions by the lawyers in each of the subgroups identified in the left-hand column. Thus, for example, the third column shows that, as a group, the 39 attorneys whose median size case had been $\$ 25,000$ or less reported committing 48 (mean) to 50 percent (median) of their time to plaintiffs' matters. 


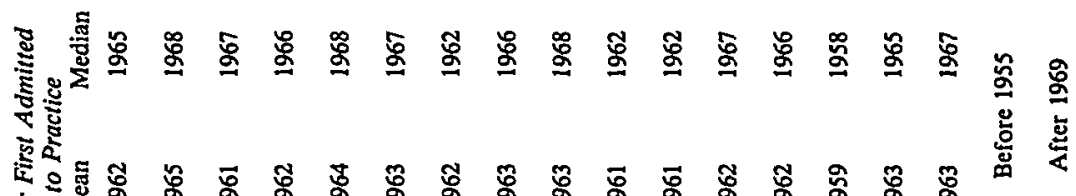

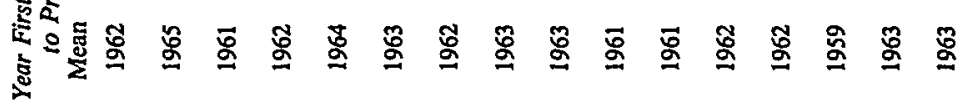

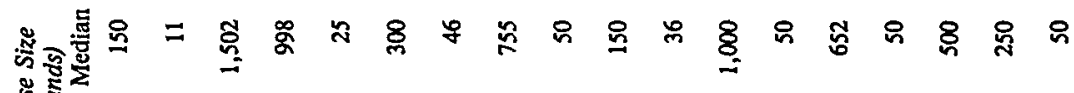
乌

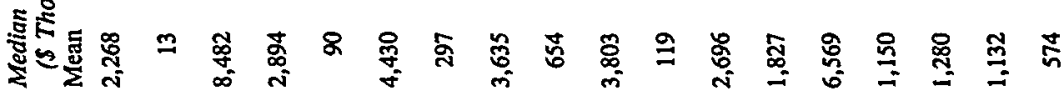

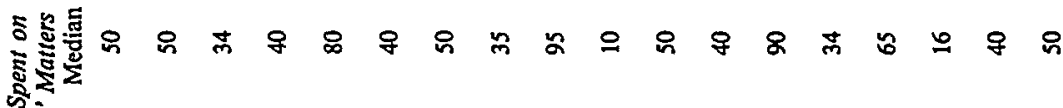
है

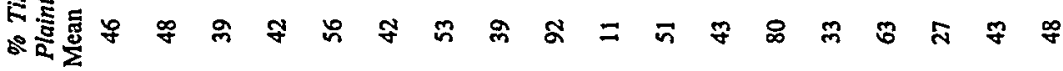

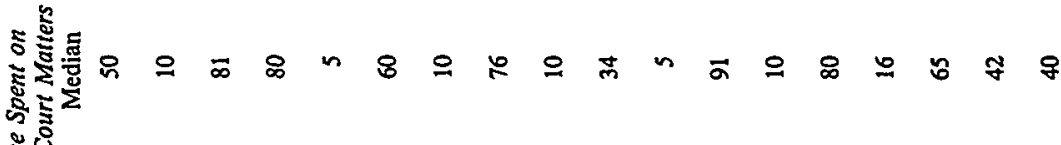
है่

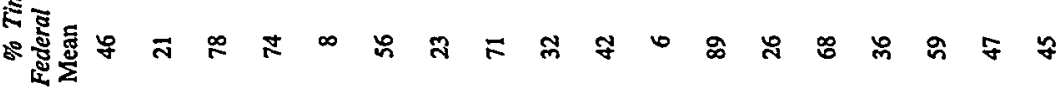

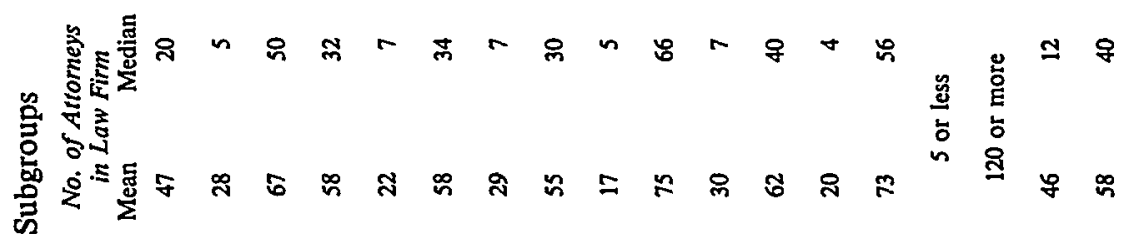

龸

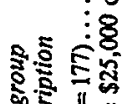


TABLE D2

Profiles of Major Subgroups: Principal Types of Cases ${ }^{a}$

\section{Case Type}

1. Miscellaneous torts

2. Auto personal injury

3. Products liability

4. Malpractice.

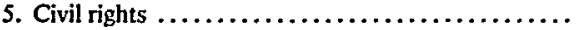

6. Commercial contracts

7. Insurance defense or insurance $\ldots \ldots \ldots \ldots \ldots \ldots$

8. Structural work act

1. Antitrust

2. Commercial contracts $\ldots \ldots \ldots \ldots \ldots \ldots \ldots \ldots$

3. Securities

4. Patent or copyright law .....................

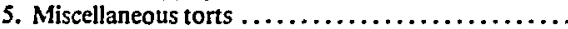

6. Business fraud

7. Civil rights

8. Products liability

1. Miscellaneous torts

2. Commercial contracts

3. Products liability

4. Antitrust

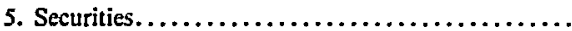

6. Auto personal injury $\ldots \ldots \ldots \ldots \ldots \ldots \ldots \ldots$

7. Malpractice.

8. Structural work act $\ldots \ldots \ldots \ldots \ldots \ldots \ldots \ldots \ldots$

9. Civil rights

10. Insurance coverage $\ldots \ldots \ldots \ldots \ldots \ldots \ldots \ldots \ldots$

11. Insurance defense, insurance.

12. Patent or copyright

1. Miscellaneous torts

2. Products liability

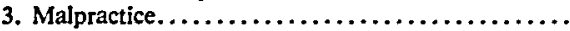

4. Auto personal injury .....................

5. Commercial contracts

6. Structural work act $\ldots \ldots \ldots \ldots \ldots \ldots \ldots \ldots \ldots$

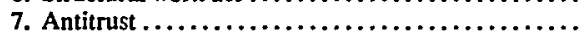

8. Civil rights $\ldots \ldots \ldots \ldots \ldots \ldots \ldots \ldots \ldots \ldots \ldots \ldots$

9. Securities.

10. Airline accidents

\section{No. of} Attorneys

$\%$ of Attorneys

Median Size Case $\$ 25,000$ or Less $(N=39)$

27

17

16

11

9

8

7

7

69
44
41
28
23
20
18
18

Median Size Case $\$ 1,000,000$ or More $(N=42)$

$\begin{array}{rr}34 & 81 \\ 26 & 62 \\ 22 & 52 \\ 13 & 31 \\ 6 & 14 \\ 5 & 12 \\ 5 & 12 \\ 5 & 12\end{array}$

Attorneys Committing $75 \%$ or More of Their Time to Defendants' Matters $(N=62)$

$\begin{array}{rr}25 & 40 \\ 24 & 39 \\ 22 & 35 \\ 21 & 34 \\ 18 & 29 \\ 13 & 21 \\ 13 & 21 \\ 9 & 14 \\ 9 & 14 \\ 8 & 13 \\ 8 & 13 \\ 6 & 10\end{array}$

Attorneys Committing 75\% or More of Their Time to Plaintiff' Matters $(N=47)$

$\begin{array}{rr}30 & 64 \\ 23 & 49 \\ 20 & 42 \\ 17 & 36 \\ 11 & 23 \\ 9 & 19 \\ 9 & 19 \\ 8 & 17 \\ 6 & 13 \\ 5 & 11\end{array}$

${ }^{a}$ Case types mentioned by fewer than 5 attorneys in the subgroup are not included. 
TABLE D2-Continued

Case Type

1. Miscellaneous torts

2. Products liability $\ldots \ldots \ldots \ldots \ldots \ldots \ldots \ldots \ldots \ldots$

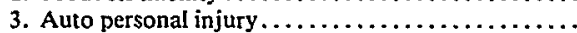

4. Malpractice.

5. Structural work act $\ldots \ldots \ldots \ldots \ldots \ldots \ldots \ldots \ldots$

6. Commercial contracts

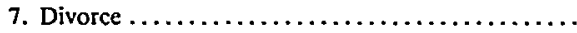

8. Insurance defense, insurance

9. Insurance coverage

10. Airline accidents

11. Workers ${ }^{*}$ compensation

1. Antitrust

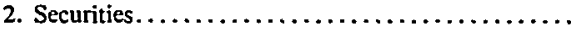

3. Commercial contracts.

4. Patent or copyright $\ldots \ldots \ldots \ldots \ldots \ldots \ldots \ldots \ldots$

5. Civil rights

6. Miscellaneous torts
No. of

$\%$ of Attorneys Attorneys

Attorneys Committing $\mathbf{8 0 \%}$ or More of Their Time to Matters Filed in State Court $(N=65)$

$\begin{array}{rr}41 & 63 \\ 36 & 55 \\ 28 & 43 \\ 27 & 42 \\ 17 & 26 \\ 12 & 18 \\ 10 & 15 \\ 7 & 11 \\ 6 & 9 \\ 5 & 8 \\ 5 & 8\end{array}$

Attorneys Committing 80\% or More of Their Time to Matters Filed in Federal Court $(N=51)$

$\begin{array}{rl}37 & 72 \\ 20 & 39 \\ 20 & 39 \\ 20 & 39 \\ 11 & 22 \\ 5 & 10\end{array}$

$\begin{array}{cr}\begin{array}{c}\text { Attorneys Practicing in } \\ \text { Firms of } 5 \text { or Fewer } \\ (N=55)\end{array} \\ 24 & \\ 17 & 44 \\ 16 & 31 \\ 15 & 29 \\ 13 & 27 \\ 12 & 24 \\ 11 & 22 \\ 11 & 20 \\ 10 & 20 \\ 8 & 18 \\ 6 & 14 \\ 5 & 11 \\ 5 & 9 \\ & 9\end{array}$

1. Miscellaneous torts $\ldots \ldots \ldots \ldots \ldots \ldots \ldots \ldots \ldots$

2. Commercial contracts

3. Antitrust

4. Products liability

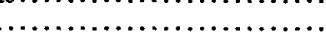

5. Auto personal injury

6. Malpractice.

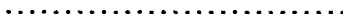

7. Civil rights $\ldots \ldots \ldots \ldots \ldots \ldots \ldots \ldots \ldots \ldots \ldots \ldots$

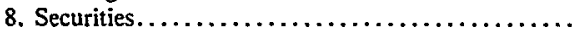

9. Divorce .

10. Patent or copyright

11. Structural work act

12. Business fraud

13. Insurance defense, insurance.

Attorneys Practicing in Firms of 120 or More $(N=35)$

1. Antitrust

$16 \quad 46$

$15 \quad 43$

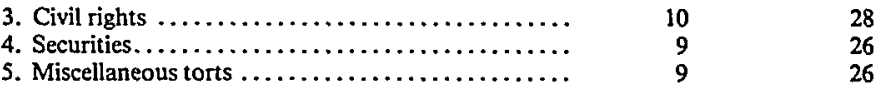

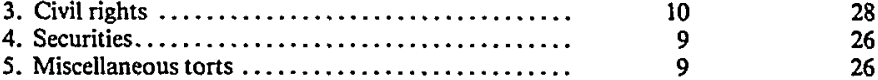

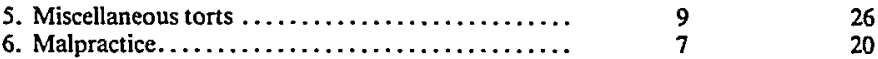

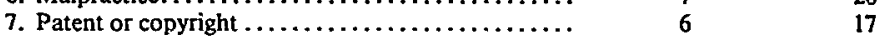

8. Products liability ...................... 6 
TABLE D2-Continued

\section{Case Type}

1. Antitrust

2. Miscellaneous torts

3. Products liability $\ldots \ldots \ldots \ldots \ldots \ldots \ldots \ldots \ldots \ldots$

5. Patent or copyright

6. Structural work act $\ldots \ldots \ldots \ldots \ldots \ldots \ldots$

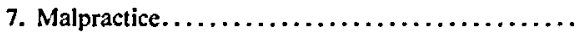

8. Auto personal injury $\ldots \ldots \ldots \ldots \ldots \ldots \ldots \ldots \ldots$

9. Securities.

1. Commercial contracts

2. Miscellaneous torts

3. Antitrust .

4. Civil rights $\ldots \ldots \ldots \ldots \ldots \ldots \ldots \ldots \ldots \ldots \ldots$

5. Products liability

6. Auto personal injury.

7. Malpractice.

8. Securities

9. Patent or copyright
4. Commercial contracts

No. of Attorneys

$\%$ of Attorneys

Attorneys First Admitted to a Bar Before $1955(N=38)$

$\begin{array}{rr}16 & 42 \\ 16 & 42 \\ 14 & 37 \\ 11 & 29 \\ 9 & 24 \\ 8 & 21 \\ 8 & 21 \\ 8 & 21 \\ 5 & 13\end{array}$

Attorneys First Admitted to a Bar After $1969(N=44)$

$\begin{array}{rr}16 & 36 \\ 16 & 36 \\ 15 & 34 \\ 14 & 32 \\ 10 & 23 \\ 9 & 20 \\ 9 & 20 \\ 8 & 18 \\ 7 & 16\end{array}$

Attorneys Doing More Than $50 \%$ of Their Work for Individuals (as Clients) $(N=47)$

1. Miscellaneous torts $\ldots \ldots \ldots \ldots \ldots \ldots \ldots \ldots \ldots$

2. Products liability .

3. Malpractice.

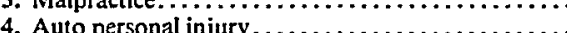

injury.........................

5. Divorce $\ldots \ldots \ldots \ldots \ldots \ldots \ldots \ldots \ldots \ldots \ldots \ldots \ldots \ldots$

6. Structural work act $\ldots \ldots \ldots \ldots \ldots \ldots \ldots \ldots \ldots$

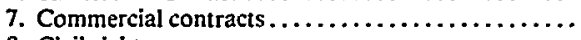

8. Civil rights

9. Antitrust .

$\begin{array}{rr}22 & 47 \\ 19 & 40 \\ 16 & 34 \\ 14 & 30 \\ 11 & 23 \\ 9 & 19 \\ 9 & 19 \\ 7 & 15 \\ 6 & 13\end{array}$

Attorneys Doing More Than $50 \%$ of Their Work for Large Corporations (as Clients) $(N=36)$

1. Antitrust

2. Commercial contracts ....................

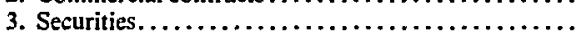

4. Patent or copyright

5. Products liability 
TABLE D3

Profiles of Major Subgroups: Principal Types of Clientsa

\begin{tabular}{|c|c|c|c|}
\hline & $\begin{array}{l}\text { No. in Subgroup } \\
\text { Who Said Client } \\
\text { Type Produced } \\
\text { Highest } \%\end{array}$ & $\begin{array}{c}\% \text { in Subgroup } \\
\text { Who Said Client } \\
\text { Type Produced } \\
\text { Highest } \%\end{array}$ & $\begin{array}{l}\text { Median \% } \\
\text { Work Produced } \\
\text { by This Client }\end{array}$ \\
\hline pes & of Work & of Work & Type \\
\hline
\end{tabular}

Median Size Case $\$ 25,000$ or Less $(N=39)$

1. Individuals

17

10

$44 \quad 98$

2. Carriers ....................

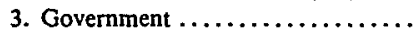

4. Large corporations

$\begin{array}{rrr}6 & 15 & 98 \\ 2 & 5 & 89\end{array}$

89

Median Size Case $\$ 1,000,000$ or More $(N=42)$

1. Large corporations .............

2. Individuals ...................

3. Small businesses ..............

4. Government .

\section{1}

6

4

3

$\begin{array}{rr}50 & 79 \\ 14 & 70 \\ 10 & 52 \\ 7 & 25\end{array}$

Principal Cases Include Antitrust Matters $(N=70)$

1. Large corporations ............

2. Individuals

35

10

3. Small businesses. ..............

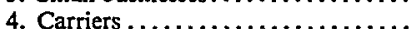

5. Government

1. Individuals

2. Carriers $\ldots \ldots \ldots \ldots \ldots \ldots \ldots \ldots$

3. Large corporations

1. Large corporations ...........

2. Individuals $\ldots \ldots \ldots \ldots \ldots \ldots \ldots$

3. Carriers..$\ldots \ldots \ldots \ldots \ldots \ldots \ldots \ldots$

4. Small businesses.

5. Government

1. Individuals

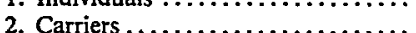

3. Large corporations ............

4. Government ..................

5. Small businesses..............

50
14
8
6
4

70

6

4

3

70

52

Principal Cases Include Auto Personal Injury $(N=31)$

$\begin{array}{rrr}15 & 48 & 100 \\ 12 & 39 & 82 \\ 2 & 6 & 70\end{array}$

Principal Cases Include Commercial Contracts $(N=72)$

$\begin{array}{rrr}30 & 42 & 60 \\ 14 & 19 & 51 \\ 8 & 11 & 68 \\ 5 & 7 & 62 \\ 3 & 4 & 25\end{array}$

Principal Cases Include Miscellaneous Torts $(N=64)$

${ }^{a}$ Client types mentioned by very few attorneys in the sample are not included.

$\begin{array}{rr}39 & 98 \\ 28 & 86 \\ 14 & 36 \\ 6 & 98 \\ 5 & 68\end{array}$


TABLE D3-Continued

Client Types

1. Large Corporations............

2. Individuals $\ldots \ldots \ldots \ldots \ldots \ldots \ldots$

3. Small businesses..............

4. Carriers

1. Individuals

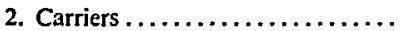

3. Large corporations

1. Carriers

2. Large corporations

3. Government

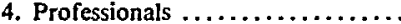

5. Individuals $\ldots \ldots \ldots \ldots \ldots \ldots \ldots$

6. Small businesses.

1. Individuals

2. Carriers . . . . . . . . . . . . . . .

3. Large corporations

1. Large corporations

2. Individuals .................

3. Government .................

4. Small businesses.

1. Individuals $\ldots \ldots \ldots \ldots \ldots \ldots \ldots$

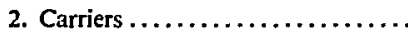

3. Large corporations .............

4. Small businesses.

No. in Subgroup
Who Said Client
Type Produced
Highest \%
of Work

$\%$ in Subgroup

Who Said Client

Highest $\%$

of Work
Type Produced
Median \%

Work Produced by This Client Type
Principal Cases Include Securities Matters $(N=45)$

$\begin{array}{rrr} & 20 & 44 \\ 5 & 18 & 52 \\ 3 & 11 & 63 \\ & 7 & 65\end{array}$

Attorneys Committing $75 \%$ or More of Their Time to Plaintiffs' Matters $(N=47)$

$\begin{array}{rrr}37 & 79 & 97 \\ 3 & 6 & 60 \\ 1 & 2 & 25\end{array}$

Attorneys Committing $75 \%$ or More of Their Time to Defendants' Matters $(N=62)$

$\begin{array}{rrr}21 & 34 & 89 \\ 20 & 32 & 80 \\ 8 & 13 & 98 \\ 3 & 5 & 60 \\ 3 & 5 & 50 \\ 2 & 3 & 60\end{array}$

Attorneys Committing $80 \%$ or More of Their Time to Matters Filed in State Court $(N=65)$

$\begin{array}{rrr}30 & 46 & 100 \\ 21 & 32 & 89 \\ 6 & 9 & 53\end{array}$

Attorneys Committing $80 \%$ or More of Their Time to Matters Filed in Federal Court $(N=51)$

$\begin{array}{rll}26 & 51 & 76 \\ 7 & 14 & 88 \\ 5 & 10 & 98 \\ 5 & 10 & 62\end{array}$

Attorneys in Law Firms of 5 or Fewer $(N=55)$

$\begin{array}{rrr}32 & 58 & 90 \\ 6 & 11 & 78 \\ 5 & 9 & 75 \\ 3 & 5 & 76\end{array}$


TABLE D3-Continued

Client Types

1. Large corporations

2. Government $\ldots \ldots \ldots \ldots \ldots \ldots \ldots$

3. Individuals $\ldots \ldots \ldots \ldots \ldots \ldots \ldots$

4. Carriers ...................

1. Large corporations ............

2. Individuals

3. Carriers

1. Individuals

2. Large corporations $\ldots \ldots \ldots \ldots \ldots$

3. Government .................

4. Carriers .................

5. Small businesses

\author{
No. in Subgroup \\ Who Said Client \\ Type Produced \\ Highest $\%$ \\ of Work
}

Median $\%$ Work Produced by This Client

Type

Attorneys in Law Firms of 120 or More $(N=35)$

$\begin{array}{rrr}15 & 43 & 52 \\ 8 & 23 & 95 \\ 6 & 17 & 92 \\ 2 & 6 & 68\end{array}$

Attorneys First Admitted to a Bar Before $1955(N=38)$

$\begin{array}{rrr}17 & 45 & 71 \\ 10 & 26 & 100 \\ 7 & 18 & 74\end{array}$

Attorneys First Admitted to a Bar After $1969(N=44)$

$\begin{array}{rrc}14 & 32 & 93 \\ 11 & 25 & 72 \\ 7 & 16 & 97 \\ 4 & 9 & 82 \\ 3 & 7 & 64\end{array}$

